\title{
LABELING HIV-1 NUCLEIC ACIDS DURING INFECTION AND EFFECT OF MOV10 IN HBV REPLICATION
}

\begin{tabular}{c} 
A Dissertation \\
Presented to \\
The Faculty of the Graduate School \\
At the University of Missouri \\
In Partial Fulfillment \\
Of the Requirements for the Degree \\
Doctor of Philosophy \\
\hline Dr. Stefan G. Sarafianos, Dissertation Supervisor \\
MAR 2018
\end{tabular}


The undersigned, appointed by the dean of the Graduate School, have examined the dissertation entitled

\section{LABELING HIV-1 NUCLEIC ACIDS DURING INFECTION AND EFFECT OF MOV10 IN HBV REPLICATION \\ Presented by Maritza N. Puray Chavez}

A candidate for the degree of

Doctor of Philosophy

And hereby certify that, in their opinion, it is worthy of acceptance.

Professor Stefan G. Sarafianos

Professor David Pintel

Professor Donald Burke

Professor Marc Johnson

Professor Bumsuk Hahm 


\section{DEDICATION}

To my husband Jorge and our daughter Amelia, to my parents, Erlinda and Faustino, and my siblings Nidia and Percy.

Dedicated to the memory of Dr. Arturo Centurion Lara a mentor, a scientist and a friend. 


\section{LABELING HIV-1 NUCLEIC ACIDS DURING INFECTION AND EFFECT OF MOV10 IN HBV REPLICATION}

\section{ACKNOWLEDGEMENTS}

I would like to express my sincere gratitude to my mentor Dr. Sarafianos for accepting me into his laboratory. Thank you for giving me the opportunity to be part of innovative and multiple projects, for your guidance, challenging work and encouragement, specially the first two years until I became more independent. Thank you for the freedom to design, perform and analyzed the results, I will be always grateful. I would like to thank my committee members Dr. David Pintel, Dr. Donald Burke, Dr. Bumsuk Hahm, and Dr. Marc Johnson. Thank you for your time to resolve my doubts on the virology field, for your constructive criticism and questioning. I would also express my gratitude to our collaborators Dr. Alan Engelman, Dr. Erik Poeshla and Dr. Mamuka Kvaratskhelia.

I would like to thank outstanding professionals who influence on my research and performance these past years, Dr. Eleftherious Michailidis, Dr. Philip Tedbury, Dr. Karen Kirby, Dr. Ong Yee, Dr. Atsuko Hachira, Professor Raquel Ore, Professor Pilar Alva, Professor William Cornejo, Dr. Cesar Naquira, Dr. Elizabeth Sanchez and Dr. Arturo Centurion Lara thank you for your time, teaching, patience and for being excellent examples to follow. Thank you Dr. Kamlendra Singh for your advices during my journey. Special thanks to the wonderful team that I had the privilege to be part of with Dr. Dan Dan Liu and Dr. Andrew Huber, thank you from the bottom of my hearth for being my pals on research and having fun doing science in the lab while we made new discoveries 
in Hepatitis B Virus research. Thanks to Dr. Anna Gres, for her friendship and lucid and sharp advises. Thanks to Dr. Zhe Li for her friendship, her kindness made a difference in the lab. Thanks to Grace Yang for the advices and sincere friendship. Thanks to Juan Ji for the initial training and all her help during these years. I also want to thank all the current and former graduate members of Sarafianos lab, Dr. Tanya Ndongwe for her patience and orientation to deal with "over-expressions and down-regulations", Dr. Obiaara Uka, Vincent Yapo, Mahmoud Farghali, Mary Casey, Maria Boftsi and Jennifer Wolf, for the exchange of ideas, healthy criticism and for the working environment and share friendly meetings outside lab, thank you so much for organize or share with my family all those special moments that we will remember forever. Thanks to Emily Coonrod, Tom Laughlin and Leonard Rogers, smart and talented young researchers that helped me while they were undergraduate students. My gratitude to two great women, Dr. Margaret Lange-Osborne and Dr. Manijeh Heidari, for their support, guidance and friendship.

I want to thank all my friends in Peru and especially Yesenia, Erika and Pilar for their support and eternal friendship. I want to thank my classmates and friends for helping me adjust in graduate school: Jacqueline, Yul Eum, Mindy and Obi. Thank you so much Yul Eum for always being there all these years, for the talks and coffee time. I want to say many thanks to Jana Clark from MMI. Thanks to Dr. Alexander Jurkevich and Dr. Frank Baker from the Molecular Cytology core and Daniel Jackson from the CIC core, for their friendship, guidance and technical support.

I am so thankful to my parents Erlinda Chavez Flores and Faustino Puray Palomino and my siblings Percy and Nidia who have been my support and my strength to 
pursue this dream than now is becoming real. Their immense support is beyond words during happy as well as in tough times. I am also grateful to my mother-in-law Isabel, my late father-in-law Jorge, and my siblings-in-law Claudia and Sandro and all my family for their continuous support and love.

I left for last the two special persons without whom I would not have finished my Ph.D. studies, my husband Jorge Durand Heredia and our daughter Amelia Andrea. I thank God who allowed me to meet you Jorge and bless our life with Amelia. We met in 2002 and since then we have been together, we were capable to overcome geographic distance and continue with a long distance relationship (you in USA and I in Peru) with your unconditional love, care and dedication. I have no enough words to express my love and gratitude for everything all these years together, you are my strength and pillar. Thank you God for showing me the right path to achieve this goal in my life. 


\section{FOOTNOTES}

The content of the dissertation thesis by Maritza Puray-Chavez is based on one published research paper and two manuscripts in preparation. The contribution of coauthors are as follows:

\section{Chapter 2 - MULTIPLE SINGLE-CELL VISUALIZATION OF NUCLEIC ACIDS}

\section{AND PROTEIN DURING HIV INFECTION}

Chapter 2 is based on a research paper published in Nature Communications in 2017. The authors and title are as follows: Puray-Chavez MN*, Tedbury PR*, Huber AD, Ukah OB, Yapo V, Liu D, Ji J, Wolf JJ, Engelman AN, Sarafianos SG. Multiplex single-cell visualization of nucleic acids and protein during HIV infection. Nat Commun. 2017 Dec 1;8(1):1882

MPC designed, performed all experiments, analyzed most of the experiments for HIV-1 and was responsible for writing part of the manuscript, material and methods, legends of all figures and part of results. TPR was responsible for writing manuscript introduction, organization of results, discussion, and analyzed part of a figure and was heavily involved in manuscript editing. ADH, DL, JJ, JJW and OBU contribute and help with experiments. VY performed all experiments for HIV-2, not presented in this dissertation. EAN edited manuscript. SGS conceived the research, oversaw all aspects of the project and edited the manuscript.

\section{Chapter 3 - LEDGF AND ANTISENSE VIRAL RNA DURING HIV INFECTION}


Chapter 3 is based on a manuscript that is in preparation. The authors and title are as follows: Puray-Chavez MN, Tedbury PR, Ukah OB, Yapo V, Achuthan V, Poeschla EM, Kvaratskhelia M, Engelman AN, Sarafianos SG. Loss of LEDGF/p75 targeted integration enhances transcription of HIV-1 antisense RNA.

MPC designed, performed and analyzed experiment and was responsible for writing the manuscript. TPR discussed the results of virologic experiments, contribute for writing the manuscript and to outline list experiments. OBU performed initial experiments in latent cells not presented in this paper. VY performed all experiments for HIV-2, not presented in this dissertation. VA shared plasmids and cells. EMP shared stable cell lines. MK and ANE shared drugs used. MK and ANE edited manuscript. SGS conceived the research, oversaw all aspects of the project and edited the manuscript. All authors discussed the results and implications and commented on the manuscript.

\section{Chapter 4 - ANTIVIRAL ACTIVITY OF MOV10 ON HEPATITIS B VIRUS INFECTION}

Chapter 4 is based on a manuscript that is in preparation. The authors and title are as follows: Puray-Chavez MN, Huber AD, Liu D, Ndongwe TP, Casey M, Sarafianos SG. Mechanism of action of an RNA binding protein MOV10 on HBV replication.

MPC designed, performed all experiments, analyzed the experiments and is responsible for writing the manuscript. ADH, DL contributed to complete qPCR and RTqPCR analysis. TPN shared plasmids and siRNA. MC and NTP adapted siRNA knockdown in HCV. SGS conceived the research, oversaw all aspects of the project and edited the manuscript. All authors provided comments on the manuscript. 


\section{TABLE OF CONTENTS}

ACKNOWLEDGEMENTS ....................................................................................... ii

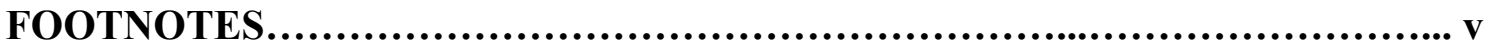

LIST OF ABBREVIATIONS ........................................................................................... ix

LIST OF FIGURES........................................................... xi

PUBLICATIONS …................................................................................................................

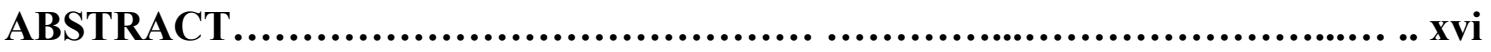

CHAPTER 1. INTRODUCTION........................................................................................... 1

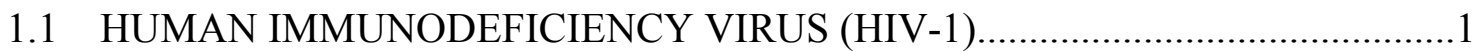

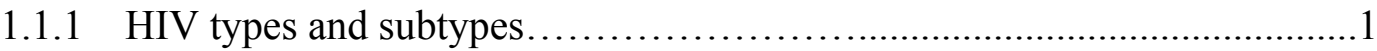

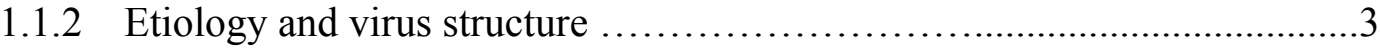

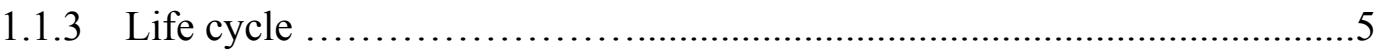

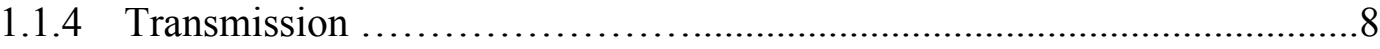

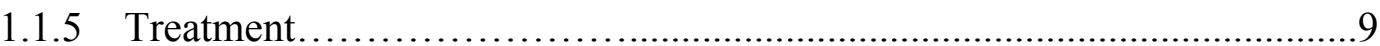

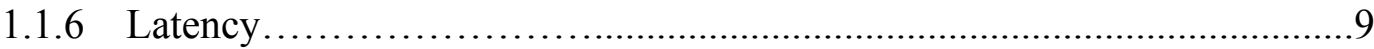

1.1.7 HIV-1 nucleic acids and protein detection at single cell level.............10

1.1.8 HIV-1 antisense RNA......................................... 10

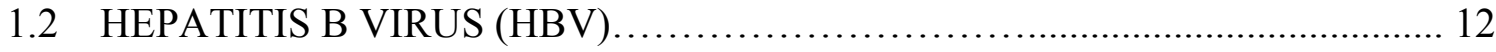

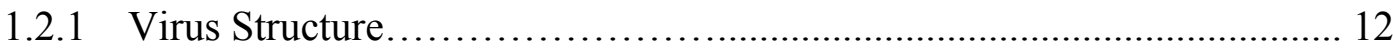

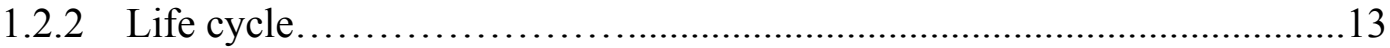

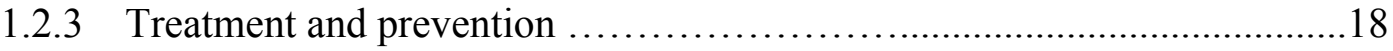

1.2.4 Immune response and role of host factors.............................18 
CHAPTER 2. MULTIPLE SINGLE-CELL VISUALIZATION OF NUCLEIC ACIDS AND PROTEIN DURING HIV INFECTION .................................................24

2.1 INTRODUCTION

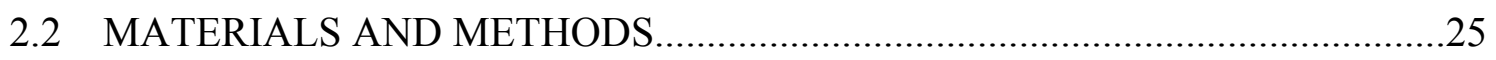

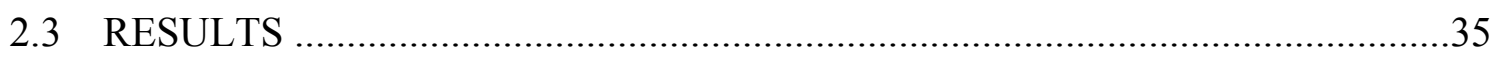

2.4 DISCUSSION

CHAPTER 3. LEDGF AND ANTISENSE VIRAL RNA DURING HIV

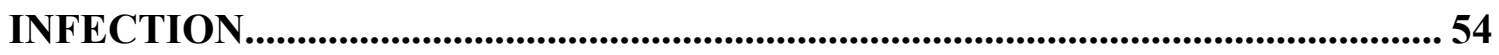

3.1 INTRODUCTION

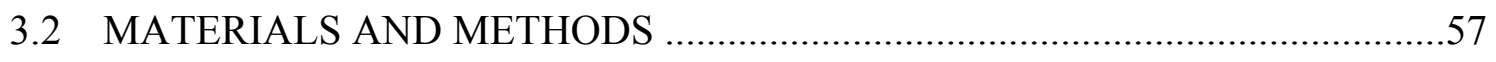

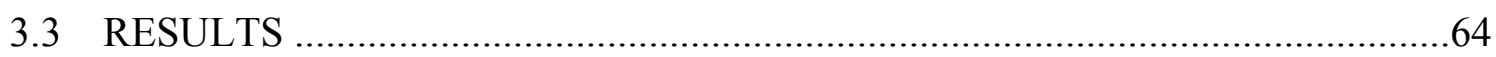

3.4 DISCUSSION AND FUTURE DIRECTIONS ..............................................

CHAPTER 4. ANTIVIRAL ACTIVITY OF MOV10 ON HEPATITIS B VIRUS

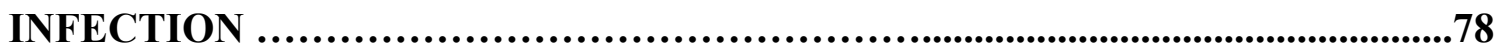

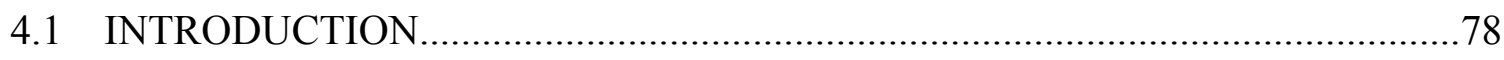

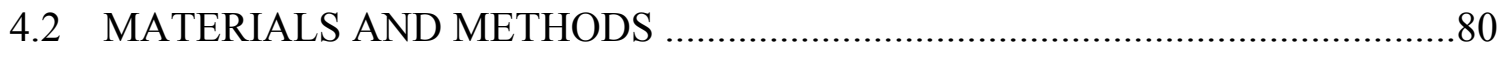

4.3 RESULTS

4.4 DISCUSSION AND FUTURE DIRECTIONS ……………….............................98

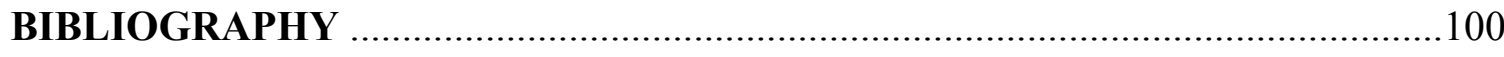

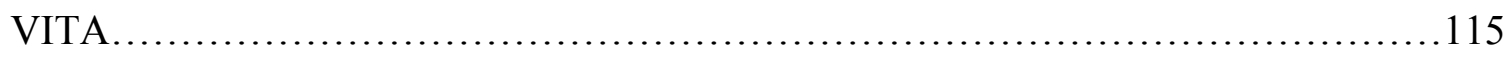




\section{LIST OF ABBREVIATIONS}

\begin{tabular}{|c|c|}
\hline AIDS & Acquired Immunodeficiency Syndrome \\
\hline $\mathrm{CA}$ & Capsid Protein \\
\hline CPSF6 & Cleavage and Polyadenylation Specificity Factor 6 \\
\hline DNA & Deoxyribonucleic Acid \\
\hline Group M & Major Group \\
\hline Group N & New Group \\
\hline Group $\mathrm{O}$ & Outlier Group \\
\hline Group P & Pending the Identification of Further Human Cases \\
\hline Gag & Group-specific Antigen \\
\hline HAART & Highly Active Antiretroviral Therapy \\
\hline HIV-1 & Human Immunodeficiency Virus Type 1 \\
\hline HIV-2 & Human Immunodeficiency Virus Type 2 \\
\hline IN & Integrase \\
\hline MA & Matrix \\
\hline MW & Molecular Weight \\
\hline $\mathrm{NC}$ & Nucleocapsid \\
\hline Nef & Negative Factor \\
\hline $\mathrm{NIH}$ & National Institutes of Health \\
\hline PEG & Polyethylene Glycol \\
\hline PIC & Pre-Integration Complex \\
\hline PR & Protease \\
\hline
\end{tabular}




$\begin{array}{ll}\text { RNA } & \text { Ribonucleic Acid } \\ \text { RT } & \text { Reverse Transcriptase } \\ \text { SDS-PAGE } & \text { Sodium Dodecyl Sulfate Polyacrylamide Gel Electrophoresis } \\ \text { Vif } & \text { Virion Infectivity Factor } \\ \text { Vpr } & \text { Viral Protein R } \\ \text { WT } & \text { Wild Type }\end{array}$




\section{LIST OF FIGURES}

Figure 1.1.1 Prevalence of HIV in 2016 from World Health Organization.................

Figure 1.1.2. Global distribution of HIV-1 subtypes and recombinants.................2

Figure 1.1.3. Schematic representation of the HIV-1 mature virion, .....................

Figure 1.1.4. HIV-1 genome. A schematic representation of the HIV-1 gene products

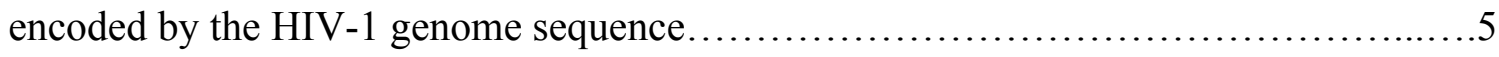

Figure 1.1.5. HIV-1 life cycle.............................................. 8

Figure 1.2.1. Schematic representation of HBV and virus structure $\ldots \ldots \ldots \ldots \ldots \ldots \ldots 13$

Figure 1.2.2. Schematic representation of HBV life cycle....................... 15

Figure 2. 1. Visualizing HIV nucleic acids...................................... 37

Figure 2.2. Time course of vRNA detection................................. 40

Figure 2.3. Degradation of vRNA during reverse transcription....................40

Figure 2.4. Time course of vDNA detection..................................41

Figure 2.5. Staining for vRNA and vDNA in particles at the plasma membrane.........41

Figure 2.6 Inhibition of HIV-1 integration..................................... 42

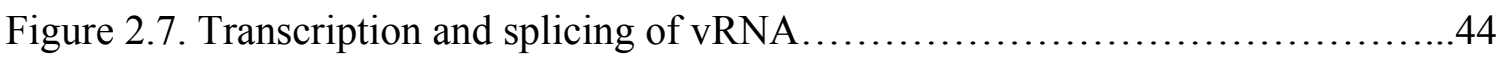

Figure 2.8. Multiplex visualization of HIV-1 nucleic acids and protein................47

Figure 2.9. Multiplex vRNA and vDNA labeling in diverse cell lines...............49

Figure 2.10. vRNA and Capsid/Gag labeling of HIV-1 clinical isolate................49

Figure 2.11. Tracking the early stages of infection of Primary CD4+ T cells...........50

Figure 3.1. RNA HIV-1 detection in HEK 293T cells...........................66

Figure 3.2. Allosteric Integrase Inhibitors (ALLINIs) used in this study ..............67

Figure 3.3. Detection of antisense RNA HIV-1 in Primary Cells.....................68 
Figure 3.4. Knockout Jurkat cells

Figure 3.5. Disruption of IN-LEDGF/p75 interaction enhances HIV-1 antisense

RNA.

Figure 3.6. Pharmacological disruption of IN-LEDGF/p75 interaction enhances HIV-1

antisense RNA

Figure 3.7. Rapid decrease of antisense RNA from infected cells .73

Figure 3.8. Antisense RNA is not found in latently infected cells...................74

Figure 3.9 Antisense RNA HIV-1 in primary cells............................. 75

Figure 4.1. MOV10 knockdown leads to increment of HBV RNA, DNA and core

protein.

Figure 4.2. By half of dose MOV10 knockdown still enhanced HBV RNA, DNA and core protein

Figure 4.3. Time course of MOV10 knockdown leads to increment of HBV RNA, DNA and core protein.

Figure 4.4. MOV10 knockdown leads to increment of HBV RNA, DNA and core protein.

Figure 4.5. MOV10 knockdown leads to increase of HBV rcDNA...................92

Figure 4.6. MOV10 overexpression leads to reduction of HBV RNA, DNA, and core protein.

Figure 4.7. MOV10 overexpression leads to reduction of HBV RNA, DNA, and core

protein.

Figure 4.8 Endogenous MOV10 is upregulated during HBV infection.................96

Figure 4.9. Endogenous MOV10 colocalizes with HBV core protein and RNA.... .97 


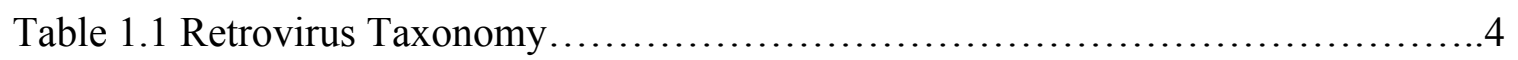

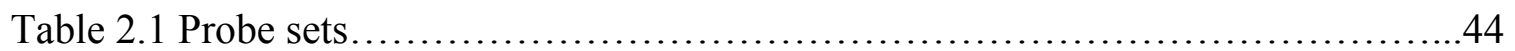




\section{LIST OF PUBLICATIONS}

1. Puray-Chavez MN*, Tedbury PR*, Huber AD, Ukah OB, Yapo V, Liu D, Ji J, Wolf JJ, Engelman AN, Sarafianos SG. Multiplex single-cell visualization of nucleic acids and protein during HIV infection. Nat Commun. 2017 Dec 1;8(1):1882.

2. Achuthan V, Perreira JM, Sowd GA, Puray-Chavez MN, McDougall WN, PaulucciHolthauzen A, Wu X, Fadel HJ, Poeschla EM, Multani AS, Hughes SH, Sarafianos SG, Brass AL, Engelman AN. Capsid-CPSF6 interaction determines the architectural basis for nuclear HIV-1 trafficking and integration site selection. Cell Host Microb. $2018 \mathrm{Jul}$

3. Huber AD, Michailidis E, Tang J, Puray-Chavez MN, Boftsi M, Wolf JJ, Boschert KN, Sheridan MA, Leslie MD, Kirby KA, Singh K, Mitsuya H, Parniak MA, Wang Z, Sarafianos SG. 3-Hydroxypyrimidine-2,4-diones as novel hepatitis B virus antivirals targeting the viral ribonuclease H. Antimicrob Agents Chemother. 2017 May 24;61(6).

4. Huber AD, Wolf JJ, Liu D, Gres AT, Tang J, Boschert KN, Puray-Chavez MN, Pineda DL, Laughlin TG, Coonrod EM, Yang Q, Ji J, Kirby KA, Wang Z, Sarafianos SG. The heteroaryldihydropyrimidine Bay 38-7690 induces hepatitis B virus core protein aggregates associated with promyelocytic leukemia nuclear bodies in infected cells. mSphere. 2018 Apr 18;3(2).

5. Huber AD*, Michailidis E*, Schultz ML, Ong YT, Bloch N, Puray-Chavez MN, Leslie MD, Ji J, Lucas AD, Kirby KA, Landau NR, Sarafianos SG. SAMHD1 has differential impact on the efficacies of HIV nucleoside reverse transcriptase inhibitors. Antimicrob Agents Chemother. 2014 Aug;58(8):4915-9. 
1. Puray-Chavez MN, Tedbury PR, Ukah OB, Yapo V, Achuthan V, Poeschla EM, Kvaratskhelia M, Engelman AN, Sarafianos SG. Loss of LEDGF/p75 targeted integration enhances transcription of HIV-1 antisense RNA. Manuscript in preparation.

2. Puray-Chavez MN, Huber AD, Liu D, Ndongwe TP, Casey M, Sarafianos SG. Mechanism of action of an RNA binding protein MOV10 on HBV replication. Manuscript in preparation.

3. Huber AD, Tang J, Michailidis E, Pineda DL, Puray-Chavez MN, Liu D, Gres AT, Boschert KN, Laughlin TG, Yang Q, Ji J, Kirby KA, Wang Z, Rice CM, Sarafianos SG. Novel Inhibition Mechanism of Hepatitis B Virus by a Capsid-Targeting Antiviral that Aggregates Core Particles and Inhibits Nuclear Entry of Viral Cores. To be submitted. 


\title{
LABELING HIV-1 NUCLEIC ACIDS DURING INFECTION AND EFFECT OF MOV10 IN HBV REPLICATION
}

\author{
Maritza N. Puray Chavez
}

Dr. Stefan G. Sarafianos, Dissertation Supervisor

\begin{abstract}
Technical limitations in simultaneous microscopic visualization of RNA, DNA, and proteins of HIV have curtailed progress in this field. To address this need we have developed a microscopy approach, multiplex immunofluorescent cell-based detection of DNA, RNA and Protein (MICDDRP), which is based on branched DNA in situ hybridization technology. MICDDRP enables simultaneous single-cell visualization of HIV spliced and unspliced RNA, cytoplasmic and nuclear DNA, and Gag. We use MICDDRP to visualize incoming capsid cores containing RNA and/or nascent DNA and follow reverse transcription kinetics. We have also reported transcriptional "bursts" of nascent RNA from integrated proviral DNA.

The major barrier towards a cure is the ability of the virus to remain dormant in long-lived cells known as the latent HIV reservoirs; however, the mechanisms that regulate latency are poorly understood. HIV-1 integration is directed to regions of the genome by the chromatin binding protein lens epitheliumderived growth factor (LEDGF/p75, referred to here as LEDGF). In the absence of LEDGF, HIV-1 infection is markedly less efficient. We report for the first time that knocking out LEDGF results in upregulation of antisense HIV-1 RNA transcription. Antisense HIV-1 transcripts are abundant in a higher proportion of cells when the
\end{abstract}


Integrase-LEDGF interaction is lost, whether by knocking out LEDGF or by pharmacological inhibition. We also demonstrate that intriguingly, antisense RNA is rapidly lost from infected cells. Using a dual reporter virus to investigate the association between HIV-1 antisense RNA and latency, we have determined that antisense RNA has low expression in "latently" infected cells.

Hepatitis B virus infection is a major health problem, there are more than 350 million people living with chronic HBV. Immune system can clear infection during the acute phase in immune-competent patients. A better understanding of the immune response against HBV infection may lead to new insights a find a cure. RNA helicases contribute to the immune response and some also have antiviral effects. MOV10 is a helicase RNA protein that has detrimental effect in HIV infection and HCV replication under MOV10 depletion or overexpression. Considering that HBV replication rely on reverse transcription to form DNA from pre-genomic RNA, we study the effect of MOV10 in HBV replication. Our data suggest that while MOV10 overexpression leads to HBV reduction, suppression of MOV10 enhances HBV replication. 


\section{CHAPTER 1 -INTRODUCTION}

\subsection{HUMAN IMMUNODEFICIENCY VIRUS (HIV-1)}

Human immunodeficiency virus-1 (HIV -1) has been well-studied since its discovery in 1983 and first reported cases in $1981(1,2)$. HIV-1 infection is a major worldwide health problem according to the World Health Organization. More than 70 million people have been infected with the HIV virus and about 35 million people have died of HIV. In 2016 about 36 million people were living with HIV and 18 million of these people receive antiretroviral therapy (Fig. 1.1.1). However, an additional 2 million people are newly infected and still there is not vaccine available $(3,4)$.

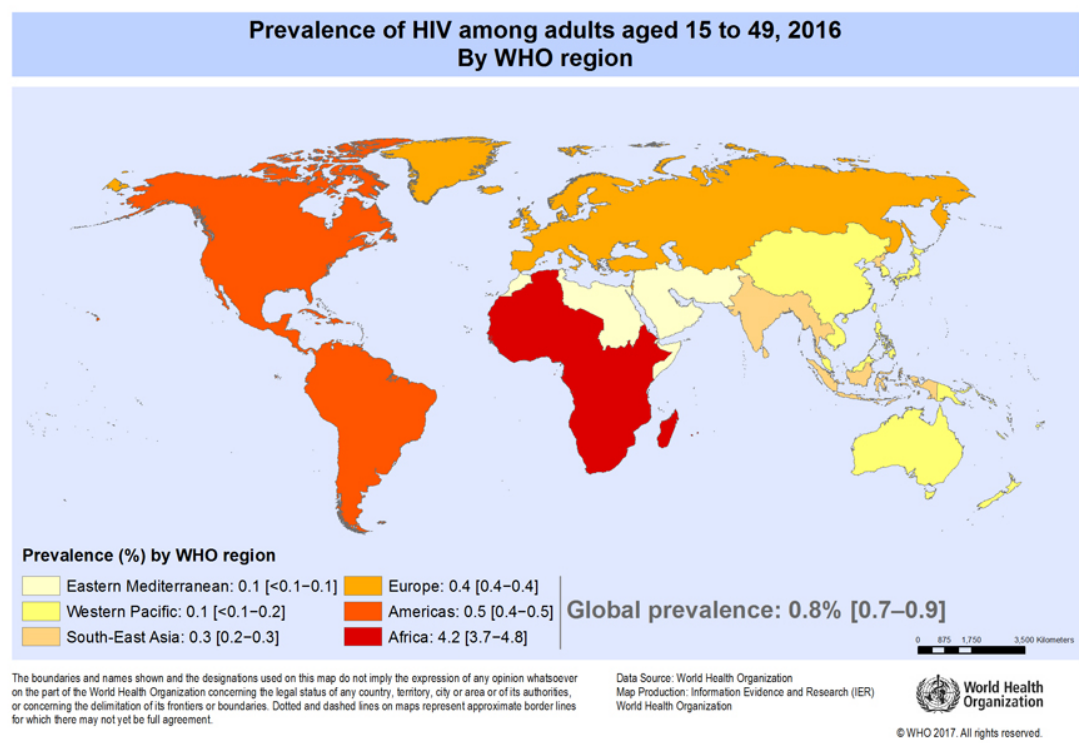

Figure 1.1.1 Prevalence of HIV in 2016 from World Health Organization. This figure is copied from WHO website with permission (260647 Permission authorization for WHO copyrighted material).

\subsubsection{HIV types and subtypes}

HIV is classified in two main types: HIV-1 and HIV-2. HIV-1 constitute $95 \%$ of 
reported cases around the world, while HIV-2 is reported mainly in West Africa and it is less infectious and progresses more slowly than $\operatorname{HIV}-1(5,6,7)$. HIV-1 strains are classified into four groups: $\mathrm{M}$ (main), $\mathrm{N}$ (non-M, non-O), O (outlier), and P. M group consist of nine subtypes: A, B, C, D; F, G, H, J and $\mathrm{K}$, additionally circulating recombinant forms (CRFs) and unique recombinant forms (URFs) $(8,9)$. Highly errorprone RT function and the fast replication of its cycle contribute to the distinctive genetic diversity of HIV. About the distribution of subtypes, subtype B predominates in America, Western Europe and Australia, while subtype $\mathrm{C}$ is the most prevalent and is responsible for the majority of the global HIV epidemic (Fig. 1.1.2) $(8,10-12)$.

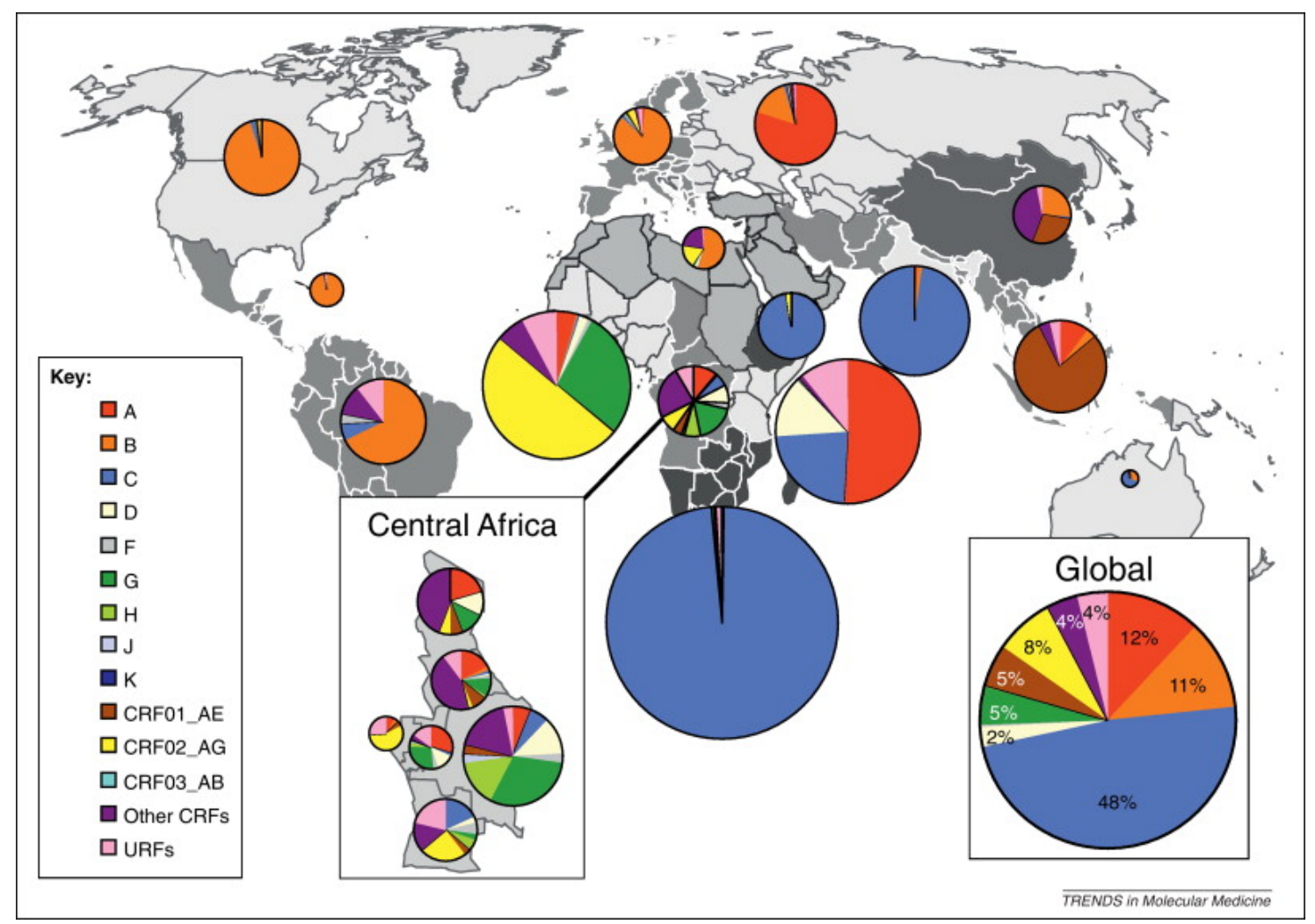

Figure 1.1.2. Global distribution of HIV-1 subtypes and recombinants. In the main figure, pie charts representing the distribution of HIV-1 subtypes and recombinants from 2004 to 2007 in each region are superimposed on the regions. The relative surface areas of the pie charts correspond to the relative numbers of people living with HIV in the regions. The colors representing the different HIV-1 subtypes and recombinants are indicated in the legend on the left-hand side of the figure. The HIV-1 subtype 
distributions found around the world and within Central African countries are shown in the insets of the main figure, as indicated. This figure is copied from (12) with permission (Licence number 4363100148175)

\subsubsection{Etiology and virus structure}

Acquired immune deficiency syndrome (AIDS) is defined by WHO as the most advanced stages of HIV infection (1). HIV-1 belongs to the Retroviridae family (13), subgroup lentiviruses (Table 1.1). It is an enveloped, single-stranded positive-sense RNA virus with an approximate diameter of $120 \mathrm{~nm}$ that contains two identical copies of genomic RNA. The nucleocapsid (NC) is bound to HIV RNA to protect it from degradation. HIV RNA is enclosed by a capsid (CA), and surrounded by a matrix (MA). MA associates with host lipid membrane containing viral envelope glycoproteins gp120 and gp41 (Fig 1.1.3). The HIV particle also carries three viral enzymes: reverse transcriptase $(\mathrm{RT})$, integrase $(\mathrm{IN})$, and protease $(\mathrm{PR})$, that participate in replication and virion maturation (14).

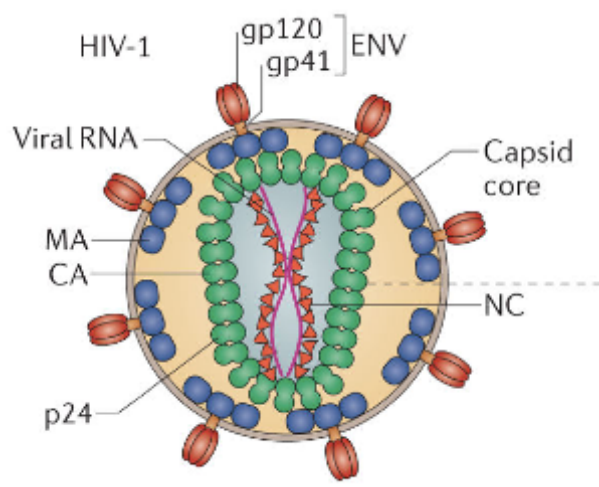

Figure 1.1.3. Schematic representation of the HIV-1 mature virion, Shown are the viral proteins envelope (Env, which is made up by gp120 subunits and gp41 subunits), and the Gag polypeptidederived proteins matrix (MA), capsid (CA) and nucleocapsid (NC). This figure is copied from (14) with permission (Licence number 4363110087255 ) 
Table 1.1 Retrovirus Taxonomy

\begin{tabular}{|c|c|c|}
\hline Subfamily & Genus & Species \\
\hline \multirow{6}{*}{ Orthoretrovirinae } & Alpharetrovirus & $\begin{array}{l}\text { Avian leukosis virus (ALV) } \\
\text { Rous sarcoma virus (RSV) }\end{array}$ \\
\hline & Betaretrovirus & $\begin{array}{l}\text { Jaagsiekte sheep retrovirus (JSRV) } \\
\text { Mouse mammary tumor virus (MMTV) } \\
\text { Mason-Pfizer monkey virus (M-PMV) }\end{array}$ \\
\hline & Deltaretrovirus & $\begin{array}{l}\text { Primate T-lymphotropic virus 1, 2, } 3 \text { (PTLV-1, 2,3) } \\
\text { Bovine leukemia virus (BLV) }\end{array}$ \\
\hline & Epsilonretrovirus & $\begin{array}{l}\text { Walleye dermal sarcoma virus (WDSV), } \\
\text { Walleye epidermal hyperplasia virus } 1,2 \text { (WEHV-1,2) }\end{array}$ \\
\hline & Gammaretrovirus & $\begin{array}{l}\text { Feline leukemia virus (FeLV) } \\
\text { Gibbon ape leukemia virus (GALV) } \\
\text { Murine leukemia virus (MuLV) } \\
\text { Reticuloendotheliosis virus (REV) }\end{array}$ \\
\hline & Lentivirus & $\begin{array}{l}\text { Bovine immunodeficiency virus (BIV) } \\
\text { Caprine arthritis encephalitis virus (CAEV) } \\
\text { Equine infectious anemia virus (EIAV) } \\
\text { Feline immunodeficiency virus (FIV) } \\
\text { Human immunodeficiency virus } 1,2 \text { (HIV-1, 2) } \\
\text { Simian immunodeficiency virus (SIV) }\end{array}$ \\
\hline Spumaretrovirinae & Spumavirus & $\begin{array}{l}\text { Bovine foamy virus (BFV) } \\
\text { Equine foamy virus (EFV) } \\
\text { Feline foamy virus (FeFV) } \\
\text { Simian foamy virus (SFV) }\end{array}$ \\
\hline
\end{tabular}

The HIV-1 genome contains three open reading frames (orfs), gag, pol and env that encode for nine viral proteins Gag, Pol, Env, Tat, Rev, Nef, Vif, Vpr, and Vpu (Vpx in the case of HIV-2) (15). gag gene encodes the viral core protein precursor $55 \mathrm{kDa}$ Gag (group specific antigen) that comprises major structural proteins: MA, CA, NC and p6, pol gene encodes the enzymes PR, RT, RNAse H and IN and env gene encodes the viral surface glycoprotein gp160, the precursor of the viral envelope proteins gp41 and gp120. 
HIV genome also encodes accessory proteins that enhance and control virus replication: Nef, Rev, Tat, Vif, Vpr, and Vpu (Fig. 1.1.4) $(15,16)$.

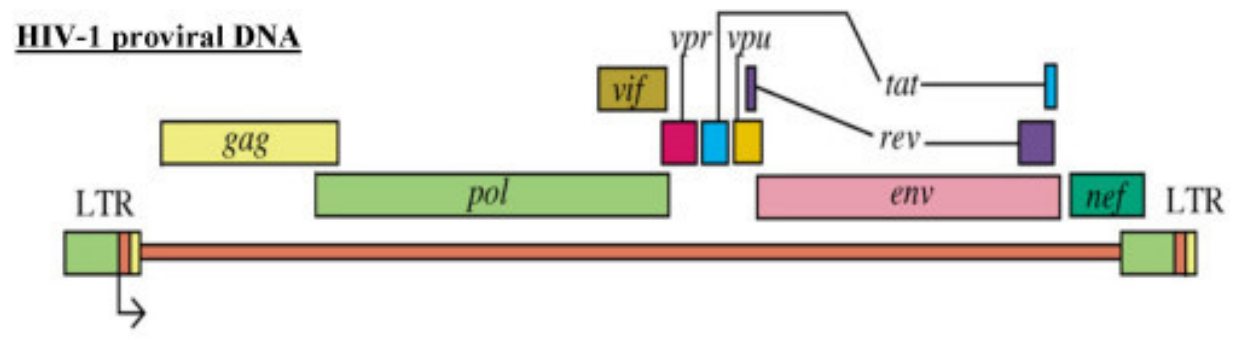

Figure 1.1.4. HIV-1 genome. A schematic representation of the HIV-1 gene products encoded by the HIV1 genome sequence. Courtesy: National Institute of Allergy and Infectious Diseases.

\subsubsection{Life Cycle}

HIV-1 mainly infects CD4+ T lymphocytes. It also replicates in myeloid cells, such us monocytes, macrophages and dendritic cells (DC), in various tissues (17). HIV replication cycle includes: attachment and fusion, reverse transcription, integration, replication, assembly, and maturation (Fig. 1.1.5).

1.1.3.1 Attachment and fusion. HIV-1 uses CD4 receptor and CCR5 and CXCR4 coreceptors on the target cell to bind to the surface. HIV-1 attaches to CD4 of the host cell through interaction of its gp120 surface protein. A conformational change in gp41 leads to membrane fusion and release of the viral core into the host cell cytoplasm $(18,19)$.

1.1.3.2 Reverse transcription. HIV capsid then may undergo uncoating or partially disassembly in the target cell (14). RT synthesizes double-stranded (ds) viral DNA from single-stranded viral RNA. $(19,20)$. RT has two enzymatic activities: DNA polymerase activity which synthesizes DNA by using either RNA or DNA as templates; and RNase $\mathrm{H}$ activity that degrades RNA from DNA-RNA intermediates, also enables appropriate 
generation of the RNA primers, termed as polypurine tracts (PPTs), which are necessary for the initiation of DNA synthesis. The PPT just upstream of the viral U3 region functions as the primer for plus-strand DNA synthesis. Upon the first 18 nucleotides of the tRNA ${ }^{3 L y s}$ are copied during the plus-strand DNA synthesis, the tRNA ${ }^{3 L y s}$ primer is removed by RNase H. Subsequently, the plus-strand DNA is transfered to the 3' end of minus-strand DNA and proceed for its synthesis. The plus-and minus-strand DNAs continue to extend, resulting in the formation of complete double-stranded viral DNA $(23,24)$.

1.1.3.3 Integration. Viral DNA is included in the pre-integration complex (PIC) for transport through the nucleopore and form viral nucleoprotein complex (NPC) that is transported to the nucleus. IN catalyzes integration of the dsDNA in interaction with host proteins into the host chromosome and the DNA is repaired to form provirus. (21). The integration process in more detail: first, 3' end processing, two nucleotides are removed from the blunt 3' end of both strands of linear viral DNA by IN, followed by DNA strand transfer into the nucleus, IN mediates the cleavage of the cellular target DNA, allowing the processed 3' end of the viral DNA to bind to the cleaved target DNA via the covalent attachment. Finally the gap is filled by cellular enzyme-mediated repair machinery, resulting in the completion of the integration process (25-27).

1.1.3.4 Transcription. The provirus functions as template for viral RNA synthesis via RNA polymerase II (pol II). Viral transcripts are expressed from the promoter located in the 5' long terminal repeat (LTR), which is generated during reverse trnascription, facilitated by host transcription machinery and enhanced by HIV-1 Tat. A set of spliced RNAs is formed first and then transported from the nucleus to the cytoplasm. Unspliced 
or partially spliced transcripts are transported later facilitated by $\operatorname{Rev}(19,22)$. The HIV LTR (630 bp) at both 5' and 3' ends of the proviral DNA are divided into three regions: unique 3' sequence (U3), repeated sequence (R) and unique 5' sequence U5 (28). The U3 region contains three regulatory domains: the core promoter region, the core enhancer region and the modulatory region (29). The core promoter has a TATA box, three SP1 binding elements, and an active initiator sequence (30). The core enhancer region comprises of two NF- $\mathrm{kB}$ binding motifs and an activator protein 1 (AP1) elements. The modulatory region contains the binding site for the upstream stimulatory factor (USF). Tat is essential for the transactivation of LTR-driven genes expression. Tat primarily promotes the elongation of HIV transcription, allowing the generation of the full-length transcripts (31).

1.1.3.5 Translation. Viral mRNAs are translated in the cytoplasm, and the Gag and Gag-Pol polyproteins become localized to the cell membrane. HIV Gag recruits viral genomic RNA and then traffics to the plasma membrane for assembly. The env mRNA is translated at the endoplasmic reticulum (ER).

1.1.3.6 Assembly. Virus particle is assembled from the Gag, and Gag-Pol polyproteins, Vif, Vpr, Nef, and the gRNA, and an immature virion begins to bud from the cell surface. The Gag polyprotein precursor Pr55 ${ }^{\mathrm{Gag}}$, consisting of MA, CA, NC and $\mathrm{p} 6$ domains, is synthesized from unspliced viral mRNA. The GagPol polyprotein precursor Pr160 GagPol, which contains MA, CA, NC, PR, RT and IN, is generated through a programmed ribosomal frameshifting event (32-34).

1.1.3.7 Release. Budding of new immature virus coated with SU gp120 and TM gp41 depends of the host cellular ESCRT machinery to exit the host cell (35). 
1.1.3.8 Maturation. Following HIV release from the plasma membrane, the immature viral particle undergoes maturation by viral PR, which cleaves Gag and Gag-Pol polyproteins into individual components. Processed proteins will reassemble to form the conical core. The mature virion is capable to infect a target cell $(34,36)$.

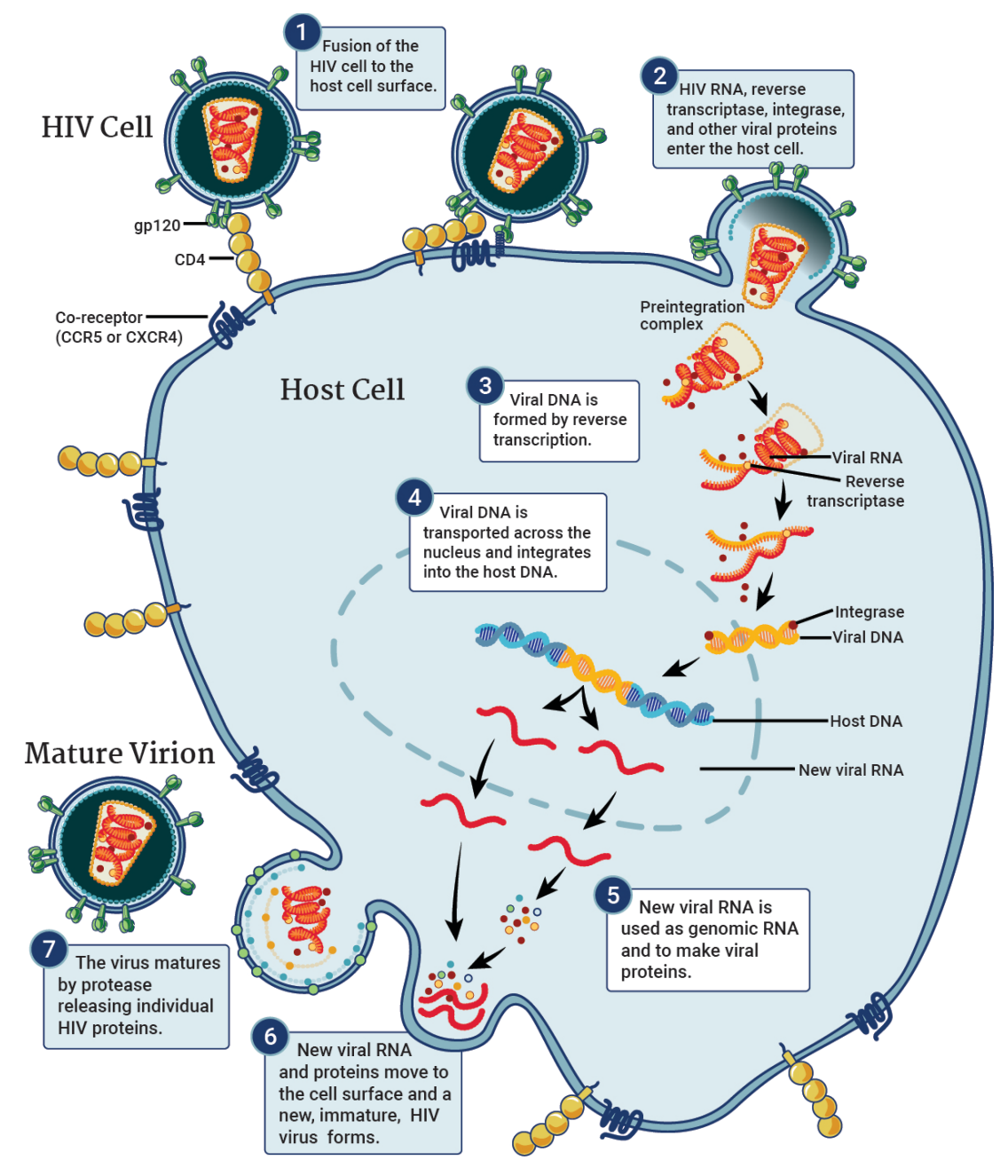

Figure 1.1.5. HIV-1 life cycle. Courtesy: National Institute of Allergy and Infectious Diseases.

\subsubsection{Transmission}


HIV-1 can be transmitted by sexual contact with mucosal surfaces and body fluids (rectum, vagina, urethra, mouth, eyes), by direct blood contact or percutaneous inoculation (sharing injection drugs, injuries from contaminated sharps), blood transfusions from infected donors and by maternal-infant exposure (37).

\subsubsection{Treatment}

The goal of antiretroviral therapy (ART) is to target, eliminate or limit the activity of viral proteins to abrogate HIV infection. The most used strategy targets the viral reverse transcriptase (RT), the key enzyme for productive HIV infection. In 1987, Zidovudine (AZT), an RT inhibitor, became the first antiretroviral drug approved by Food and Drug Administration (FDA) and nowadays more than 25 drugs have been approved. These drugs are generally divided into 6 classes that target and inhibit HIV replication at different steps of the life cycle: co-receptor antagonists, fusion inhibitors, nucleoside-analog reverse transcriptase inhibitors (NRTIs), non-nucleoside reverse transcriptase inhibitors (NNRTIs), integrase inhibitors, and protease inhibitors (PIs) (38, 39).

\subsubsection{Latency}

A succesful antiretroviral therapy (ART) allows to control the viral load under undetectable levels in infected patients, however HIV can persist in patients under ART due of long-lived resting memory T-cells that sustain the latent viral reservoir (40-44). These resting memory $\mathrm{CD} 4+\mathrm{T}$ cells harbouring an integrated, replication competent HIV genome (45), if these cells remain quiescent, the provirus stays transcriptionally silent (45). Latency has been shown in vivo in central and transitional memory T-cells (42) and naive T-cells and can also be established in monocyte-macrophages, microglia, 
hepatopoietic stem cells (HPCs) and astrocytes (44-48). Mechanisms for viral latency and reactivation remain elusive, additionally epigenetic reprogramming and modulated expressions of host factors are involved in viral latency that extends the complexity for further investigation.

\subsubsection{HIV-1 nucleic acids and protein detection at single cell level}

The HIV-1 life cycle, ART effectiveness and drug molecular mechanism of action have been traditionally studied using molecular or structural biology, biochemical and genetic tools. The more recent improvements on fluorescence in situ hybridization (FISH) along with viral protein detection and advancements in microscopic techniques offer options for visualizing virus at single cell level $(148,203,204)$. FISH strategy allows visualization of vRNA or vDNA until we recently reported the ability to label both nucleic acids of the HIV- replication cycle (203). The challenge of single-cell nucleic acid visualization techniques in HIV is to label transcription from individual integration sites. One of the first approaches to label HIV-1 provirus, called single-cell imaging of HIV-1 provirus (SCIP), introduces a restriction enzyme cut site into the vDNA, allowing proviruses to be detected with an exogenous endonuclease (121). A modified dNTPs, 5ethynyl-2- deoxyuridine (EdU), label reverse transcribed nascent vDNA by EdU incorporation follow by chemical click fluorescent azides, but this method is mainly apply to non-dividing cells (118). The modified FISH combine a sensitive branch-chain DNA (bDNA) plus immunostaining to visualize events in early HIV-1 infection in fixed cells. Importantly, the combination of fluorescence nucleic acid detection and protein labeling will provide new insights to understand HIV-1 infection.

\subsubsection{HIV-1 antisense RNA}


The existence of an HIV-1 antisense RNA (asRNA) and a protein translated from an antisense transcript was suggested 30 years ago (168) and later identified as $2242 \mathrm{bp}$ transcript (169). However, the role of the antisense RNA and the Antisense Protein (ASP) in HIV-1 infection is not well understood. Recent findings suggest ASP is involved in HIV-1 replication and latency (181). In contrast a well-studied retroviral asRNAs, the HTLV-1 bZIP factor (HBZ) RNA, expressed from the antisense strand of the HTLV-1 provirus, has been reported to be involved in the regulation of sense transcription and leukemogenesis by HTLV-1. Further investigation of HIV-1 asRNA is urgent to understand its role into the pathogenic mechanisms of HIV-1 and latency. 


\subsection{HEPATITIS B VIRUS (HBV)}

Worldwide more than 240 million people are chronically infected with hepatitis B virus (HBV), and every year 600,000 people die as consequences of HBV chronic infection which promote hepatocellular failure by cirrhosis and hepatocellular carcinoma (HCC) (49-51). HBV is a small, partially double-stranded enveloped DNA virus of the Hepadnaviridae family and has highly specific tropism for liver cells $(49,52)$. HBV enters host hepatocytes by an initial attachment to cells surface proteoglycans; follow by interaction with specific receptor. Upon entry HBV encounters host cell defense and enhances a response that is mediated by type I Interferon (IFN) and IFN-stimulated genes (ISG) (188), this response is able to clear infection over $90 \%$ of cases during the acute phase. During last years $\mathrm{DExD} / \mathrm{H}-$ box helicases shown to contribute to antiviral response by sensing viral nucleic acids or by facilitating downstream signaling events. Among those helicases we found MOV10 an RNA helicase that has a potent and broad antiretroviral activity, but its effect in HBV infection was only partially described.

\subsubsection{Virus Structure}

The HBV virion contains a $3.2 \mathrm{~Kb}$ double-stranded DNA genome (termed relaxed

circular DNA, rcDNA) and a viral reverse transcriptase (RT) enclosed in a capsid assembly made of 240 identical copies of capsid protein, surrounded by a lipid bilayer envelope that contains 3 viral surface glycoproteins, large (L), middle (M) and small (S) surface protein (53) (Fig.1.2.1). 

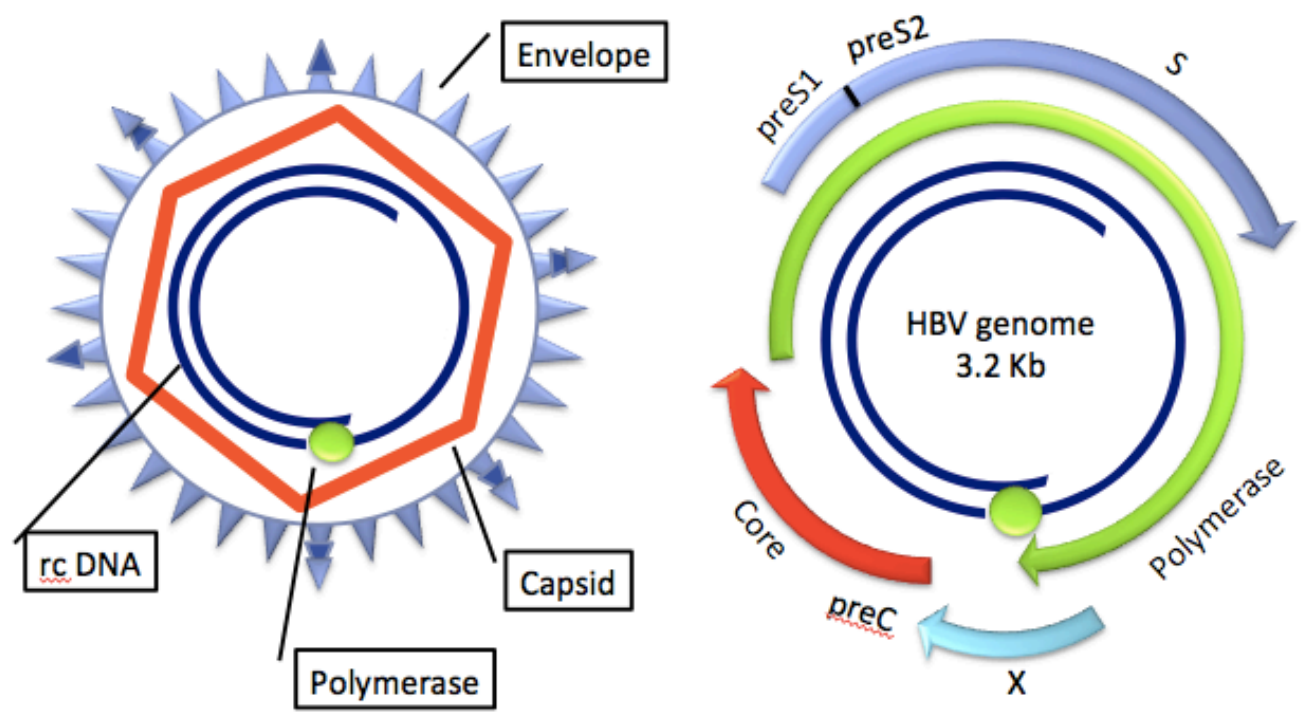

Figure 1.2.1. Schematic representation of $\mathrm{HBV}$ and virus structure. This figure was modified from (52)

The HBV genome encodes seven proteins: HBx, core, polymerase, L-, M-, and S$\mathrm{HBsAg}$, and precore/HBeAg. Of these proteins, $\mathrm{HBx}$ is a non-structural regulatory protein, $\mathrm{HBeAg}$ is not incorporated into virions and is independently secreted from the cells, the polymerase is responsible for genome replication, and the core and HBsAg proteins form the structural aspects of the virion (50) (Fig. 1).

\subsubsection{Life cycle}

A schematic of the life cycle is shown in Figure 1.2.1 (51). Entry is mediated by envelope $\mathrm{L}$ protein of the HBV virion that interacts with sodium taurocholate cotransporting polypeptide (NTCP), a transmembrane domain protein located on the surface of hepatocytes, to initiate receptor-mediated entry by endocytosis follow by fusion (54). The released core particle traffics to the cell nucleus through microtubules and interaction with importin $\beta(55,56)$. Then, core particle disassembles in the nuclear 
pore and releases the viral rcDNA into the nucleus. rcDNA is converted to covalently closed circular DNA (cccDNA) by a combination of RT activity and cellular host factors. cccDNA serves as the template for transcription of RNAs that are translated to the structural and non-structural proteins (core, S, M, L, RT, X, and E). Pre-genomic RNA (pgRNA) codes for core and RT and is packaged into the core particle. Then, RT converts pgRNA to rcDNA, and the particle can traffic to the nucleus to amplify the cccDNA pool or assemble through the endoplasmic reticulum, acquiring an envelope with S, M, and L, and exit the cell.

\subsubsection{Entry}

L- and S-proteins are crucial for viral entry of HBV (57). L-proteins contain S, preS1 and preS2 domains, M-proteins have S and preS1 domains, while S-proteins have $\mathrm{S}$ domain only (58). Early studies demonstrated that the preS1 domain of the $\mathrm{L}$ protein is required for viral infectivity (59-62). Yan et al. identified human sodium taurocholate cotransporting polypeptide (NTCP) as a receptor for HBV (54). They characterized the interaction between NTCP and an inhibitory preS1-derived lipopeptide and proved the role of NTCP for the susceptibility to HBV/HDV infection. Ectopic expression of human NTCP in non permissive HepG2 and HuH-7 hepatoma cells made these cells susceptible to HBV infection. NTCP is encoded by SLC10A1 gene and it is localized at the sinusoidal membrane of hepatocytes (63-65). NTCP expression is regulated by various effectors such us bile acids, cytokines, and hormones (66). HepG2-hNTCP cells are now being used as cell culture system for drug screening, host factors and HBV life cycle studies. 


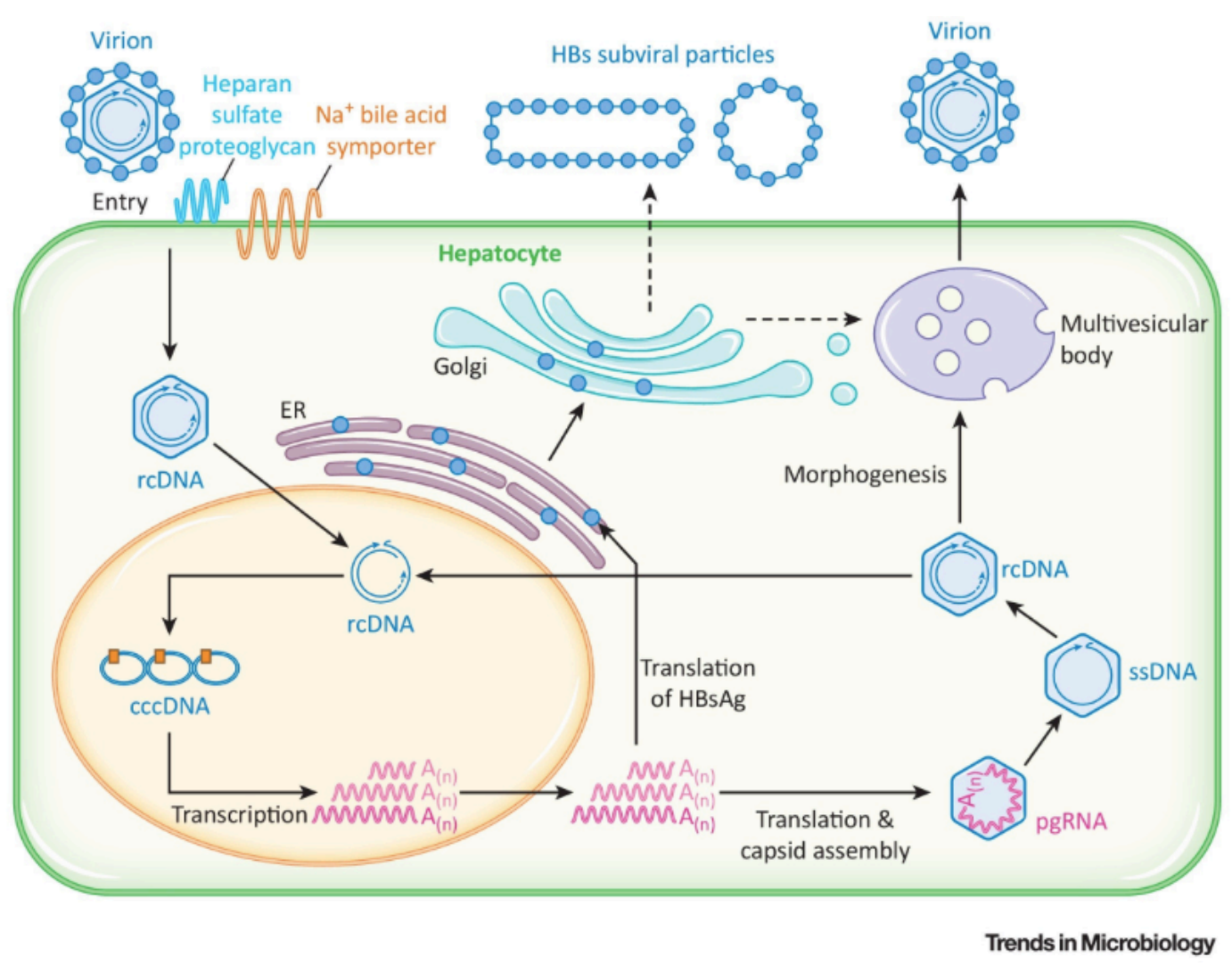

Figure 1.2.2. Schematic representation of HBV life cycle. This figure is copied from (53) with permission (Licence number 4363120355612)

\section{Endocytosis and membrane fusion.}

Endocytosis is the process of internalization induced after the plasma membrane folds inward. Cells use endocytosis to internalize cargo molecules from the cell surface. Some viruses have the capacity to penetrate into the cytosol directly through the plasma membrane, but most depend on endocytic uptake. HBV entry into liver cells probably depends on endocytic processes involving different host cellular proteins and factors. Caveolin and clathrin have been described to participate in HBV entry into HepaRG cells and Hus-E/2 immortalized primary human hepatocytes (PHH) (67-70). Most enveloped viruses that use endocytosis rely on $\mathrm{pH}$-dependent processes in order to trigger fusion of the vesicular and viral membrane. However, ammonium chloride and chloroquine, which 
raises the endosomal $\mathrm{pH}$, did not interfere with $\mathrm{HBV}$ infection (71). Bafilomycin $\mathrm{A} 1$, which neutralizes the luminal $\mathrm{pH}$ of the endosomes and interferes with formation and maturation of endosomal carrier vesicles from early endosomes, inhibited HBV infection (72). Rab5 and Rab7, early and late endosome markers, are required for HBV infection of HepaRG cells (73). These evidences support the hypothesis that HBV is transported from early to late endosomes.

\subsubsection{Trafficking}

After nucleocapsid is released from endosome by an unknown mechanism, it is thought to use the microtubule network for transit to the nucleus via interaction with motor proteins. The precise location and timing of nucleocapsid release from endosomes remain unknown. To study the translocation of HBV nucleocapsids, Rabe et al. introduced those into non-susceptible, but replication competent HuH-7 cells using a microinjection method (74) or a lipid-based delivery system (75). Viral DNA was detected in the nuclei at $1 \mathrm{~h}$ post-lipofection. Treatment of cells with actin-depolymerizing drugs (cytochalasin D or latrunculin B) did not significantly impair the transportation of nucleocapsids. However, treatment with nocodozale, a microtubule-depolymerizing drug, impaired nuclocapsid translocation (76). Microtubules connect the cell periphery to the interior of the cell. The less dynamic minus ends converge at the microtubule-organizing center near the nucleus. While some transport is mediated by polymerization and depolymerization of microtubules, movement of macromolecules is mainly accomplished via motor proteins, including kinesin, which transports material toward the periphery (anterograde), and dynein, which transports material towards the nucleus (retrograde) $(77,78)$. 


\subsubsection{3 cccDNA}

cccDNA formation from rcDNA starts after core particle is disassembled at nuclear pore complex. cccDNA synthesis include removal of the covalently linked RT from (-) strand DNA, removal of the RNA primer from (+) strand DNA, completion of (+) strand DNA synthesis, and ligation of the ends of both DNA strands to form the covalently closed product. Tyrosyl-DNA phosphodiesterase 2 (TDP2) has been suggested as the factor responsible for removal of RT from the viral DNA (79). DNA polymerase $\kappa$ (polк) has been suggested as a factor involved in completion of DNA synthesis to form cccDNA (80). cccDNA becomes a "minichromosome" $(81,82)$ due its interaction with histones, it is very stable and it can be 2 to 50 copies in the nucleus of infected cells.

\subsubsection{Transcription and translation}

cccDNA serves as the template for transcription of 5 main unspliced RNAs that are translated into the 7 viral proteins: Core, S, M, L, RT, X, and E. The transcripts are unspliced, polyadenylated, and possess a 5' cap structure. Pre-genomic RNA (pgRNA) encodes for Core and RT and is packaged into the core particle (83).

\subsubsection{Assemble and release}

After translation RT recognizes and binds pgRNA, then core protein binds and assembles around pgRNA for packaging. After formation of the core particle, $\mathrm{P}$ initiates reverse transcription of the RNA genome leading to the synthesis of minus-strand DNA and digestion of pgRNA by the ribonuclease $\mathrm{H}(\mathrm{RNaseH})$ domain of $\mathrm{P}$. Minus-strand DNA then serves as a template for the synthesis of plus-strand DNA, resulting in the formation of a relaxed circular, partially dsDNA genome (84). Mature capsids are either enveloped and secreted from the cell or transported to the nucleus, amplifying the pool of 
cccDNA. Secretion of virus particles is mediated by interactions of the capsid with the large hepatitis B surface antigen (L-HBsAg) at the endoplasmic reticulum (ER). Independent of infectious virus particles (Dane particles), noninfectious subviral particles (SVPs) containing small, medium, and large forms of HBsAg are also released from the infected cell (84).

\subsubsection{Treatment and prevention}

Current HBV therapy approved by the FDA targets the RT enzyme. Nucleos(t)ide reverse transcriptase inhibitors (NRTIs) are analogs of natural nucleos(t)ides that are incorporated into viral DNA and act as "chain terminators" by preventing further DNA synthesis. NRTIs are used in both HIV and HBV treatments, and 2 drugs, lamivudine and tenofovir, can be used to treat both viruses. There are 5 approved NRTIs for HBV treatment: lamivudine, adefovir, telbivudine, tenofovir, and entecavir (85-87). An effective vaccine is available, that confers protection over $90-95 \%$ of immunized people, however it has no effect on infected patients.

\subsubsection{Immune response and role of host factors}

HBV causes an acute and chronic stage of infection, $90 \%$ of acute cases will recover due immune response (88). Innate immune response promotes the expression of proinflammatory cytokines and type-I interferons (IFNs), which affect IFN-stimulated genes (ISGs) that counteract virus replication and spread (89). Studies focused on HIV have helped scientists to discover another group of proteins that are also part of the innate immune response: restriction factors (RFs), which are cellular proteins that can restrict or block viral replication in a cell-specific way, and which normally respond to IFN stimulation (90). 
RFs are determinants of viral susceptibility restrictions. They can target viruses in different parts of their cycles and can restrict and overcome viral infection, but viruses have also developed strategies to overcome RFs. If immune response is capable to abrogate $\mathrm{HBV}$ infection in more than $90 \%$ of immune-competent patients during acute phase of infection, further investigation on host factors involve in HBV infection may lead to new insights to cure chronic infection since the antiretroviral therapy is not capable to clear infection. Since new HBV DNA synthesis in infected cells rely on reverse transcription from pre-genomic RNA, the RNA helicases may play an important role for vRNA detection and possible targeting. To date the identified RFs that affects HBV are: APOBEC3, AID, MX, MOV10, DDx3, SAMHD1 and Tetherin.

\subsubsection{APOBEC}

The apolipoprotein $\underline{\mathbf{B}}$ mRNA-editing enzyme catalytic polypeptide (APOBEC) family of cytidine deaminases consists of 11 members: APOBEC-1 (Apo1), APOBEC-2 (Apo2), activation-induced cytidine deaminase (AID), APOBEC-3A, -3B, -3C, -3DE, 3F, -3G, $-3 \mathrm{H}(\mathrm{Apo} 3 \mathrm{~A}-\mathrm{H})$, and APOBEC-4 (Apo4). All APOBEC proteins have one or two copies of zinc-coordinating deaminase domain, known as $\mathrm{Z}$ domain with a motif HxEx23-28PCxxC, which catalyzes cytidine deamination that converts cytosines to uracils. APOBEC members are able to edit ssDNA and/or RNA sequences, and, more specifically, are $\mathrm{C} \rightarrow \mathrm{U}$ editing enzymes. The N-terminal domain of APOBEC-like proteins is the catalytic domain, while the C-terminal domain is a pseudo-catalytic domain (91). The APOBEC3 subgroup includes A3A, A3B, A3C, A3DE, A3F, A3G, and $\mathrm{A} 3 \mathrm{H}$. These genes are tandemly arrayed on human chromosome 22 . $\mathrm{A} 3 \mathrm{~A}, \mathrm{~A} 3 \mathrm{C}$, and $\mathrm{A} 3 \mathrm{H}$ have one copy of $\mathrm{Z}$ domain, whereas A3B, A3DE, A3F, and A3G have two. The role of 
APOBEC3 proteins extends to HBV, HIV, HTLV, HCV, HPV, HSV-1, and EBV. APOBEC3 inhibits these viruses through a series of editing-dependent and independent mechanisms. APOBEC3G for example produces $\mathrm{G}-\mathrm{A}$ or $\mathrm{C}-\mathrm{T}$ mutations on the viral plus strand DNA, the cytidine is deaminated to uracil on the minus strand DNA. Uracil containing DNA is attacked by uracil DNA glycosylase (UNG) that removes the uracil generating an abasic site and DNA becomes a target for endonucleases that lead to DNA degradation. These hypermutations were thought to be the only method of viral inhibition, however other options are under investigation (92-94).

\subsubsection{AID}

Activation-induced cytidine deaminase (AID) is a member of APOBEC family and is essential to the somatic hypermutation (SHM) and class-switch recombination (CSR) of immunoglobulin $(\mathrm{Ig})$ genes $(95,96)$. In the DNA deamination model, AID converts cytidine bases in DNA into uridine. The uridine is recognized by the DNA repair system, which produces DNA strand breakages and point mutations. AID can deaminate the nucleocapsid RNA of HBV and its up-regulation is mediated by IL-1 $\beta$ and TNFa in vitro $(95,96)$.

\subsubsection{MX}

(MX) proteins belong to a superfamily of proteins, the large guanosine triphosphatases (GTPases), which includes the dynamins that are known to be involved in intracellular vesicle trafficking and organelle homeostasis. MX GTPases are induced by interferon and share structural and functional properties with dynamin, such as selfassembly and association with intracellular membranes $(97,98)$. A unique property of some MX GTPases is their antiviral activity against a wide range of RNA viruses, such as 
influenza viruses (97). MX proteins consist of three domains, namely an N-terminal GTPase domain that binds and hydrolyses GTP, a middle domain mediating selfassembly known as "central interactive domain" (CID), and a carboxy-terminal GTPase effector domain with leucine zipper motifs (LZ) (99). Murine myxovirus resistance protein 1 (MX1) is located in the nucleus and was the first cellular ISG with potent antiviral activity to be identified by Horisberger et al. in the 1980s, in studies of influenza viruses in murine models. In humans, the ortholog MxA is a GTPase of the dynamin superfamily, the expression of which is potently induced by type I and type III IFNs and HBV is a MxA-sensitive virus (24).

\subsubsection{MOV10}

Moloney Leukemia Virus 10 (MOV10) is a GTP-binding protein originally discovered as MOV10 mouse strain, which derived from pre-implantation embryos infected with Moloney murine leukemia virus (MLV). MOV10 has been classified as a RNA helicase and may have up to seven helicase motifs (I, Ia, II, III, IV, V, and VI), which are classified into three super families (SF-1, SF-2, SF-3) and two small families (F-4, F-5). Motif I has a GxxxxGKT/S consensus and binds to phosphates; and motif II has a DExx consensus and binds to magnesium $(100,101)$. Mov10 and APOBEC3G (A3G) localize to cytoplasmic granules called processing bodies ( $\mathrm{P}$ bodies), incorporate into human immunodeficiency virus type 1 (HIV-1) virions, and inhibit viral replication. Others have reported that overexpression of the P-body-associated protein MOV10 can inhibit other retroviruses, including simian immunodeficiency virus (SIV), murine leukemia virus (MLV), and equine infectious anemia virus (EIAV) $(101,102)$. MOV10 
may inhibit HBV replication in MOV10 overexpressed cells at dosis dependend manner, while reducttion of its expression may lead to virus inhibition (103).

\subsubsection{SAMHD1}

Sterile alpha motif and HD ((histidine-aspartic) domain-containing protein 1 (SAMHD1) contains 626 amino acids and has 2 domains, SAM domain with residues from 45 to 110 amino acids, and HD domain with residues from 164 to 319 amino acids. SAM domains are known to perform a number of functions such protein-protein and protein-nucleic acid interactions in organisms from yeast to humans, docking sites for kinases, signal transduction and regulation of transcription. HD domain containingproteins are characterized by a doublet of histidine and aspartic acid catalytic residues, and have been shown to possess putative nuclease, dGTP triphosphatase activities (104, 105). The human SAMHD1 protein has dNTP triphosphatase activity, specifically dGTPstimulated dNTP triphosphohydrolase activity, and nuclease activity against singlestranded DNA and RNA, which is associated with its HD domain. SAMHD1 restricts HBV infection (106).

\subsubsection{Tetherin}

Tetherin (BST-2 or CD317) was originally identified as a specific cell surface marker of terminally differentiated B-cells. Tetherin also known as bone marrow stromal antigen 2 is a lipid raft associated protein in humans and it is encoded by the BST2 gene (107-109). Tetherin is an interferon (IFN)-inducible type II membrane protein, consisting of a short amino-terminal cytoplasmic tail (CT) followed by an $\alpha$-helical transmembrane (TM) domain, a coiled-coil extracellular (EC) domain, and a carboxy-terminal glycophosphatidylinositol (GPI) component that acts as a second membrane anchor 
(110). Three cysteine residues located at the EC domain form intermolecular disulfide bonds, resulting in homodimerization of the protein. At the cell surface, tetherin is located in cholesterol-rich lipid microdomains, also termed lipid rafts, through the GPI anchor. The TM domain resides outside the lipid rafts, placing the CT in a suitableposition to indirectly interact with the actin cytoskeleton. Tetherin is physiologically endocytosed from lipid rafts in a clathrin-dependent manner through interaction with $\alpha$-adaptin of the AP-2 complex. Tetherin affects HBV infection (106).

\subsubsection{DDX3}

DDX3 belongs to the DEAD (D-E-A-D: Asp-Glu-Ala-Asp)-box RNA helicase family, which is an ATPase-dependent RNA helicase. DDX3 has two homologs designated DDX3X (DBX) and DDX3Y (DBY), which were located on $\mathrm{X}$ and $\mathrm{Y}$ chromosomes, respectively (112). DDX3X is ubiquitously expressed in most tissues and it is involved in various RNA metabolism, including transcription, translation, RNA splicing, RNA transport, and RNA degradation $(113,114)$. DDX3 specifically binds to the HBV Pol and is incorporated into nucleocapsid together with HBV Pol (115) also suppresses transcription from HBV promoter (116).

The innate immune system plays a central role to avoid HBV infection. Deciphering the regulation of IFN-induced and no-IFN induced anti-viral restriction factors, their potential to cooperate and achieve virus inhibition could instruct innovative antiviral strategies, better vaccine design or immunomodulation against viruses. 


\section{CHAPTER 2 - MULTIPLE SINGLE-CELL VISUALIZATION OF NUCLEIC ACIDS AND PROTEIN DURING HIV INFECTION}

As found in: Puray-Chavez MN*, Tedbury PR*, Huber AD, Ukah OB, Yapo V, Liu D, Ji J, Wolf JJ, Engelman AN, Sarafianos SG. Multiplex single-cell visualization of nucleic acids and protein during HIV infection. Nat Commun. 2017 Dec 1;8(1):1882.

\section{$2.1 \quad$ INTRODUCTION}

Despite progress in nucleic acid visualization techniques, visualization of HIV transcription from individual integration sites has proven elusive. Moreover, there is a need for an integrated approach to simultaneously monitor changes in spliced and unspliced viral RNA (vRNA), viral DNA (vDNA), and proteins at a single-cell level during the various steps of the HIV replication cycle. Various approaches have been reported over the past few years for the combined imaging of HIV nucleic acids and proteins. One of the first approaches to allow visualization of integrated HIV-1 proviruses exploited the recruitment of specific histones to sites of DNA damage in combination with a reporter virus containing a rare restriction site (117). This single-cell imaging of HIV-1 provirus (SCIP) approach provided sensitive labeling of integrated provirus, but not unintegrated vDNA, in apparent contrast to later techniques. Others exploited 5-ethynyl-2- deoxyuridine (EdU), which can be incorporated into nascent DNA and then labeled with fluorescent azides by click chemistry $(118,119)$. This approach can be used with native virus, rather than a reporter virus, and has been successfully employed in non-dividing cells. The use of EdU is challenging in dividing cells, however, as EdU is incorporated into the genome of the infected cell, generating high background. 
For nucleic acid labeling in dividing cells, several groups have applied variations of fluorescence in situ hybridization (FISH): either immuno-DNA FISH (120) or branched DNA (bDNA)-FISH (121). These FISH approaches allowed investigators to examine the vDNA localization at various points during infection and to identify the number and position of viral integration sites in the host genome. Each method has strengths and shortcomings, such as being limited to either RNA or DNA labeling or requiring treatment of the infected cell during reverse transcription to label the viral genome.

Here we describe Multiplex Immunofluorescent Cell-based Detection of DNA, RNA, and Protein (MICDDRP), a bDNA-FISH method with the ability to label the native nucleic acids of the HIV-1 replication cycle, and show how it can be used to track various intermediates of HIV replication, focusing on the kinetics with which various species appear following infection. We follow the appearance of vDNA, nuclear import of vDNA, vRNA transcription from integrated vDNA, splicing of vRNA, and nuclear export of vRNA. The ability to visualize these nucleic acid intermediates in the context of viral or host proteins will advance efforts to elucidate mechanisms of antiviral inhibition by small molecules or host restriction factors, enhance our understanding of latency reactivation, and further efforts for novel drug development.

\subsection{MATERIALS AND METHODS}

\section{Cell culture}

TZM-bl (NIH AIDS Reagent Program catalog \#8129) are HeLa-derived human epithelial cells that stably express the HIV-1 receptor (CD4) and co-receptors (CXCR4 and CCR5) (122-126). TZM-bl cells additionally express $\beta$-galactosidase and firefly 
luciferase enzymes under the control of the HIV-1 promoter. TZM-bl cells were cultured in Dulbecco's modified Eagle's medium (DMEM; Gibco) supplemented with 10\% heatinactivated fetal bovine serum (FBS) and $2 \mathrm{mM}$ L-glutamine (Gibco) in a humidified incubator at $37{ }^{\circ} \mathrm{C}$ with $5 \% \mathrm{CO}$. HEK 293-FT cells are derived from human embryonic kidney cells transformed with the SV40 large T antigen (ThermoFisher Scientific; catalog \#R70007). These cells were cultured in the same medium and conditions as described for TZM-bl.

Jurkat cells (NIH AIDS Reagent Program catalog \#177) are a human, CD4 and CXCR4 positive, T lymphocyte cell line (127). Jurkat cells were cultured in Roswell Park Memorial Institute 1640 medium (RPMI; Gibco) supplemented with $10 \%$ heatinactivated FBS and $2 \mathrm{mM} \mathrm{L}$-glutamine in a humidified incubator at $37{ }^{\circ} \mathrm{C}$ with $5 \% \mathrm{CO} 2$. THP-1ATCC cells (NIH AIDS Reagent Program catalog \#9942) are a monocytic cell line that expresses CD4, CXCR4, and (following activation) CCR5. They were cultured as described for Jurkats. Lymphocytes were purified from peripheral blood mononuclear cells (PBMC; STEMCELL Technologies catalog \#70025) as previously described (128, 129). Briefly, MDMs were isolated by adherence to the culture vessel, and non-adherent cells were removed and stimulated with $60 \mathrm{U} / \mathrm{mL}$ interleukin-2 (IL-2) (PeproTech) and 4 $\mu \mathrm{g} / \mathrm{mL}$ phytohemagglutinin (PrepoTech) for 3 to 4 days prior to infection.

Primary lymphocytes were cultured in RPMI supplemented with $10 \%$ heat inactivated FBS and $60 \mathrm{U} / \mathrm{mL}$ IL-2 in a humidified incubator at $37{ }^{\circ} \mathrm{C}$ with $5 \% \mathrm{CO} 2$. For time course experiments and clinical isolate infection, primary CD4+ $\mathrm{T}$ cells were isolated from PBMCs using EasySep ${ }^{\mathrm{TM}}$ Human CD4+ $\mathrm{T}$ Cell Enrichment Kit 
(STEMCELL Technologies), following the manufacturer's instructions. T cells were cultured and stimulated in RPMI supplemented with 10\% heat-inactivated FBS, 2 mM Lglutamine, $60 \mathrm{U} / \mathrm{mL}$ IL-2, and $25 \mu \mathrm{L} / \mathrm{mL}$ ImmunoCult ${ }^{\mathrm{TM}}$ Human CD3/CD28/CD2 $\mathrm{T}$ Cell Activator for 8 days prior to infection. Cells were maintained in a humidified incubator at $37^{\circ} \mathrm{C}$ with $5 \% \mathrm{CO} 2$, and with fresh media added every $2-3$ days.

\section{Antibodies and compounds}

Capsid antibody, mouse monoclonal anti-p24 (NIH AIDS reagent Program mab24-2 catalog \#6457) $(130,131)$, was used at a 1:2000 dilution followed by goat antimouse secondary antibodies at a 1:2000 dilution, conjugated to either Alexa Fluor 647 (Invitrogen catalog \#A-21235) or Alexa Fluor 568 (Invitrogen catalog \#11004). RNase H inhibitor naphthyridinone $\left\{4-\left[\left(4^{\prime}\right.\right.\right.$-aminomethyl-1,1'-biphenyl)methyl]-1-hydroxy-1,8naphthyridin-2-one (NAPHRHI) $\}$ is derived from 1-hydroxy-1,8-naphthyridin-2(1H)one. It was prepared as described by Williams et al. (132). Briefly, the benzyl esterprotected scaffold was saponified and decarboxylated, and the resulting phenol was converted to triflate. NAPHRHI was formed by Negishi coupling with a benzylzinc reagent obtained by treating 4-bromobenzyl bromide with diethyl zinc, followed by

Suzuki coupling of the bromide with 4-(N-Boc- aminomethyl)phenylboronic acid and by deprotection with $\mathrm{HBr}$ (132) (U.S. patent application 20100056516). Raltegravir (133) (ISENTRESS/MK-0518) was obtained from the AIDS Reagent Program.

\section{Nucleic acid probes}

All probes were purchased from Advanced Cell Diagnostics. To detect HIV-1 vRNA, two anti- sense probes were used; the first probe targets the Gag coding region of 
HIV-1 (HIV vRNA anti- sense probe-1, PS-1 [probe channel C1 or C2]) (134), and the second probe targets non-Gag-Pol regions coding envelope and accessory proteins (HIV vRNA anti-sense probe-3, PS-3, [probe channel C3]). For HIV-1 vDNA detection, a sense probe targeting the Gag-Pol coding region was used to avoid binding to the vRNA (HIV vDNA sense probe-2, PS-2, [probe channel ID C1]). Supplementary Table 1 contains a complete list of the probe sets used in this study.

\section{HIV-1 infection}

Infectious HIV-1 particles were prepared by transfection of $3 \times 10^{6} 293 \mathrm{FT}$ cells (ThermoFisher Scientific) with $10 \mu \mathrm{g}$ NL4-3 proviral plasmid (135) in a $10 \mathrm{~cm}$ dish, using $30 \mu \mathrm{L}$ Fugene 6 (Promega) in $500 \mu \mathrm{L}$ Opti-MEM (Gibco). Media were changed 16 $\mathrm{h}$ post-transfection. Supernatant was harvested $48 \mathrm{~h}$ after transfection, cleared by centrifugation for $5 \mathrm{~min}$ at $700 \mathrm{x} \mathrm{g}$ followed by filtration through a $0.45 \mu \mathrm{M}$ polyvinylidene fluoride filter, and stored in aliquots at $-80{ }^{\circ} \mathrm{C}$. Virus particles were titrated in TZM-bl cells using 5 -fold serial dilutions in the presence of $20 \mu \mathrm{g} / \mathrm{mL}$ DEAEDextran. After $48 \mathrm{~h}$, cells were fixed, and the number of blue forming units (bfu) was determined. This titer was used to determine multiplicity of infection (MOI) for future experiments, where MOI of 1 is $1 \mathrm{bfu}$ per cell. It should be noted that differences in experimental conditions (e.g., reduced incubation time or infection of different cell types) may alter the observed MOI of the experiments, relative determined in titration. In these cases, the apparent MOI for the experiment was quoted rather than the MOI expected under the titration conditions. Semi-synchronous infections of TZM-bl cells were

performed using $2 \times 10^{4}$ cells plated on $12 \mathrm{~mm}$ collagen-coated coverslips (GG-12- 
Collagen; Neuvitro) (136). Cells and virus were pre-chilled separately at $4{ }^{\circ} \mathrm{C}$ for $10 \mathrm{~min}$, then virus was added to cells and incubated at $4{ }^{\circ} \mathrm{C}$ for 20 to $30 \mathrm{~min}$ in the presence of 20 $\mu \mathrm{g} / \mathrm{mL}$ DEAE-Dextran before being placed at $37^{\circ} \mathrm{C}$ in a $\mathrm{CO}_{2}$ incubator. Virus-containing media were removed after $2 \mathrm{~h}$, and cells were washed twice with Dulbecco's phosphate buffered saline (DPBS; Sigma). Fresh media were added, and the cells were cultured at $37^{\circ} \mathrm{C}$. To harvest, cells were washed twice with DPBS, fixed with $4 \%$ paraformaldehyde in DPBS for $30 \mathrm{~min}$ at room temperature, and then washed three times with DPBS.

To infect Jurkat and THP-1 cells, 5 x $10^{5}$ pre-chilled cells were mixed with prechilled virus then seeded into 12-well plates with RPMI and $8 \mu \mathrm{g} / \mathrm{mL}$ polybrene. Plates were centrifuged at $1200 \mathrm{x} \mathrm{g}$ for $40 \mathrm{~min}$ at $4^{\circ} \mathrm{C}$ to promote virus attachment then placed at $37^{\circ} \mathrm{C}$. Media were removed after $2 \mathrm{~h}$, and cells were washed twice by resuspension in DPBS followed by centrifugation at $300 \mathrm{x}$ g for $5 \mathrm{~min}$. To harvest, cells were washed once with DPBS then seeded onto poly-L lysine-coated coverslips (coated overnight with $0.01 \% \mathrm{w} / \mathrm{v}$ poly-L lysine in water [Sigma] at $4{ }^{\circ} \mathrm{C}$ then washed three times with DPBS before use) and allowed to attach for $40 \mathrm{~min}$ at room temperature. Cells were fixed with 4\% paraformaldehyde in DPBS for 30 min at room temperature then washed twice with DPBS. Infections of primary cells were performed as described for Jurkat and THP-1 cells.

For the time course of infection in primary CD4+ T cells, HIV-1 NL4-3 was used, concentrated with Lentivirus precipitation solution (Alstem), following the manufacturer's instructions. For the infection of primary CD4+ T cells, the HIV-1Ba-L isolate was used $(137,138)$ as provided by the AIDS Reagent program. For both 
experiments, $3-5 \times 10^{5}$ pre-chilled CD4+ T cells (activated 8 days earlier) were mixed with pre-chilled virus then seeded into 12 -well plates with RPMI and $8 \mu \mathrm{g} / \mathrm{mL}$ polybrene. Plates were centrifuged at $1200 \mathrm{x}$ g for $1 \mathrm{~h}$ at $16-20{ }^{\circ} \mathrm{C}$ then placed at $37{ }^{\circ} \mathrm{C}$ in a $\mathrm{CO}_{2}$ incubator. Media were removed after $4 \mathrm{~h}$, and cells were washed twice by resuspension in DPBS followed by centrifugation at $300 \mathrm{x}$ g for $5 \mathrm{~min}$. To harvest, cells were washed once with DPBS then seeded in 20-30 $\mu \mathrm{L}$ suspensions onto poly-L-lysine-coated coverslips (coated overnight with $0.01 \% \mathrm{w} / \mathrm{v}$ poly-L-lysine [Sigma] in water at $4{ }^{\circ} \mathrm{C}$ then washed three times with DPBS before use and not allowed to dry throughout). The suspension was distributed with a tip and allowed to attach for $10 \mathrm{~min}$ at $37{ }^{\circ} \mathrm{C}$. Cells were fixed with $4 \%$ paraformaldehyde in DPBS for $30 \mathrm{~min}$ at room temperature then washed twice with DPBS.

\section{In situ vRNA detection}

HIV-1 vRNA in cells was probed using RNAscope reagents (Advanced Cell Diagnostics). The manufacturer's protocol was used with some modifications (139). Following fixation, cells were dehydrated by removal of DPBS and sequential replacement with $50 \%, 70 \%$, then $100 \%$ ethanol. Samples were incubated for $5 \mathrm{~min}$ at room temperature in each solution. Ethanol solutions were prepared as volume-to-volume ratios in ultrapure water (Synergy; Millipore). The 100\% ethanol was replaced with fresh $100 \%$ ethanol and incubated at room temperature for a final $10 \mathrm{~min}$. At this point, coverslips could be stored in $100 \%$ ethanol at $-20{ }^{\circ} \mathrm{C}$. To rehydrate cells, the sequence was reversed, and the cells were incubated for 2 min at room temperature in each solution. The cells were not allowed to dry in air at any time during the process. Finally, 
$50 \%$ ethanol was replaced with PBS, and the cells were hydrated at room temperature for 10 min. Cells were then washed with $0.1 \%$ Tween in PBS for 10 min and twice more in PBS for 1 min. Prior to hybridization, coverslips were immobilized on glass slides; a small drop of nail polish was placed on a glass slide, and the coverslip edge was placed on the nail polish drop. Using an ImmEdge hydrophobic barrier pen (Vector Laboratories), a circle was drawn around the coverslip, and PBS was added to prevent sample dehydration. The manufacturer's protease solution (Pretreat 3) was diluted in PBS as appropriate prior to the experiment (a 1:2 dilution was used when staining incoming virions, and a 1:15 dilution was used when staining for transcription and translation) and incubated in a humidified HybEZ oven (Advanced Cell Diagnostics) at $40{ }^{\circ} \mathrm{C}$ for $15 \mathrm{~min}$. Protease solution was discarded, and the slides were washed twice by immersion in PBS at room temperature for $1 \mathrm{~min}$. Specific pre-designed antisense probes (Supplementary Table 1) that recognized the HIV-1 vRNA were added to the coverslip as specified by the manufacturer (Advanced Cell Diagnostics): C1 probes were added directly, and C3 probes (PS-3 and PS-5) were diluted 1:50 in probe dilution buffer or in $\mathrm{C} 1$ probe. Probes were allowed to hybridize with the samples in a humidified HybEZ oven at $40^{\circ} \mathrm{C}$ for $2 \mathrm{~h}$. The probes were then discarded, and the coverslips were washed twice using the proprietary wash buffer. All wash steps were performed on a rocking platform at room temperature for 2 min using the proprietary wash buffer. The probes were visualized by hybridizing with preamplifiers, amplifiers, and finally, fluorescent label. Pre-amplifier 1 (Amp 1-FL) was hybridized to its cognate probe in a humidified HybEZ oven at $40{ }^{\circ} \mathrm{C}$ for 30 min. Samples were washed twice then hybridized with Amp 2-FL in a humidified HybEZ oven at $40{ }^{\circ} \mathrm{C}$ for $15 \mathrm{~min}$ to suppress background staining. After a two more 
washes, amplifier (Amp 3-FL) was hybridized to Amp 1-FL in a humidified HybEZ oven at $40{ }^{\circ} \mathrm{C}$ for $30 \mathrm{~min}$. Samples were washed twice, then fluorescent label Amp 4-FL was hybridized to Amp 3-FL in a humidified HybEZ oven at $40{ }^{\circ} \mathrm{C}$ for $15 \mathrm{~min}$, then washed twice more. For HIV-1 experiments, the labeled probe set Amp 4B-FL was used, labeling the $\mathrm{C} 1$ probes with Atto 550 and the $\mathrm{C} 3$ probe (PS-3) with Atto 647. For subsequent protein staining, the RNA-labeled samples were washed with PBS, and immunostaining was performed as described below. Otherwise, the final step was to counter- stain nuclei with the manufacturer-supplied 4',6'-diamino-2-phenylindole (DAPI; Advanced Cell Diagnostics) for 30 seconds at room temperature then remove the DAPI and immediately mount the coverslips on slides using Prolong Gold Antifade (Invitrogen).

\section{In situ vDNA detection}

For vDNA detection, following protease treatment, samples were washed three times with ultrapure water for $2 \mathrm{~min}$, treated with $5 \mathrm{mg} / \mathrm{mL}$ RNase A (Qiagen) in PBS for $30 \mathrm{~min}$ at $37^{\circ} \mathrm{C}$, washed three times for $2 \mathrm{~min}$ with ultrapure water, and heated at $50{ }^{\circ} \mathrm{C}$ for $30 \mathrm{~min}$ with hybridization buffer $(1.7 \mathrm{M}$ ethylene carbonate, $100 \mu \mathrm{g} / \mathrm{mL}$ dextran sulfate [average MW $>500 \mathrm{kDa}$ ], $600 \mathrm{mM} \mathrm{NaCl}, 0.1 \%$ Tween-20, and $10 \mathrm{mM}$ sodium citrate, $\mathrm{pH}$ 6.2) to denature the double-stranded DNA (140). For labeling of vDNA in PBMCs, denaturation was performed at $67{ }^{\circ} \mathrm{C}$ for $10 \mathrm{~min}$ (141). The hybridization buffer was then removed, and the probe (in the manufacturer-supplied buffer) was diluted 1:1 with hybridization buffer then allowed to hybridize with the samples in a humidified HybEZ oven at $40{ }^{\circ} \mathrm{C}$ for $2 \mathrm{~h}$. Washes and hybridization of pre-amplifiers and amplifiers to the probes were performed as described for vRNA. 


\section{Simultaneous in situ vRNA and vDNA detection}

For co-staining of vRNA and vDNA, samples were first treated as described for vRNA staining up to the point of vRNA probe hybridization for $2 \mathrm{~h}$ at $40{ }^{\circ} \mathrm{C}$. Following vRNA probe hybridization, samples were washed twice in the manufacturer's wash buffer then incubated with vDNA probes for $2 \mathrm{~h}$ at $40{ }^{\circ} \mathrm{C}$ in hybridization buffer, but without heating to avoid loss of the vRNA signal. The hybridization of pre-amplifiers and amplifiers to the probes was performed as described for vRNA. Addition of the vRNA probe prior to denaturation of the DNA prevented hybridization of the probe to the coding strand of the vDNA.

\section{Immunostaining}

Staining for protein was performed after staining for nucleic acids. Coverslips were blocked with $1 \%$ bovine serum albumen (BSA) and 10\% FBS in PBS containing 0.1\% Tween-20 (PBST) at room temperature for $1 \mathrm{~h}$. Capsid protein (CA), or the capsid domain of Gag protein, was then probed with anti-p24 diluted 1:2000 in PBST supplemented with $1 \%$ BSA and incubated at room temperature for $1 \mathrm{~h}$. Samples were washed twice in PBST at room temperature for $10 \mathrm{~min}$ with rocking. Fluorescently labeled secondary antibodies were used at 1:2000 and incubated at room temperature for $1 \mathrm{~h}$; then the samples were washed once with PBST at room temperature for $10 \mathrm{~min}$ with rocking. Nuclei were either stained using the DAPI provided in the RNAscope kit or using $0.5 \mu \mathrm{g} / \mathrm{mL}$ Hoescht-33258 in PBS at room temperature for $10 \mathrm{~min}$. Coverslips were washed twice in PBST at room temperature for 10 min with rocking and washed once

with PBS for 1 min. Finally, coverslips were mounted on slides using Prolong Gold 
Antifade then sealed with nail polish.

\section{Imaging and imaging quantification}

Unless otherwise stated, images were taken with a Leica TCS SP8 inverted confocal microscope equipped with a $63 \mathrm{x} / 1.4$ oil-immersion objective and a tunable supercontinuum white light laser. The excitation / emission bandpass wavelengths used to detect DAPI, Alexa 488, ATTO 550, Alexa 568, and Alexa 647 were set to 405/420-480, 488/505-550, 550/560-610, 568/580-630, and 647/655-705 nm, respectively. Confocal data sets were deconvolved using Huygens Professional software (Version 16.10, SVI). Some images were captured using a Zeiss LSM 880 Airyscan confocal microscope. When images were captured with the LSM 880, a Plan- Apochromat 63x/1.4 oil objective was used in the Airyscan super-resolution mode. Following full 3D capture with a Z-step size of 0.16 microns, raw images were subjected to the standardized Airyscan processing routine (which includes photon reassignment and linear parametric 3D deconvolution). Movies were produced based on volume-rendered Z-stacks of confocal images using LAS X (Leica Microsystems) or ZEN (Zeiss) imaging software and edited using Fiji $(142,143)$. For time course experiments, fields of view were selected randomly based on the DAPI signal. Images were taken of the DAPI, vRNA, and vDNA staining (10 images per sample using the $63 \mathrm{x}$ objective). The numbers of nuclei and vRNA or vDNA foci were quantified using Gen5 software (BioTek), and the number of foci for each image was divided by the number of nuclei in the image to determine the average number of foci per cell. To determine the number of nuclear vDNA foci, a mask was applied to the image based on the DAPI stain; vDNA foci that fell within the DAPI mask were counted as nuclear vDNA foci. 


\subsection{RESULTS}

\section{Specific visualization of HIV-1 RNA and DNA}

FISH techniques have been established for detection of nucleic acids in cells but lack the sensitivity required for some applications and are often incompatible with immunofluorescent labeling. More recently, bDNA-FISH techniques (144) have been developed to enhance the sensitivity and specificity of RNA detection (e.g., PrimeFlow (145), ViewRNA (Affymetrix), and RNAscope (139) and permit co-staining by immunofluorescence. bDNA-FISH approaches have also been adapted for imaging of HIV-1 nucleic acids $(121,146)$. Based on the RNAscope method (121), bDNA-FISH protocols that enable visualization of HIV-1 vRNA and vDNA were developed and optimized. Protocols described in Methods were used with probes that target the gag region of HIV-1 RNA, enabling confocal microscopy-based detection of unspliced genomic vRNA in the cytoplasm of cells shortly after infection with HIV-1 (Fig. 2.1a, top panel and Supplementary Movie 2.1). For specific detection of vDNA and not vRNA, probes that target the gag-pol region of negative-strand vDNA were used (to avoid labeling of the positive-strand RNA), and conditions were established to optimize denaturation of dsDNA and hybridization of probes (Fig. 2.1a, lower panels). Labeling of vRNA and vDNA was highly specific, with no fluorescence detected in uninfected cells (Fig. 2.1a, leftmost panels). This approach permitted specific detection of vRNA or vDNA, as shown by susceptibility or resistance of the fluorescent signal to treatment with RNase A or DNase I (Fig. 2.1a). In addition, a protocol for simultaneous observation of both HIV vRNA and vDNA was developed. This protocol enabled monitoring of vDNA without very significant reduction of the vRNA signal. Using this method, colocalization 
of incoming viral genomic vRNA with nascent vDNA was demonstrated at 4 hours postinfection (hpi) (Fig. 2.1b). Hence, this protocol allows single-cell imaging of vRNA and vDNA individually and multiplexed, with sufficient sensitivity to discern what we interpret to be individual virions. Such highly sensitive staining of viral nucleic acid during entry may be used to track the progress of infection. 
a

VRNA
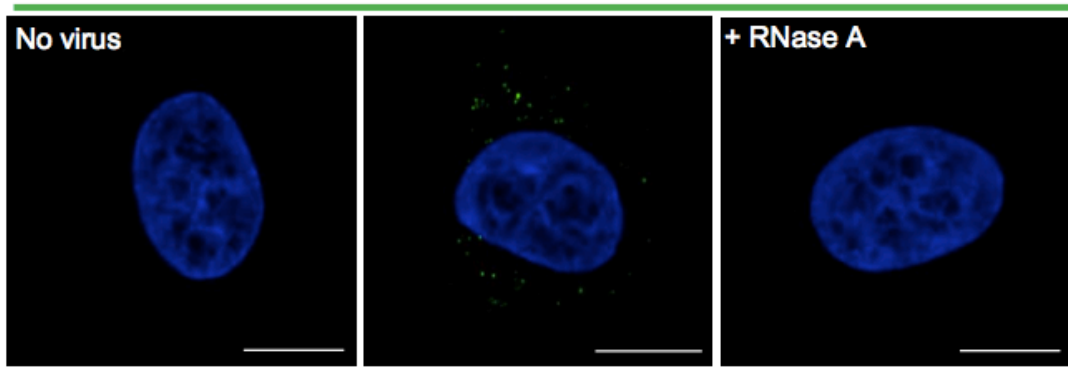

+ DNase I
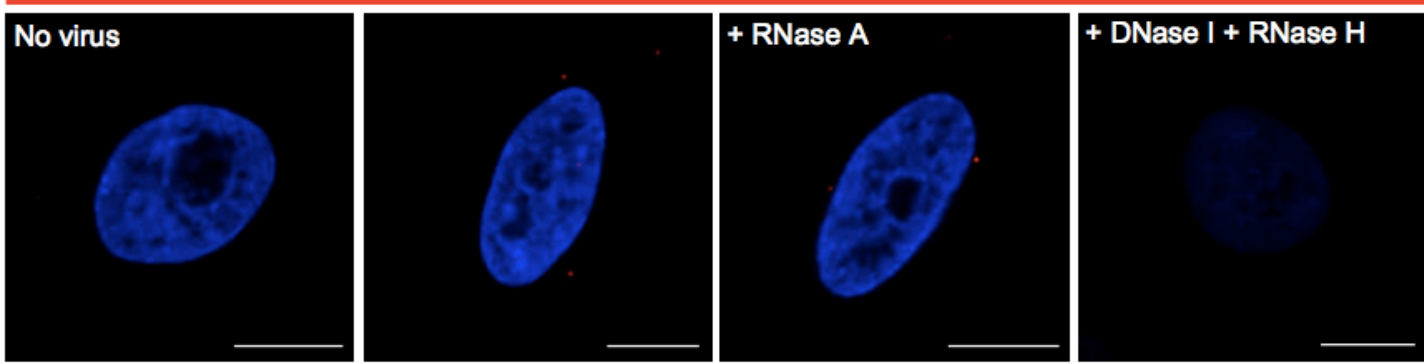

\section{b VRNA vDNA}

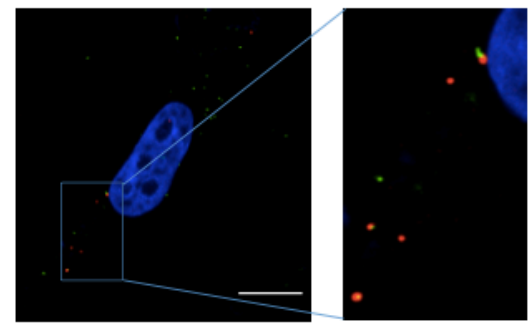

Figure 2. 1. Visualizing HIV nucleic acids. a vRNA (top panel): TZM-bl cells were infected with HIV-1 at a MOI of 1; at 5 hpi cells were fixed and stained. Prior to RNA labeling, cells were treated with buffer alone, RNase A, or DNase I. Probe set 1 (PS-1) was used for vRNA (green); nuclei are DAPI stained and shown in blue throughout the figure. vDNA (bottom panel): Prior to DNA labeling, cells were treated with RNase A or RNase H followed by DNase I. PS-3 was used for vDNA (red). b Simultaneous detection of vRNA and vDNA of incoming virus in the cytoplasm. TZM-bl cells were infected with HIV-1 at a MOI of 1; at 4 hpi cells were fixed and stained for vRNA (PS-2; green), vDNA (PS-3; red), and nuclei (blue). Enlarged image shows co-localization between vRNA and vDNA. Scale bars represent $10 \mu \mathrm{m}$ for a and $\mathrm{b}$. This figure is copied from (203) with permission under a Creative Commons Attribution 4.0 International License 


\section{Time course of reverse transcription and nuclear entry}

The protocols for detection of vRNA and vDNA were subsequently used to study the kinetics of HIV infection in a representative cell line (TZM-bl cells). Semisynchronized cells were infected (136), fixed, then processed at $2 \mathrm{~h}$ intervals for vRNA visualization (Fig. 2.2). Cells were infected at a relatively low multiplicity of infection (approximately 0.2 ) to prevent saturation of relevant cellular interactions, and foci of vRNA were quantified from multiple randomized images per time point for more than 300 cells per time point. Under these conditions, automated quantitation produced an estimate of 12 vRNA foci per cell following infection, and 0.26 foci per cell in the absence of infection; the vRNA signal subsequently decreased to an average of 1-2 vRNA foci per cell by 10 hpi (Fig. 2.2), presumably due to RNase $\mathrm{H}$ activity during reverse transcription. In fact, addition of an RNase $\mathrm{H}$ inhibitor (132) counteracted the loss of vRNA signal, visualized at 12 hpi (Fig. 2.3). These data suggest that reverse transcription is completed by $\sim 10 \mathrm{hpi}$, which is consistent with previous estimates based on other experimental techniques that follow uncoating and reverse transcription kinetics $(147,148)$. Although not part of these analyses, the signal may be expected to increase again at later time points as cells begin transcribing vRNA. At this time, it is no longer possible to track incoming genomes; the density of synthesized vRNA may also present problems for the enumeration of individual foci. At these later time points, measurement of the fluorescence intensity may more accurately represent the extent of vRNA production. The appearance and localization of vDNA was additionally monitored as reverse transcription progressed during HIV-1 infection; HIV-1 vDNA was detected mainly in the cytoplasm of TZM-bl cells, and to a lesser degree in nuclei, at 2 hpi (Fig. 
2.4). Both signals increased over time. Total cellular vDNA reached a peak of 1.3 foci per cell, and nuclear vDNA reached a peak of 0.27 foci per cell (compared to 0.04 and 0.011 foci per cell in uninfected cells), at $12 \mathrm{hpi}$, presumably as reverse transcription and nuclear import were completed. The number of vDNA foci was then observed to drop between 12 and 24 h, likely reflecting the degradation of unintegrated vDNA; this effect was more pronounced in the cytoplasm of the cell, presumably because the nuclear foci include integrated proviral vDNA, which is stably maintained. Nuclear localization was determined when foci overlapped the nucleus (DAPI stained) in $\mathrm{x}$ and $\mathrm{y}$ dimensions. To verify that the vDNA signal at 2 hpi truly represented newly synthesized reverse transcription products, virions were attached to cells at $4{ }^{\circ} \mathrm{C}$ then stained for vRNA, vDNA, and CA (Fig. 2.5). It would be expected that only CA and vRNA should be present in HIV-1 particles prior to fusion with a target cell. If a signal was detected for vDNA, that would suggest reverse transcription occurred prior to infection or, more likely, that a significant portion of the vDNA signal is a false positive. Consistent with the accepted model of HIV-1 replication, signals were observed only for the vRNA probe and CA antibody, not for vDNA, confirming that no vDNA is present prior to infection and that the vDNA probe is specific. In principle, the probes should label both integrated and unintegrated vDNA. To assess labeling in the absence of integration, TZM-bl cells were infected in the presence of $1 \mu \mathrm{M}$ integrase inhibitor raltegravir (RAL) ${ }^{14}$ (Fig. 2.6). Consistent with its specific inhibition of integration, RAL had no apparent effect on the number of cytoplasmic and nuclear vDNA foci, but nascent vRNA transcription was almost entirely suppressed by the inhibitor. These findings confirm the labeling of integrated and unintegrated vDNA and suggest transcription of vRNA coding Gag-Pol is 
greatly enhanced by integration into the host genome, as previously reported (149).

a

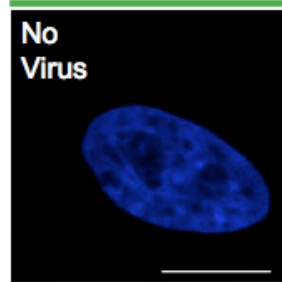

$6 \mathrm{~h}$

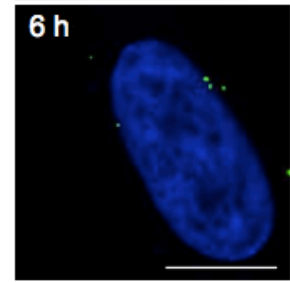

\section{$12 \mathrm{~h}$}

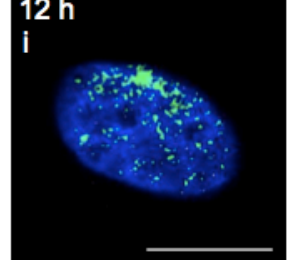

vRNA

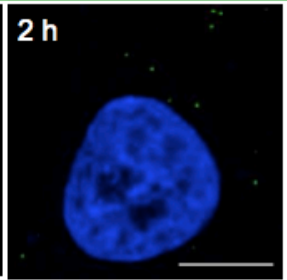

$8 \mathrm{~h}$
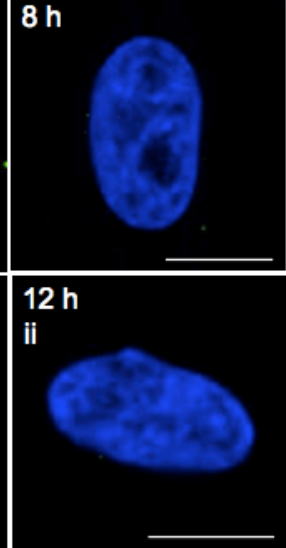

b

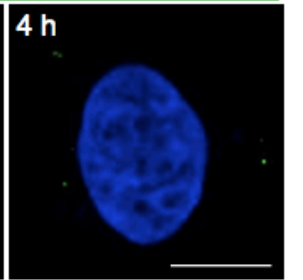

$10 \mathrm{~h}$
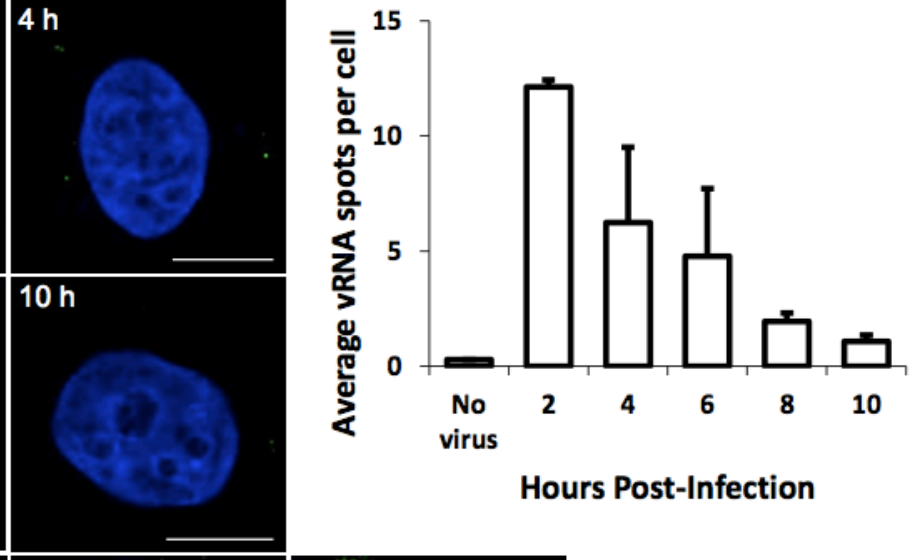

Hours Post-Infection
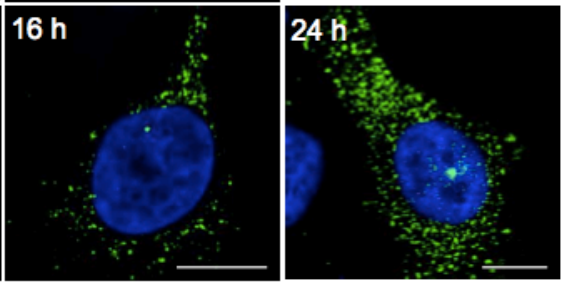

Figure 2.2. Time course of vRNA detection. a TZM-bl cells were infected with HIV-1 at a MOI of 0.2. Cells were then fixed and stained at the indicated times. Cells were stained for vRNA (PS-1; green) and nuclei (blue). At $12 \mathrm{hpi}, \sim 15 \%$ of infected cells exhibited a transcription burst $(12 \mathrm{~h}, \mathrm{i})$ whereas most cells did not yet produce nascent vRNA (12 h, ii). Scale bars represent $10 \mu \mathrm{m}$. b Foci of vRNA were counted in 300-340 cells per time point using Gen5 software. The average number vRNA foci per cell was calculated and shown in the graph with standard deviation indicated ( $n=2$ independent experiments). This figure is copied from (203) with permission under a Creative Commons Attribution 4.0 International License

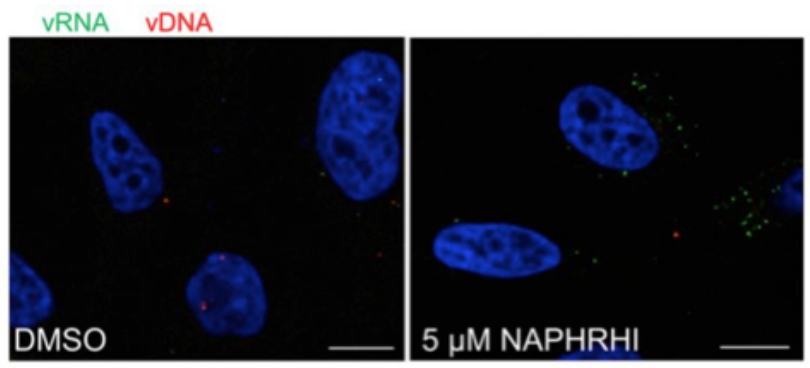

Figure 2.3. Degradation of vRNA during reverse transcription. TZM-bl cells were treated with DMSO (control) or NAPHRHI (RNase $\mathrm{H}$ inhibitor) at $5 \mu \mathrm{M}$ for $1 \mathrm{~h}$ then infected with HIV-1 at a MOI of 0.4 ; at 12 hpi, cells were fixed and stained for HIV-1 vRNA (PS-2; green), vDNA (PS-3; red), and nuclei (blue). Scale bars represent $10 \mu \mathrm{m}$. This figure is copied from (203) with permission under a Creative Commons Attribution 4.0 International License 
a

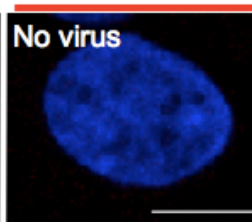

$6 \mathrm{~h}$

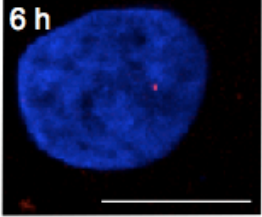

$12 \mathrm{~h}$
vDNA

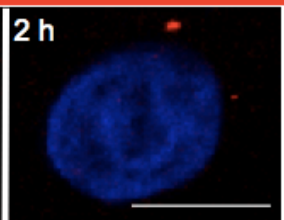

$8 \mathrm{~h}$

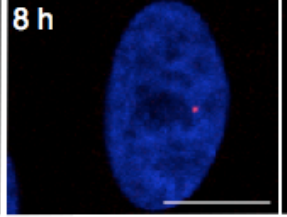

$24 \mathrm{~h}$ b

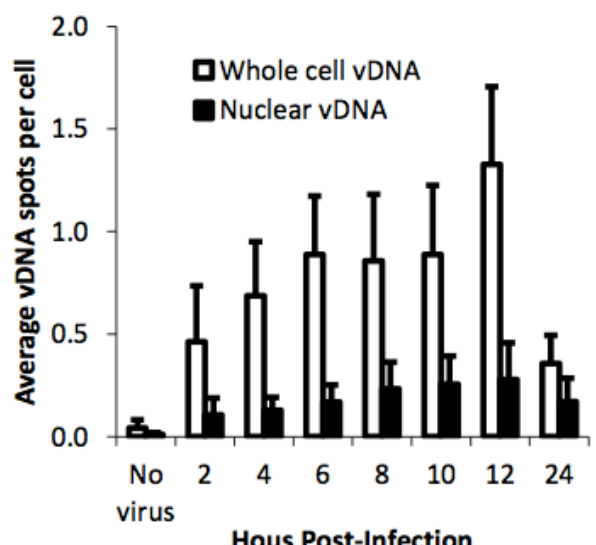

Hous Post-Infection

Figure 2.4. Time course of vDNA detection. a TZM-bl cells were infected with HIV-1 at an MOI of $\sim 0.2$; at indicated times, cells were fixed and stained for vDNA (PS-3; red) and nuclei (blue). Scale bars represent $10 \mu \mathrm{m}$. b Foci of vDNA were counted in 300-340 cells per time point, using Gen5 software. The average number of vDNA foci per cell was calculated and shown in the graph with standard deviation indicated ( $n=3$ independent experiments, except for $24 \mathrm{~h}$ time point, where $n=2)$. This figure is copied from (203) with permission under a Creative Commons Attribution 4.0 International License
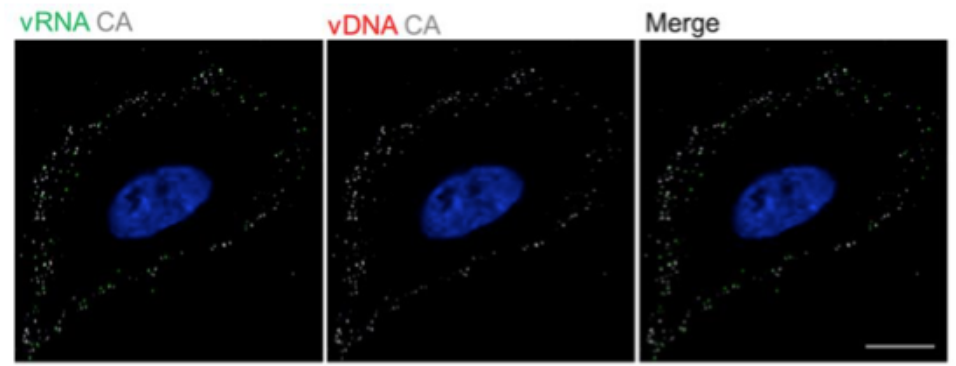

Figure 2.5. Staining for vRNA and vDNA in particles at the plasma membrane. TZM-bl cells were spinoculated with HIV-1 particles at a MOI of 2 for $2 \mathrm{~h}$ at $4{ }^{\circ} \mathrm{C}$, to prevent membrane fusion. The samples were then fixed immediately and stained for vRNA (PS-1; green), vDNA (PS-3; red), and CA (white). Scale bar represents $10 \mu \mathrm{m}$.. This figure is copied from (203) with permission under a Creative Commons Attribution 4.0 International License

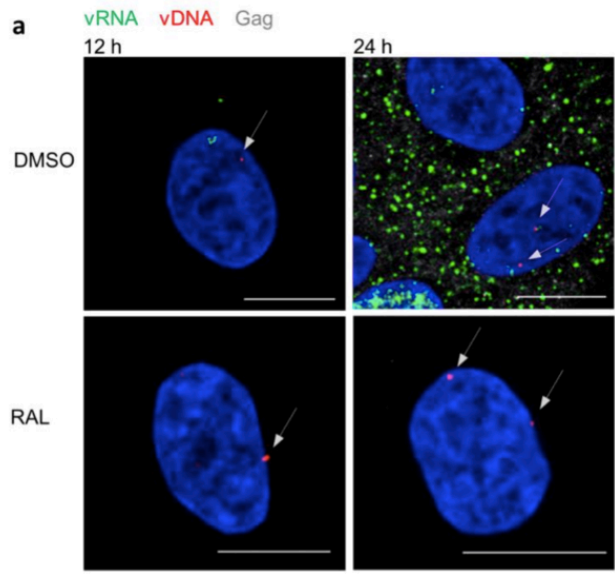

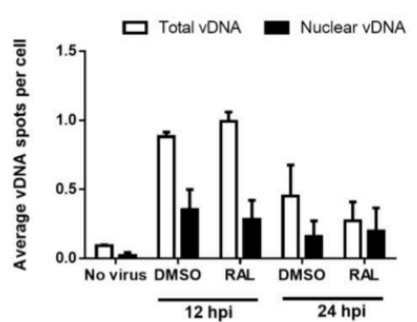


Figure 2.6. Inhibition of HIV-1 integration. a TZM-bl cells were infected with HIV-1 at a MOI of $\sim 0.3$ in the presence of $0.5 \%$ DMSO or $1 \mu \mathrm{M}$ raltegravir (RAL) $/ 0.5 \%$ DMSO. Cells were fixed at the indicated times and stained for vRNA (PS-2; green), vDNA (PS-3; red, indicated by white arrows), Gag (gray), and nuclei (blue). Scale bars represent $10 \mu \mathrm{m}$. b Foci of vDNA were quantified for 10 fields of view for each condition using Gen5 software. Average results are plotted in the graph with standard deviation indicated ( $\mathrm{n}=2$ or 3 independent experiments). This figure is copied from (203) with permission under a Creative Commons Attribution 4.0 International License

\section{Transcription from integrated vDNA}

Study of HIV transcription from individual proviruses has been hindered by the lack of an efficient method for simultaneous detection of both vRNA and vDNA in individual cells. By employing this protocol, it is now possible to observe HIV-1 vDNA, which is often associated with sites of vRNA transcription (Fig. 2.7a). Intense accumulation of nascent unspliced vRNA transcripts was observed in $\sim 15 \%$ of infected TZM-bl cells shortly after completion of reverse transcription, at 12 hpi, and strictly within the nucleus (Fig. 2.7b and Movie 2.2); at later time points, vRNA distribution matured, with the vRNA transcripts present predominantly in the cytoplasm (Fig. 2.2). This phenotype is consistent with reports on transcription of host as well as HIV-1 RNAs occurring in bursts and accumulation of HIV-1 RNA in the nucleus prior to bursts of vRNA export to the cytoplasm (150-152).

\section{RNA splicing and nuclear export}

Export of unspliced HIV vRNA is dependent on Rev, a protein coded by a multispliced vRNA (153). It should therefore be possible to detect spliced vRNA in the cytoplasm before the newly- synthesized Rev exports the unspliced vRNA (154). Conditions were established for simultaneous detection of unspliced and multispliced vRNA in individual cells. Probe set 1 (PS-1) (Table 2.1) targets the gag region of the 
HIV genome and is thus specific for unspliced vRNA. PS-3 targets a region common to spliced and unspliced RNA and thus detects both; the probes bind distinct regions of the vRNA, and there is incomplete overlap in staining, potentially owing to the length of the molecule or the efficiency of hybridization. Comparison of the fluorescent signals at various times post-infection illustrates that multispliced vRNA was present in the cytoplasm hours prior to unspliced vRNA (Fig. 2.7c and 2.7d). At later times, presumably following Rev expression, the majority of vRNA, regardless of splicing, localized to the cytoplasm (Fig. 2.7c and 2.7d). These timelines were consistent with the time-course of infection, which used a probe for unspliced vRNA; at 12 hpi the vRNA was exclusively nuclear, but by 16 hpi, vRNA was predominantly cytoplasmic (Fig. 2.2).
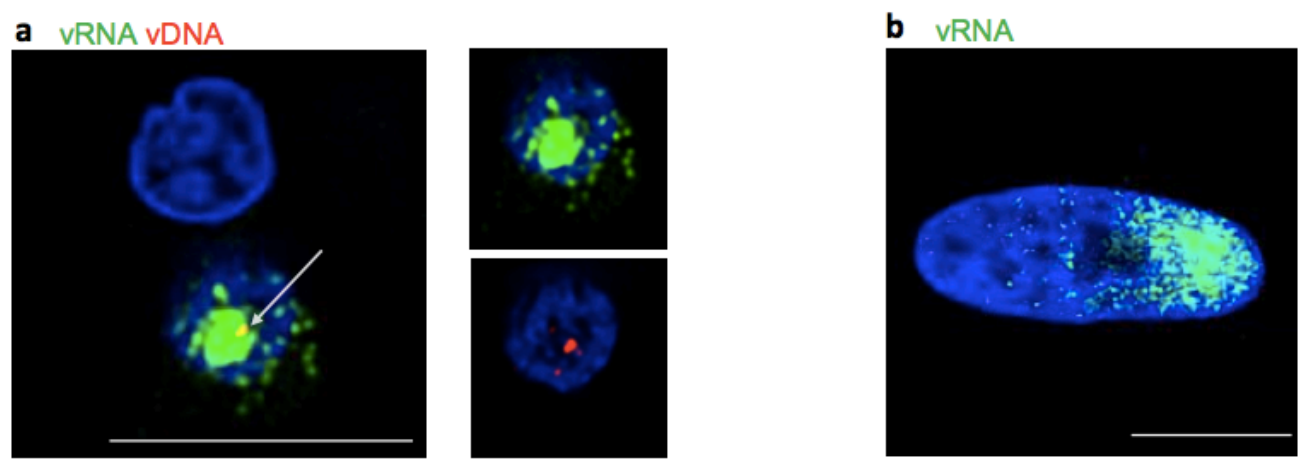

c Total vRNA Unspliced vRNA
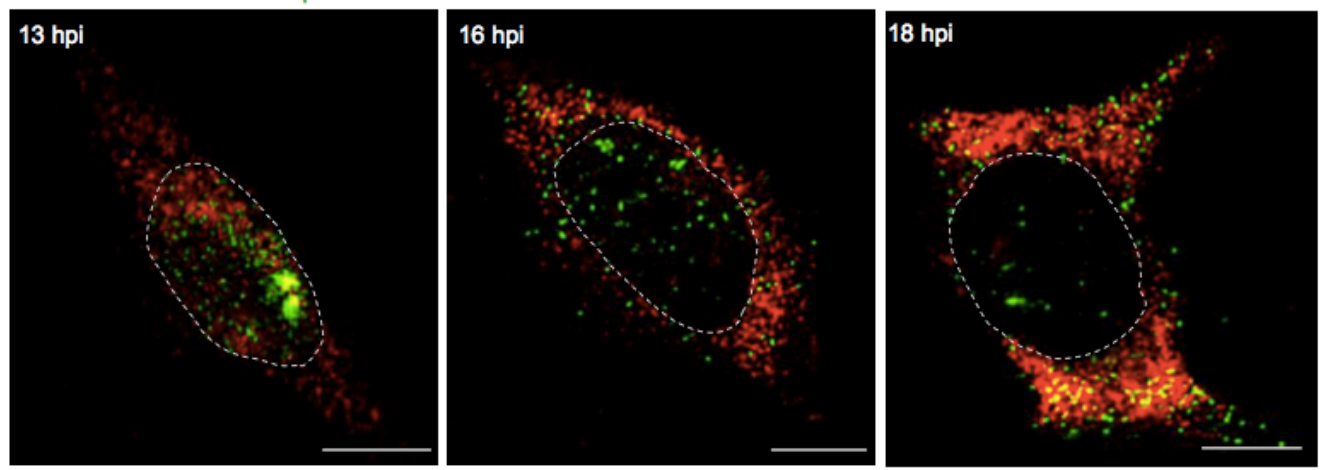


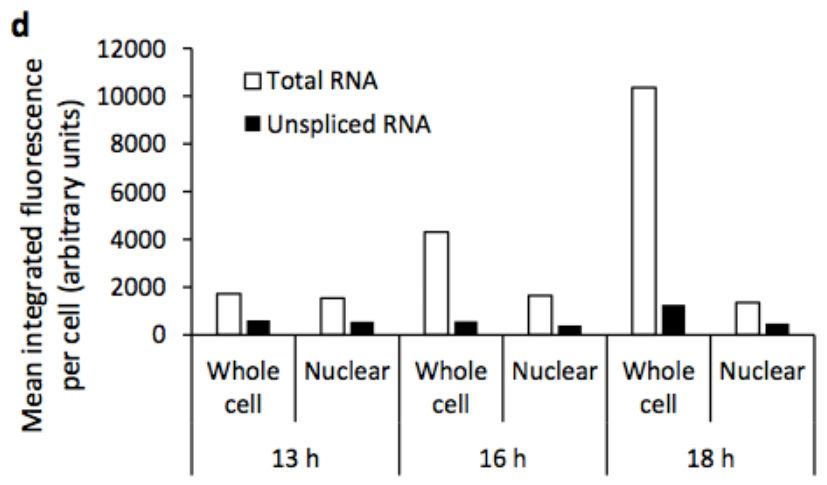

Figure 2.7. Transcription and splicing of vRNA. a Nascent vRNA transcribed from nuclear vDNA in primary cells. The viral transcription site is indicated with a white arrow and appears in yellow because of newly formed vRNA (PS-2; green) and vDNA (PS-3; red) co-localization. Separate red and green channels are shown to the right. PBMCs were infected at a MOI of 0.2 ; at 48 hpi they were fixed and stained. b HIV1 transcriptional burst phenotype. TZM-bl cells were infected at a MOI of 0.2 ; at 12 hpi they were fixed and stained for unspliced vRNA (PS-1; green) and nuclei (blue). c Multiplex detection of total and unspliced vRNA informs temporal differences in localization. TZM-bl cells were infected with HIV-1 at a MOI of 0.5 . At the indicated times, cells were fixed and stained with PS-4 for total vRNA (spliced and unspliced; PS-4; red), unspliced vRNA (PS-1; green), and nuclei (outline). d Spliced and unspliced vRNA were quantified for the whole field of view and within the nuclei. 200-300 cells per time point were analyzed using Gen5 software to measure the total fluorescence signal (the sum of the pixel intensities) per cell either in the complete field of view (whole cell) or within a nuclear mask (nuclear). Scale bars represent $10 \mu \mathrm{m}$ in $\mathrm{a}, \mathrm{b}$, and $\mathrm{c}$. This figure is copied from (203) with permission under a Creative Commons Attribution 4.0 International License

\begin{tabular}{|c|c|c|c|c|}
\hline $\begin{array}{l}\text { Probe } \\
\text { Set (PS) }\end{array}$ & Name & $\begin{array}{l}\text { ACD } \\
\text { Catalog } \\
\text { No. }\end{array}$ & $\begin{array}{l}\text { Number } \\
\text { of ZZ } \\
\text { pairs }\end{array}$ & Description \\
\hline PS-1 & $\begin{array}{l}\text { HIV-1 vRNA anti- } \\
\text { sense probe-set } 1\end{array}$ & $311921-C 1$ & 10 & $\begin{array}{l}\text { Anti-sense probe targeting } \\
\text { within } 801-1393 \text { bp of HIV-1 } \\
\text { (gag). Accession No } \\
\text { NC_001802.1 }\end{array}$ \\
\hline PS-2 & $\begin{array}{l}\text { HIV-1 vRNA anti- } \\
\text { sense probe-set } 1\end{array}$ & 446211-C2 & 10 & $\begin{array}{l}\text { Anti-sense probe targeting } \\
\text { within } 801-1393 \text { bp of HIV-1 } \\
\text { (gag). Accession No } \\
\text { NC_001802.1 }\end{array}$ \\
\hline PS-3 & $\begin{array}{l}\text { HIV-1 vDNA sense } \\
\text { probe-set } 2\end{array}$ & $317701-\mathrm{C} 1$ & 60 & $\begin{array}{l}\text { Sense probe targeting within } \\
507-4601 \text { bp of HIV-1 (gag, } \\
\text { pol) Accession No } \\
\text { NC_001802.1 }\end{array}$ \\
\hline PS-4 & $\begin{array}{l}\text { HIV-1 vRNA anti- } \\
\text { sense probe-set } 3\end{array}$ & $317711-\mathrm{C} 3$ & 40 & $\begin{array}{l}\text { Anti-sense probe targeting } \\
\text { within 4988-9181 bp of HIV-1. } \\
\text { (vif, vpr, tat, rev, vpu, env, and } \\
\text { nef) Accession } \\
\text { NC_001802.1 }\end{array}$ \\
\hline
\end{tabular}

Table 2.1. Probes sets 


\section{Multiplex imaging of nucleic acid and protein}

Incompatibility with optimal conditions for immunofluorescence staining is a major shortcoming of conventional FISH methods. In contrast, bDNA-FISH is readily compatible with immunofluorescence $(119,139)$, permitting the visualization of vRNA and viral proteins in virions during cell entry (Fig. 2.8a) and release (Fig. 2.8b). We combined the protocol for vDNA and vRNA labeling with immunofluorescence to simultaneously label vDNA, vRNA, and viral proteins. We defined this technique as Multiplex Immunofluorescent Cell-based Detection of DNA, RNA, and Protein (MICDDRP). MICDDRP allowed co-visualization of transcription from integrated proviruses and translation of viral protein, in this case Gag or CA, at the single-cell level (Fig. 2.8c and Movie 2.3). Importantly, this development may enable investigation of selective transcription in cells with multiple nuclear vDNA sites and of the factors that affect viral transcription (Fig. 2.8d and Movie 2.4). 


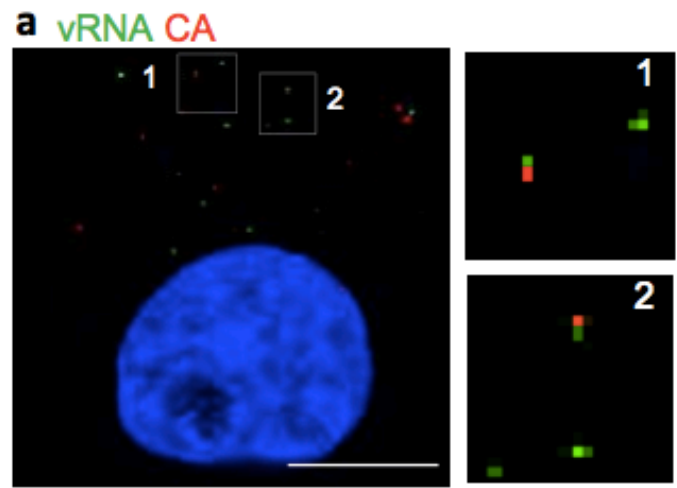

b vRNA Gag
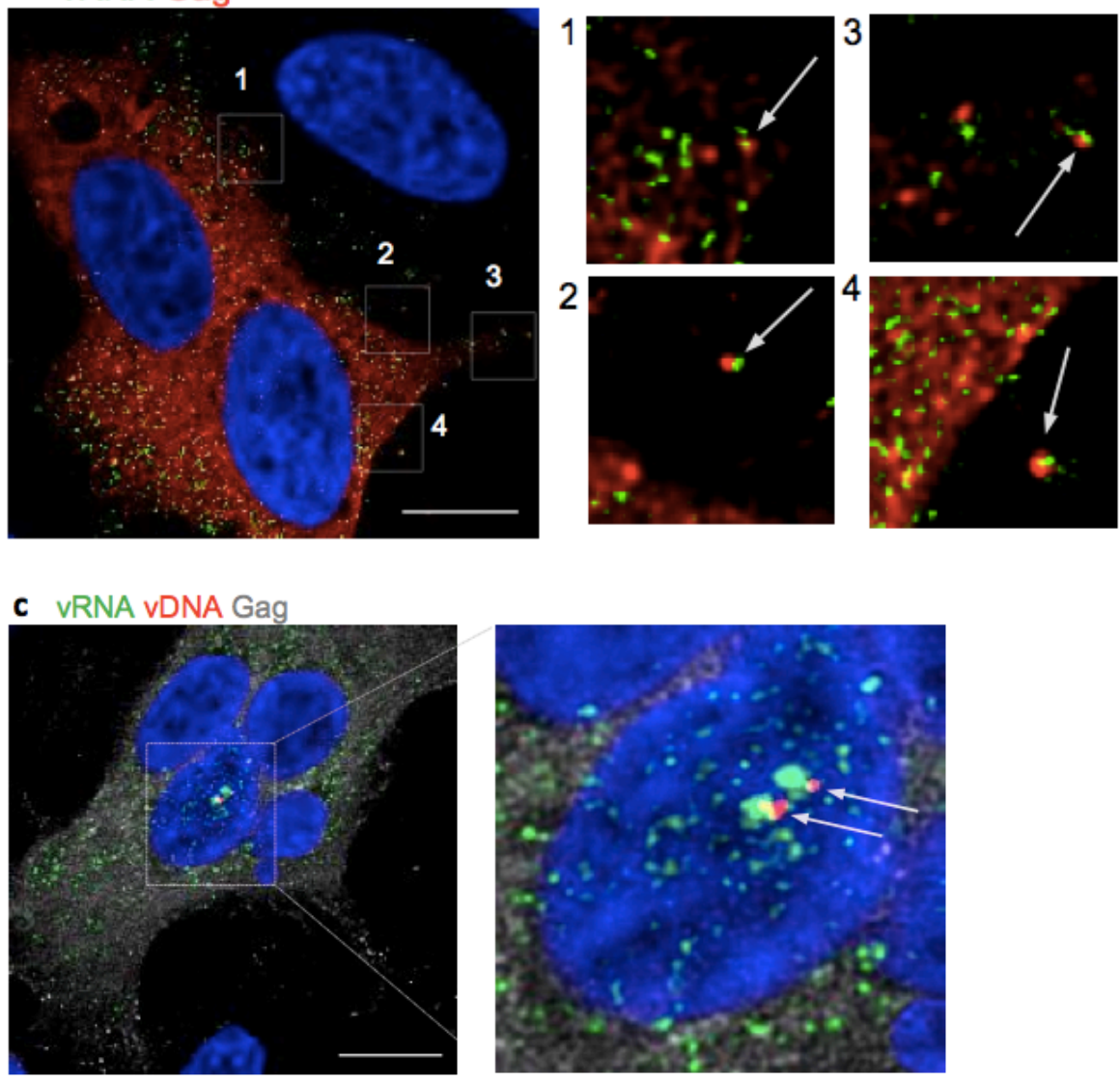

d VRNA vDNA Gag
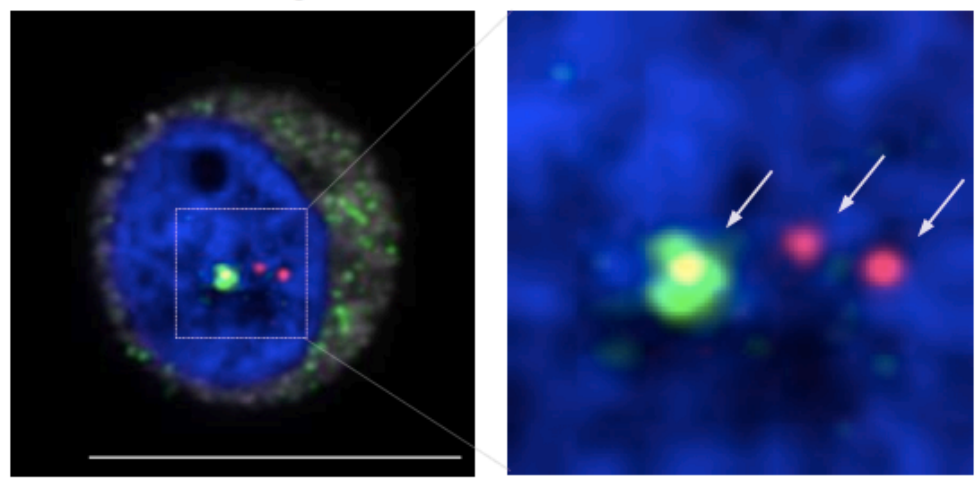
Figure 2.8. Multiplex visualization of HIV-1 nucleic acids and protein. a Examples of colocalized vRNA and capsid (CA). TZM-bl cells were infected with HIV-1 at a MOI of 0.2; at 2 hpi cells were fixed and stained for unspliced vRNA (PS-1; green), CA (red), and nuclei (blue). Enlarged images indicate colocalization between genomic vRNA of incoming virus and CA. b Apparent formation of nascent virions. TZM-bl cells were infected with HIV-1 at a MOI of 0.2 ; at 24 hpi cells were fixed and stained for vRNA (PS-1; green), Gag (red), and nuclei (blue). Arrows indicate putative virions. c Multiplex visualization of transcribed vRNA (PS-2; green) from vDNA (PS-3; red, indicated by white arrows) and of translated Gag (gray). TZM-bl cells were infected with HIV-1 at a MOI of 2; at 30 hpi cells were fixed and stained. d Discordant expression from nuclear vDNA sites. Jurkat cells were infected with HIV-1 at a MOI of 2; at 24 hpi cells were fixed and stained for vRNA (PS-2; green), vDNA (PS-3; red, indicated with white arrows), Gag (gray), and nuclei (blue). For all, images were captured with an LSM 880 confocal microscope, and scale bars represent $10 \mu \mathrm{m}$. This figure is copied from (203) with permission under a Creative Commons Attribution 4.0 International License.

\section{Imaging with primary cells and virus isolates}

To verify the potential utility of this method when handling primary tissue samples, a variety of physiologically relevant human cell types were stained following infection with NL4-3-FL (Fig. 2.9) or the primary HIV-1 isolate BaL (Fig. 2.10). These cell types included HEK 293T, Jurkat (T lymphocyte cell line), primary peripheral blood

mononuclear cells (PBMCs), and monocyte-derived macrophages (MDMs), demonstrating high flexibility for the study of transcription and translation from integrated proviruses in diverse relevant cell types. A time course comparable to that described in Figures 2 and 3 was also performed using CD4+ T-cells infected with NL43, simultaneously stained for vRNA and vDNA (Fig. 2.11a and 2.11b). Similar to the observations with TZM-bl cells, the levels of vRNA were found to be relatively high at early time points, between 4 and 7 foci per cell at 4 hpi, compared to 0.01 foci per cell in uninfected cells. The number of vRNA foci then dropped as reverse transcription proceeded. vDNA increased over time in measurements of both the whole cell and the nucleus, peaking at 1.3 and 0.6 foci per cell, respectively following infection and 0.075 and 0.05 foci per cell in the cell and nucleus, respectively, in the absence of infection. These data demonstrate that the signal to noise ratio is higher for vRNA staining than 
vDNA (in this low MOI experiment, approximately 500 to 1 and 10 to 1 , respectively) and that vDNA non-specific staining is mainly observed in the nucleus. Treatment of a separate set of samples with RNase A slightly reduced staining in infected and uninfected cells but did not significantly change the vDNA signal (Fig. 2.11c). Finally, the peak signals for number of vRNA, vDNA, and nuclear vDNA foci were compared, as well as transcriptionally active cells (Fig. 2.11d). The signal reduces at each step of the transition from vRNA to actively transcribing cell, as no process is $100 \%$ efficient. In this case, we observed a number of vRNA foci per cell that was orders of magnitude greater than the MOI; approximately 5 vRNA foci per cell, yielding a MOI of only 0.05 . Even at this low MOI, the signal from infection was far higher than the non-specific staining. The conversion rate of cytoplasmic vRNA to an actively infected cell will almost certainly vary depending on cell type used and potentially between HIV isolates.
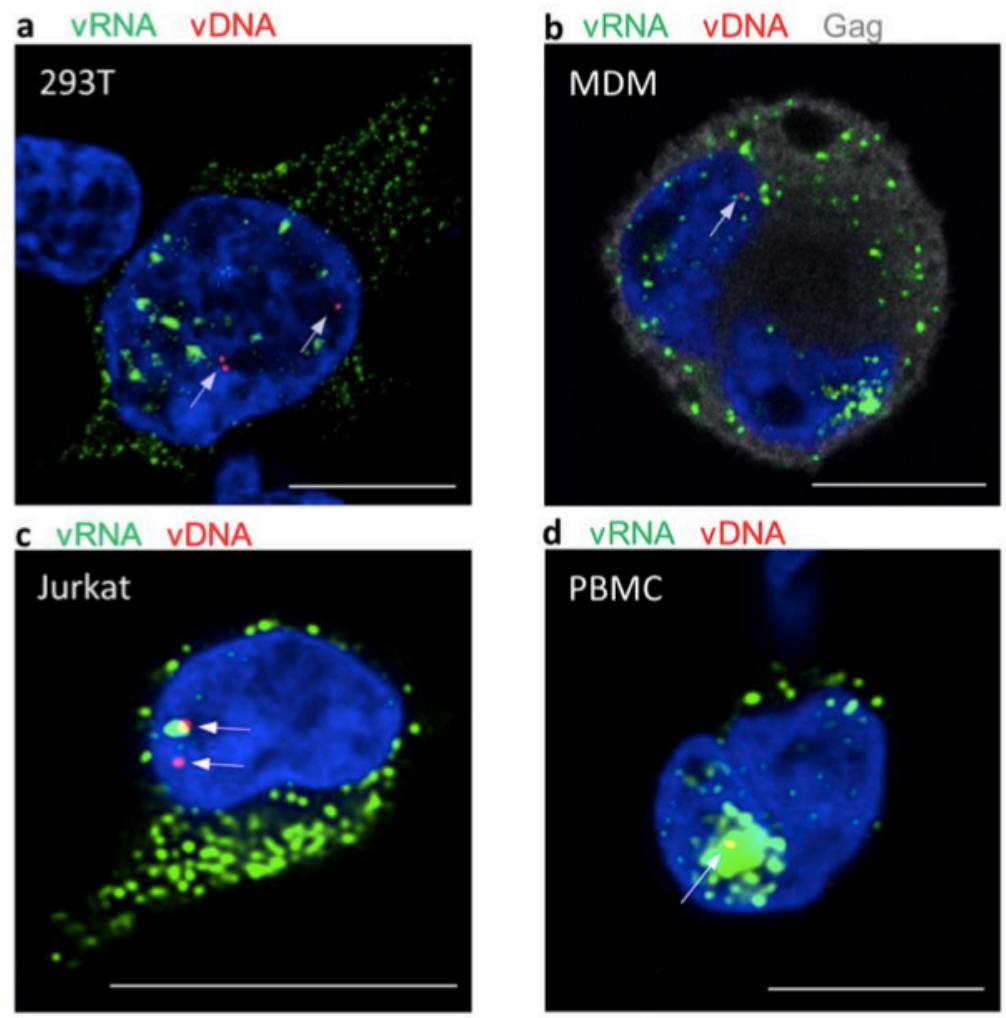
Figure 2.9. Multiplex vRNA and vDNA labeling in diverse cell lines. a HEK293T cells were infected with VSV-G-pseudotyped HIV-1 at a MOI of 2 ; at 15 hpi cells were fixed and stained for vRNA (PS-2; green), vDNA (PS-3; red), and nuclei (blue). b Monocyte derived macrophages were infected with HIV-1 at a MOI of $\sim 2$; at 48 hpi cells were fixed and stained for vRNA (PS-2; green), vDNA (PS-3; red), Gag (gray), and nuclei (blue). c Jurkat cells were infected with HIV-1 at a MOI of 2; at 24 hpi cells were fixed and stained as in a. d Primary lymphocytes were infected with HIV-1 at a MOI of 0.2; at 24 hpi cells were fixed and stained as in a. Scale bars represent $10 \mu \mathrm{m}$ in all. This figure is copied from (203) with permission under a Creative Commons Attribution 4.0 International License
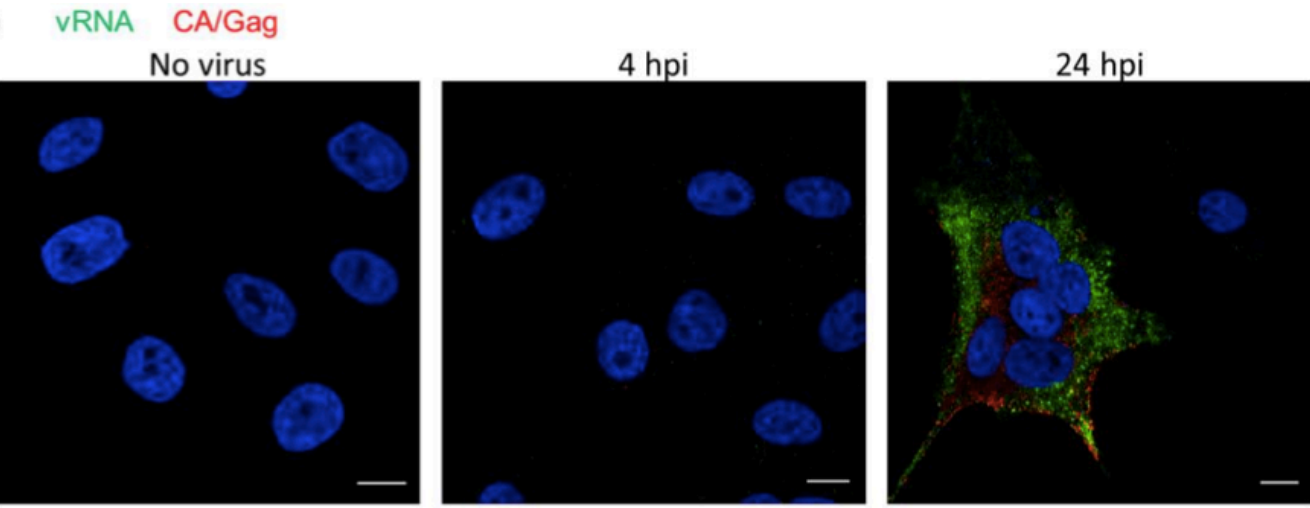

b VRNA CAVGag
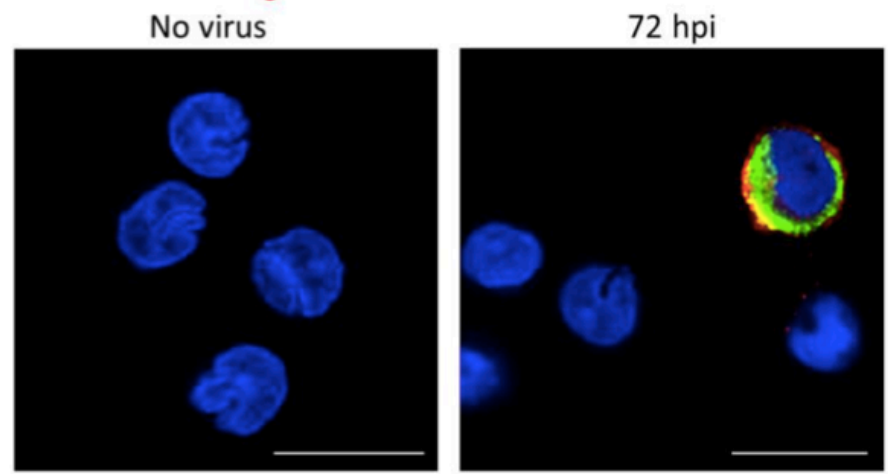

Figure 2.10. vRNA and Capsid/Gag labeling of HIV-1 clinical isolate. a TZM-bl cells were infected with HIV-1Ba-L clinical isolate at a MOI of $\sim 1$; at 4 hpi and 24 hpi cells were fixed and stained for vRNA (PS-1; green), CA/Gag (red), and nuclei (blue). b Primary CD4+ T cells were infected with HIV-1Ba-L clinical isolate at a MOI of $\sim 0.02$; at 72 hpi cells were fixed and stained for vRNA (PS-1; green), Gag (red), and nuclei (blue). Scale bars represent $10 \mu \mathrm{m}$ in all. This figure is copied from (203) with permission under a Creative Commons Attribution 4.0 International License 
$12 \mathrm{~h}$

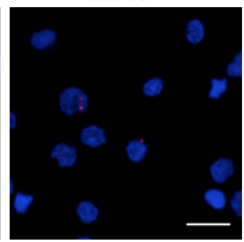

$16 \mathrm{~h}$

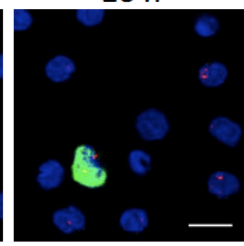

$24 \mathrm{~h}$

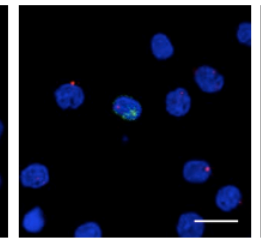

$72 \mathrm{~h}$

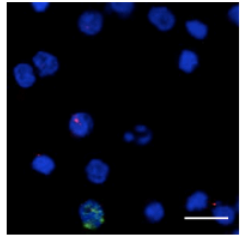

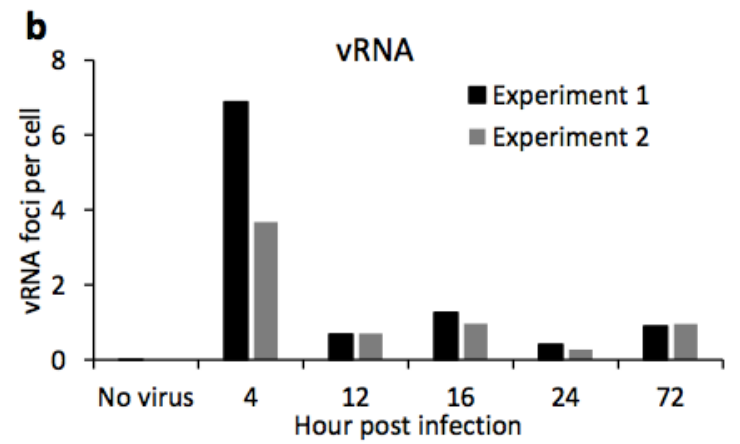
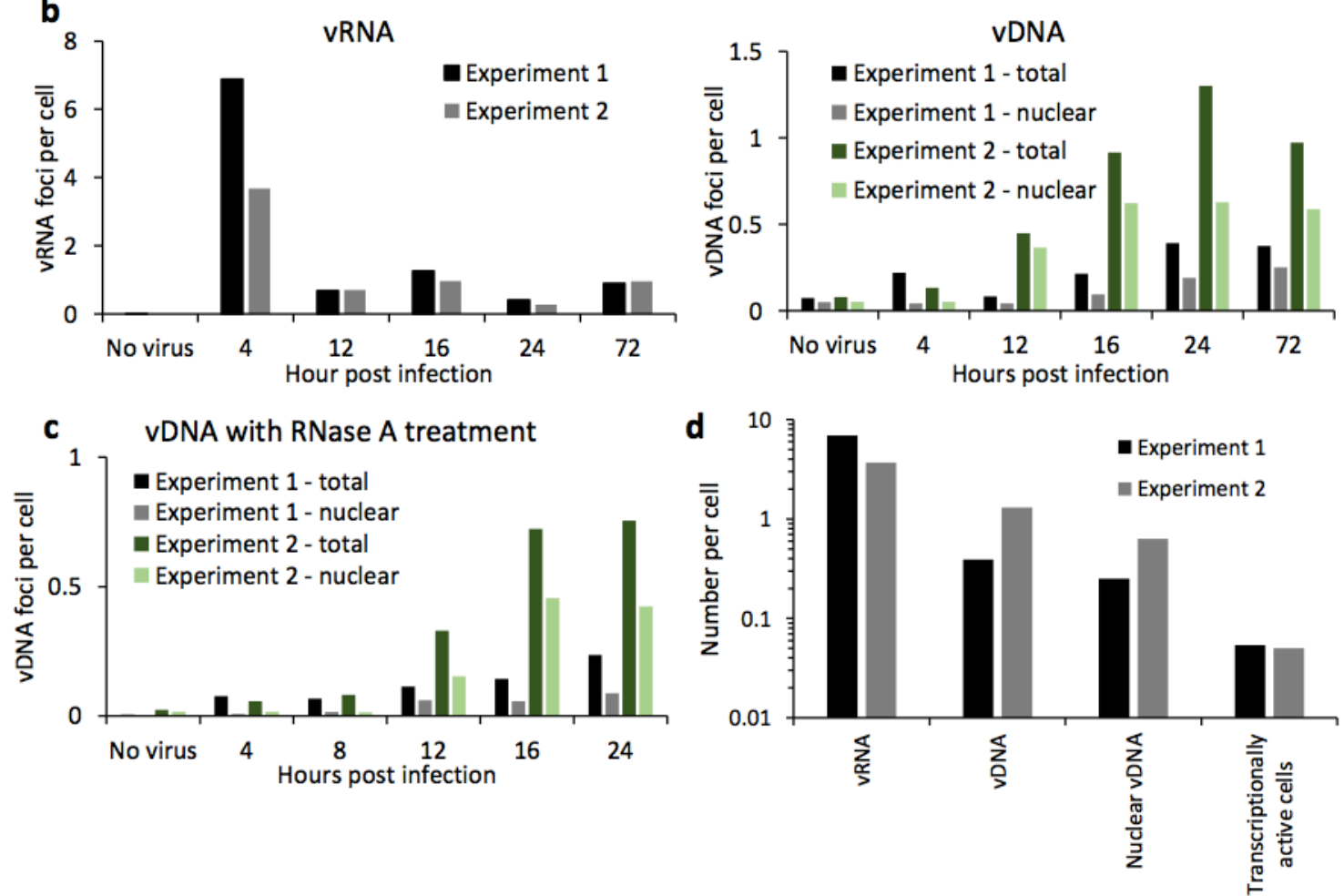

Figure 2.11. Tracking the early stages of infection of Primary CD4+ $\mathbf{T}$ cells. Primary CD4+ T cells were isolated from PBMCs, activated, and infected with HIV-1 NL4-3 at a MOI of 0.05. Cells were then fixed and stained at the indicated times. a Cells were stained for vRNA (PS-4; green), vDNA (PS-3; red) and nuclei (blue). Foci of vRNA and vDNA were counted in 1500-3500 cells per time point (4-24 h) or 500-1000 cells (no virus control and $72 \mathrm{~h}$ ). Foci were counted in the complete field of view (whole cell) or within a nuclear mask (nuclear). Scale bars represent $10 \mu \mathrm{m}$. b Number of vRNA and vDNA foci per cell of two independent experiments were calculated. Number of total vDNA foci or vDNA foci within nuclei (nuclear) are also shown. c Staining of vDNA was repeated with RNase A treatment. d Peak values for foci of vRNA, vDNA, nuclear vDNA, and transcriptionally active cells were calculated,to determine the efficiency of each stage in the infection process. This figure is copied from (203) with permission under a Creative Commons Attribution 4.0 International License. 


\subsection{DISCUSSION}

Here we introduce MICDDRP, a microscopy method based on bDNA-FISH (139) that can be used to visualize nucleic acid intermediates during HIV replication. This method has been applied to label the viral molecules at various stages of the replication cycle, including the incoming genomic vRNA at early time points and the various transcribed vRNAs at late time points. Probe sequences have been selected for specific labeling of either the unspliced vRNA that codes for Gag and GagPol and is packaged into particles as the genomic vRNA, or that is transcribed from integrated vDNA and exported in a Rev-dependent manner, or for labeling of total vRNA (spliced and unspliced). Similarly, various vDNA species may be labeled, including the nascent cytoplasmic vDNA (resulting from reverse transcription of the genomic vRNA), integrated proviral vDNA (following integration into the host chromosomes), and nonintegrated vDNA (including circular and linear species). Labeling the various species of vRNA and vDNA by this approach is highly sensitive, specific, and compatible with protein immunofluorescence and can be used to study a wide variety of processes, including reverse transcription of vRNA to vDNA, RNaseH activity to degrade vRNA, nuclear import of vDNA, transcription of vRNA from integrated proviral vDNA, splicing of vRNA, export of vRNA from the nucleus, and translation of viral proteins. This approach could also be used for specific questions that were not addressed, such as tracking the completion of reverse transcription. Our current vDNA probe labels the first strand of synthesized vDNA, showing that reverse-transcription begins in the cytoplasm, consistent with current models of the HIV-1 replication cycle. Labeling of the vDNA requires denaturation of the double-stranded vDNA. If a denaturing protocol were 
combined with RNase A treatment (to prevent labeling of the positive-stranded vRNA), it should be possible to stain the second (positive) strand of the vDNA and visualize the site where reverse transcription is completed. The high sensitivity achieved by bDNA-FISH also lends itself well to diagnostic applications; the high signal to noise ratio results in no "infected" cells being scored in the uninfected controls in our experiments.

The RNAscope technology has been applied to identify infected cells in tissue samples, with a sensitivity and specificity comparable to the "gold-standard" method of radiolabeled ISH (146). The investigators were also able to adapt the technique to label vDNA and vRNA simultaneously in simian immunodeficiency virus (SIV) infected tissues, allowing identification of actively and latently infected cells. Beyond identification of latently infected cells, bDNA-FISH has also been combined with immunofluorescent staining to permit highly sensitive identification of reactivated HIV transcription and translation in reactivated, patient-derived samples (155). Our ongoing studies focus on exploring possible factors that influence the onset of transcription from integrated vDNA. There is particular interest in the characterization of defective proviruses, that is, viruses that are integrated but cannot be transcribed or can be transcribed but not translated. Latent proviruses accumulate during antiviral therapy; some retain the variable capacity to be reactivated, while others may contribute to pathogenesis despite being incapable of producing infectious virus $(156,157)$. The scarcity of latently infected cells renders the problem of latency particularly challenging, and even with the ability to label integrated vDNA, in the absence of transcription, it would require considerable effort to identify and isolate the infected cells. Nevertheless, MICDDRP will be a useful tool, alongside many others, for addressing this major barrier 
to an HIV cure. In conclusion, we have developed a method for direct visualization of HIV vRNA, vDNA, and protein in the same cell. MICDDRP can be employed to follow early infection events, including the entry of HIV cores in the cytoplasm, the loss of vRNA and appearance of vDNA during reverse transcription, and vDNA trafficking to the nucleus. MICDDRP also allows for differentiation and quantitation of spliced and unspliced RNA. The addition of protein staining allows the expression of viral genes to be addressed as well as the transcription of RNA from integrated provirus. Similar work has been performed using the EdU labelling method (119; however, that approach requires labeling of the virus during reverse transcription. The bDNA-FISH used in MICDDRP and similar methods can be applied to patient-derived samples. This method should be a valuable tool for studies of HIV transcription, latency, co- infection, drug mechanisms of action, and host-cell interactions. Furthermore, MICDDRP should be applicable to a wide range of viruses and other nucleic acid-protein interactions. 


\section{CHAPTER 3 - LEDGF AND ANTISENSE VIRAL RNA DURING HIV INFECTION}

This work will constitute most of the material that will be submitted for publication after further developments outlined at the end of the chapter. Anticipated co-authors include: Puray-Chavez MN, Tedbury PR, Ukah OB, Yapo V, Achuthan V, Poeschla EM, Kvaratskhelia M, Engelman AN, Sarafianos SG. Loss of LEDGF/p75 targeted integration enhances transcription of HIV-1 antisense RNA. Manuscript in preparation.

\subsection{INTRODUCTION}

HIV-1/AIDS is a major health problem with over 36 million people infected worldwide and an estimated 1.8 million new cases in 2016, i.e. about 5,000 new infections per day. 20.9 million people living with HIV are accessing antiretroviral therapy (ART) globally (158). Current antiretroviral therapy can control viral load and infection; however, these drugs do not provide a cure for HIV/AIDS. The major barrier to a cure is the ability of the virus to remain dormant in long-lived cells known as the latent HIV reservoirs; however, the mechanisms regulating latency are poorly understood. Therefore, new strategies, including new ARTs, are under investigation. Targeting virus integration constitutes one strategy to reduce the HIV reservoir (159). HIV-1 integration is directed to regions of the genome by the chromatin binding protein lens epitheliumderived growth factor (LEDGF/p75, referred to here as LEDGF). In the absence of LEDGF, HIV-1 infection is markedly less efficient. Here, we report for the first time that knocking out LEDGF results in upregulation of antisense HIV-1 RNA transcription after infection. The mechanism and implications of this finding are currently unknown; 
although it has been reported that ablating the HIV-1 integrase-LEDGF (IN-LEDGF) interaction leads to increased HIV-1 latency, and also LEDGF depletion hampers HIV-1 reactivation (160-162). A relevant and highly useful tool for studing the function of LEDGF is the availability of integration inhibitors known as allosteric integration inhibitors (ALLINIs or LEDGINs), that block the interaction of HIV integrase and LEDGF, by binding at a pocket at the interface of two integrase molecules where the integrase-binding domain (IBD) of LEDGF also binds.

In recent years, antisense transcripts have been shown to suppress the expression of their sense gene through various mechanisms (163). The most studied retroviral antisense transcript is the human T cell leukemia virus 1 (HTLV-1) basic leucine zipper factor (HBZ), known since 1989 (164, 165) and characterized in 2002 and 2007 (166, 167). Hbz RNAs have regulatory roles promoting cell proliferation and inhibiting apoptosis, which is supported mostly by their nuclear localization. The HBZ proteins are also nuclear, promote persistent HTLV-1 latent infection and $\mathrm{T}$ cell proliferation, and inhibit apoptosis and autophagy. The existence of an antisense gene in the HIV-1 genome was first proposed in 1988 (168). Subsequent studies showed the HIV-1 antisense gene might give rise to several transcripts of different lengths $(169,170)$. A number of studies have assessed the ratio of sense vs. antisense transcription from the HIV-1 proviral genome (171-181), suggesting that antisense transcripts are 100-2,500 times and 1,000 times $(170,174)$ less abundant than sense transcripts in lymphoid and myeloid cells infected in vitro respectively $(170,174)$. However, studies in peripheral blood mononuclear cells of early-stage asymptomatic patients assessed antisense transcription showed that it represents as low as $1.3 \%$ and as high as $94 \%$ (mean $33 \%$ ) of total HIV-1 
proviral transcription (169). An HIV-1 transcript encoding the antisense protein (ASP) might play a role in viral replication $(170,175)$.

Here we show the antisense HIV-1 transcripts are abundant in a higher proportion of cells when the IN-LEDGF interaction is lost, whether by knocking out LEDGF or by pharmacological inhibition (treatment with ALLINIs). We also demonstrated that intriguingly, antisense RNA is rapidly lost from infected cells in a time course analysis post infection. Using a dual reporter virus to investigate the association between HIV-1 antisense RNA and latency, we determined antisense RNA has low expression in latently infected cells. 


\subsection{MATERIALS AND METHODS}

\section{Cell culture}

HEK 293-FT cells are derived from human embryonic kidney cells. HEK 293-FT cells were transformed with the SV40 large T antigen (ThermoFisher Scientific; catalog \#R70007). HEK 293T LEDGF knockout, CPSF6 knockout, and double knockout (LEDGF/CPSF6 -/-) cells were provided by Dr. Eric Poeschla from University of Colorado. Cells were cultured in Dulbecco's modified Eagle's medium (DMEM; Gibco), supplemented with $10 \%$ fetal bovine serum (FBS) and $2 \mathrm{mM}$ L-glutamine (Gibco) in a humidified incubator at $37^{\circ} \mathrm{C}$ with $5 \% \mathrm{CO} 2$.

Jurkat cells (NIH AIDS Reagent Program catalog \#177) are a human CD4 and CXCR4 positive T lymphocyte cell line (127). Jurkat LEDGF knockout and Jurkat LEDGF/p75 Integration Binding Domain (IBD) knockout cells were provided by Dr. Eric Poeschla. Cells were cultured in Roswell Park Memorial Institute 1640 medium (RPMI; Gibco) supplemented with $10 \%$ heat-inactivated FBS and $2 \mathrm{mM}$ L-glutamine in a humidified incubator at $37{ }^{\circ} \mathrm{C}$ with $5 \% \mathrm{CO} 2$.

Primary CD4+ T cells were isolated from PBMCs using EasySep ${ }^{\mathrm{TM}}$ Human CD4+ T Cell Enrichment Kit (STEMCELL Technologies) following the manufacturer's instructions. T cells were cultured and stimulated in RPMI supplemented with $10 \%$ heatinactivated FBS, $2 \mathrm{mM}$ L-glutamine, $60 \mathrm{U} / \mathrm{mL}$ IL-2, and $25 \mu \mathrm{L} / \mathrm{mL}$ ImmunoCult $^{\mathrm{TM}}$ Human CD3/CD28/CD2 T Cell Activator for 6-8 days prior to infection. Cells were maintained a humidified incubator at $37{ }^{\circ} \mathrm{C}$ with $5 \% \mathrm{CO} 2$, and every 2-3 days fresh media was added. 


\section{Nucleic acid probes}

All probes were purchased from Advanced Cell Diagnostics. To detect HIV-1 vRNA, an anti-sense probe targeting non-Gag-Pol regions coding envelope and accessory proteins (HIV vRNA anti-sense probe-1, PS-1, [probe channel C3]) were used (134). For antisense HIV-1 vRNA detection, two sense probes were used; the first probe targets the Gag-Pol coding region (HIV sense probe-2, PS-2, [probe channel ID C1]), and the second probe targets non-Gag-Pol regions coding envelope and accessory proteins (HIV sense probe-3, PS-3, [probe channel C3]). To avoid binding to the vDNA, no denaturation treatment was included. For simultaneous detection of HIV-1 vRNA and antisense HIV-1 vRNA, the probe PS-1 was directly diluted into PS-2 probe at a ratio of 1:50. The mixture was added to coverslips as recommended by the manufacturer. Supplementary Table 1 contains a complete list of the probe sets used in this study.

\section{HIV-1 infection}

Infectious HIV-1 particles were prepared by transfection of $3 \times 10^{6} 293 \mathrm{FT}$ cells (ThermoFisher Scientific) with $10 \mu \mathrm{g}$ NL4-3 proviral plasmid (135) in a $10 \mathrm{~cm}$ dish, using $30 \mu \mathrm{L}$ Fugene 6 (Promega) in $500 \mu \mathrm{L}$ Opti-MEM (Gibco). Media were changed 16 $\mathrm{h}$ post-transfection. Supernatant was harvested $48 \mathrm{~h}$ after transfection, cleared by centrifugation for $5 \mathrm{~min}$ at $700 \mathrm{x} \mathrm{g}$ followed by filtration through a $0.22 \mu \mathrm{M}$ polyvinylidene fluoride (PVDF) filter, and stored at $-80{ }^{\circ} \mathrm{C}$. Virus particles were expanded in MT-2 cells for 3-4 days. Supernatant was harvested and cleared by centrifugation for $5 \mathrm{~min}$ at $700 \mathrm{x}$ g followed by filtration through a $0.22 \mu \mathrm{M}$ PVDF filter, concentrated with Lentivirus precipitation solution (Alstem) following the manufacturer's 
instructions, and stored in aliquots at $-80^{\circ} \mathrm{C}$. Semi-synchronous infections of Jurkat cells

or $\mathrm{CD} 4+\mathrm{T}$ cells (activated 8 days earlier) were performed using $1-3 \times 10^{6}$ cells plated on a 6 well plate format with RPMI and $8 \mu \mathrm{g} / \mathrm{mL}$ polybrene. Plates were centrifuged at $1200 \mathrm{x} \mathrm{g}$ for $40 \mathrm{~min}$ at $20{ }^{\circ} \mathrm{C}$ then placed at $37^{\circ} \mathrm{C}$. Media were removed after $4 \mathrm{~h}$, and cells were washed once by resuspension in Dulbecco's phosphate buffered saline (DPBS) followed by centrifugation at $300 \mathrm{xg}$ for $10 \mathrm{~min}$. At specific times, samples were washed and prepared for images or quantification by Fluorescence-activated cell sorting (FACS).

For imaging analysis, to harvest, cells were washed once with DPBS in a ratio of 1:10 volume (cell suspension: DPBS) and spun down at $300 \mathrm{x} \mathrm{g}$ for $10 \mathrm{~min}$. Pellets were re-suspended in $20 \mu \mathrm{L}$ of DPBS per coverslip, then seeded in 20-30 $\mu \mathrm{L}$ DPBS, then placed onto poly-L-lysine-coated coverslips (coated overnight with $0.01 \% \mathrm{w} / \mathrm{v}$ poly-L lysine in water [Sigma] at $4{ }^{\circ} \mathrm{C}$ then washed three times with DPBS before use) (12 mm collagencoated coverslips (GG-12-Collagen; Neuvitro)) (136). For a $1 \times 10^{6}$ sample, the sample was divided on to 3 coverslips with approximately $3 \times 10^{5}$ cells per coverslip. Resuspended cells were dispersed on the coverslip to cover $12 \mathrm{~mm}$ diameter. It is recommended to prepare a few coverslips at a time, 2 to 3 , and allow cells to attach for 10 min at $37{ }^{\circ} \mathrm{C}$. Cells were fixed with $4 \%$ paraformaldehyde in DPBS for 30 min at room temperature then washed twice with DPBS (203). For FACS analysis, cells were collected and washed once with $10 \mathrm{~mL}$ DPBS in $15 \mathrm{~mL}$ tube before proceeding with RNA staining.

\section{In situ vRNA and antisense vRNA detection}


HIV-1 vRNA in cells was probed using RNAscope reagents (Advanced Cell Diagnostics). The manufacturer's protocol was used with some modifications (139). Following fixation, cells were dehydrated by removal of DPBS and sequential replacement with $50 \%, 70 \%$, then $100 \%$ ethanol, and the samples were incubated for 5 min at room temperature in each solution. Ethanol solutions were prepared as volume-tovolume ratios in ultrapure water (Synergy; Millipore). The 100\% ethanol was replaced with fresh $100 \%$ ethanol and incubated at room temperature for a final $10 \mathrm{~min}$. At this point, coverslips could be stored in $100 \%$ ethanol at $-20{ }^{\circ} \mathrm{C}$. To rehydrate cells, the sequence was reversed, and the cells were incubated for $2 \mathrm{~min}$ at room temperature in each solution; the cells were not allowed to dry in air at any time during the process. Finally, 50\% ethanol was replaced with PBS, and the cells were hydrated at room temperature for $10 \mathrm{~min}$. Cells were then washed with $0.1 \%$ Tween in PBS for $10 \mathrm{~min}$ and twice more in PBS for 1 min. Prior to hybridization, coverslips were immobilized on glass slides; a small drop of nail polish was placed on a glass slide, and the coverslip edge was placed on the nail polish drop. Using an ImmEdge hydrophobic barrier pen (Vector Laboratories), a circle was drawn around the coverslip and PBS was added to prevent sample dehydration. The manufacturer's protease solution (Pretreat 3) was diluted in PBS as appropriate prior to the experiment, a 1:2 dilution, and incubated in a humidified HybEZ oven (Advanced Cell Diagnostics) at $40{ }^{\circ} \mathrm{C}$ for 15 min. Protease solution was discarded, and the slides were washed twice by immersion in PBS at room temperature for 1 min. Specific pre-designed antisense and sense probes (Supplementary Table 1) were added as specified by the manufacturer (Advanced Cell Diagnostics): C3 probes (PS-1) were diluted 1:50 in C1 probe (PS-2). Probes were allowed to hybridize with the 
samples in a humidified HybEZ oven at $40{ }^{\circ} \mathrm{C}$ for $2 \mathrm{~h}$. The probes were then discarded and the coverslips washed twice using the proprietary wash buffer. All wash steps were performed on a rocking platform at room temperature for 2 min using the proprietary wash buffer. The probes were visualized by hybridizing with preamplifiers, amplifiers, and finally, fluorescent labels. Pre-amplifier 1 (Amp 1-FL) was hybridized to its cognate probe in a humidified HybEZ oven at $40{ }^{\circ} \mathrm{C}$ for $30 \mathrm{~min}$. Samples were washed twice then hybridized with Amp 2-FL in a humidified HybEZ oven at $40{ }^{\circ} \mathrm{C}$ for 15 min to suppress background staining. After two more washes, amplifier (Amp 3-FL) was hybridized to Amp 1-FL in a humidified HybEZ oven at $40{ }^{\circ} \mathrm{C}$ for $30 \mathrm{~min}$. Samples were washed twice, then fluorescent label Amp 4-FL was hybridized to Amp 3-FL in a humidified HybEZ oven at $40{ }^{\circ} \mathrm{C}$ for $15 \mathrm{~min}$, then washed twice more. For HIV-1 experiments, the labeled probe set Amp 4C-FL was used, labeling the $\mathrm{C} 1$ probes with Atto 550 and the $\mathrm{C} 3$ probe (PS-3) with Alexa 488. For subsequent protein staining, the RNA-labeled samples were washed with PBS and immunostaining was performed as described below. Otherwise, the final step was to counterstain nuclei with the manufacturer-supplied 4',6'diamino-2-phenylindole (DAPI, Advanced Cell Diagnostics) for 30 seconds at room temperature then remove the DAPI and immediately mount the coverslips on slides using Prolong Gold Antifade (Invitrogen).

\section{Immunostaining}

Staining for protein was performed after staining for nucleic acids. Coverslips were blocked with $1 \%(\mathrm{~W} / \mathrm{V})$ bovine serum albumen (BSA) and 10\% FBS in PBS containing $0.1 \%$ Tween-20 (PBST) at room temperature for $1 \mathrm{~h}$. Capsid protein (CA), or the capsid domain of Gag protein, was then probed with anti-p24 diluted 1:2000 in PBST 
supplemented with $1 \% \mathrm{BSA}$ and incubated at room temperature for $1 \mathrm{~h}$. Samples were washed twice in PBST at room temperature for $10 \mathrm{~min}$ with rocking. Fluorescently labeled secondary antibodies were used at 1:2000 and incubated at room temperature for $1 \mathrm{~h}$, then the samples were washed once with in PBST with at room temperature for 10 min with rocking. Nuclei were stained either using the DAPI provided in the RNAscope kit or with $0.5 \mu \mathrm{g} / \mathrm{mL}$ Hoescht-33258 in PBS at room temperature for $10 \mathrm{~min}$. Coverslips were washed twice in PBST at room temperature for 10 min with rocking and washed once with PBS for 1 min. Finally, coverslips were mounted on slides using Prolong Gold Antifade then sealed with nail polish.

\section{FACS vRNA and antisense vRNA detection}

For FACS quantification of HIV-1 vRNA and antisense HIV-1 vRNA in Jurkat and CD4+ $\mathrm{T}$ cells, cells were probed using RNAflow reagents (Advanced Cell Diagnostics). The manufacturer's protocol was used with some modifications $(134,139)$. Following the wash step, cells were collected by centrifugation at room temperature (20$25^{\circ} \mathrm{C}$ ) for $10 \mathrm{~min}$ at $300 \mathrm{x} \mathrm{g}$. Then, cells were re-suspended in the manufacturer's solution, $10 \mathrm{ml}$ of $1 \mathrm{x}$ CellPrep (diluted 1:50 of 50x CellPrep), with consecutive centrifugation as described. Cells were fixed using $1 \mathrm{ml}$ of 1x Fix/Perm buffer, and the suspension was transferred to a $1.7 \mathrm{ml}$ microcentrifuge tube and incubated for $30 \mathrm{~min}$ in a $37^{\circ} \mathrm{C}$ incubator on a rocker. Cells were collected by centrifugation for $2 \mathrm{~min}$ at $1200 \mathrm{x} \mathrm{g}$ and re-suspended in $1 \mathrm{ml}$ of 1x CellWash followed by centrifugation as described. Cells were resuspended in PBS. For staining, PBS was removed and cells were incubated with $100 \mu \mathrm{l}$ of the appropriate $1 \mathrm{x}$ Target Probe for $3 \mathrm{~h}$ at $40^{\circ} \mathrm{C}$. Cells were washed twice with 1x HybWash and centrifuged for 2 min at $1200 \mathrm{~g}$. Then, RNAflow Amp1 was added and 
cells were incubated for $40 \mathrm{~min}$ at $40{ }^{\circ} \mathrm{C}$. Cells were washed three times. Follow by RNAflow Amp3 and incubated for $30 \mathrm{~min}$ at $40{ }^{\circ} \mathrm{C}$. Cells were washed twice. Then, RNAflow Amp4 was added, samples were incubated for 25 min at $40{ }^{\circ} \mathrm{C}$, then samples were washed again twice. Finally, cells were resuspended in PBS.

\section{Imaging and imaging quantification}

Unless otherwise stated, images were taken with a Leica TCS SP8 inverted confocal microscope equipped with a $63 \mathrm{x} / 1.4 \mathrm{NA}$ and 100x/1.4 NA oil-immersion objectives and a tunable supercontinuum white light laser. The excitation / emission bandpass wavelengths used to detect DAPI, Alexa 488, ATTO 550, Alexa 568, and Alexa 647 were set to 405/420-480, 488/505-550, 550/560-610, 568/580-630, and 647/655-705 nm, respectively. Confocal data sets were deconvolved using the Huygens Professional software (Version 16.10, SVI). 


\subsection{RESULTS}

\section{Visualization of antisense HIV-1 RNA at single cell level}

Previous studies have described antisense transcripts formed during virus infection; viruses capable of forming these antisense transcripts include HTLV-1 and HIV-1, among others. HTLV transcripts have been intensively studied, while the HIV-1 antisense transcripts are still under investigation. Both HIV-1 antisense transcripts and perturbation of the interaction between HIV-1 IN and the host protein LEDGF have been reported to be involved in latency (160-162). To study further the role of LEDGF in HIV infection, and the potential relationship between it and HIV-1 antisense RNA, we followed the detection of nucleic acids using sense probes and antisense probes (Table 2.1) by in situ hybridization at a single cell level. Protocols described in Methods were used with sense probes that targeted the Gag-Pol region of HIV-1 and antisense probes to target the non-Gag-Pol region of HIV-1, enabling confocal microscopy.

In LEDGF knockout (LKO) HEK 293 T infected cells, the sense probe captured a "disturbed" staining (Fig. 3.1a) at 16 hpi. This staining was not evident in the wild type cell or in the knockout of CPSF6, but remained clearly detectable in the double knockout LEDGF/CPSF6. To characterize the nature of the nucleic acid, we further evaluated the susceptibility or resistance of the signal to treatment with RNase (Fig. 3.1b). The signal was abrogated in the presence of RNase A treatment in HEK 293T LKO cells. We attempted to reproduce this finding using integrase targeting inhibitors that disrupts the IN-LEDGF interaction, LEGINs or ALLINIs (Fig. 3.2). Interestingly, we found same accumulation of antisense nucleic acid in cells treated with $10 \mu \mathrm{M}$ BI-D (ALLINI) and the signal was sensitive to RNase A treatment while the control Dimethyl sulfoxide 
(DMSO) treated cells contain mostly sense vRNA that is also abrogated by RNase A treatment (Fig. 3.1c). To limit the detection of vDNA, we avoided the use of a denaturation step; this preserved the double-stranded DNA, rendering it inaccessible for probe annealing. To demonstrate the observation in physiological relevant cells, we infected CD4+ T cells and demonstrated that the nucleic acid detected is RNA (Figure $3.3)$. 
+veRNA -veRNA

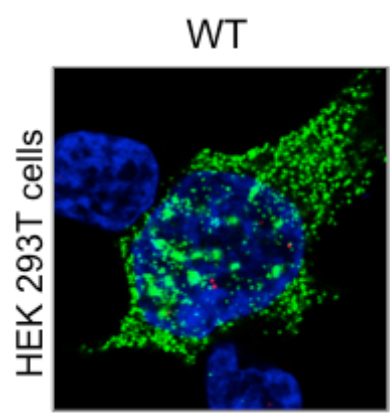

b

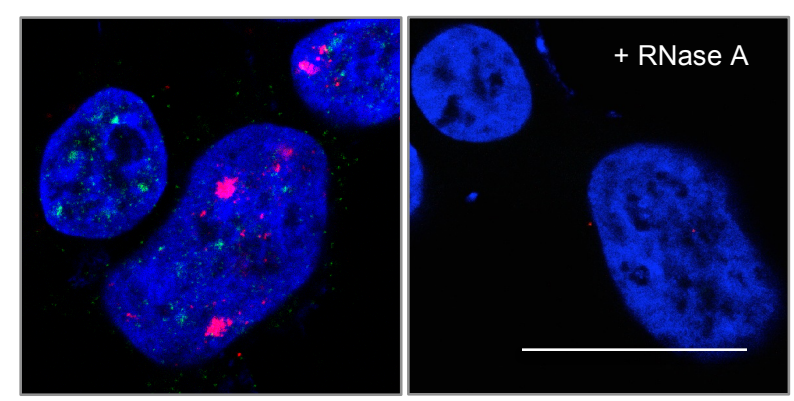

C HEK 293T

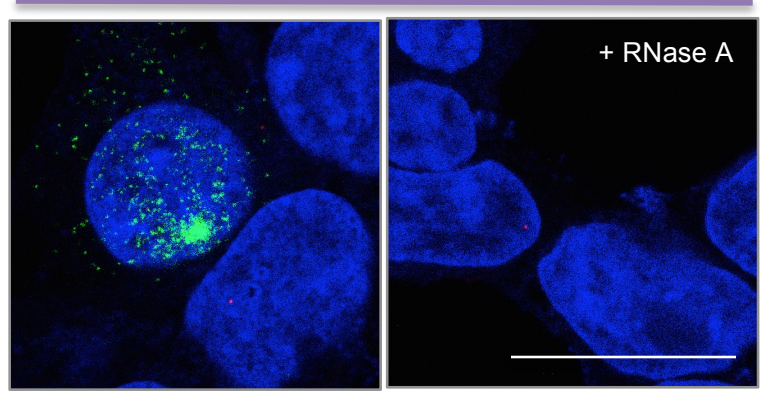

BI-D

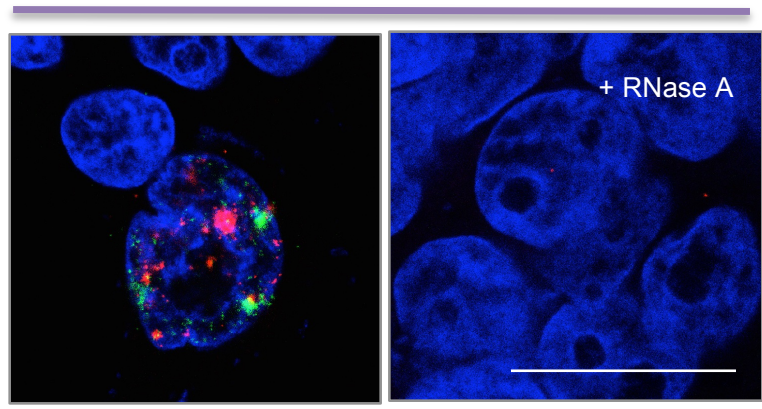

HEK 293T KO LEDGF
KO LEDGF /

KO CPSF6
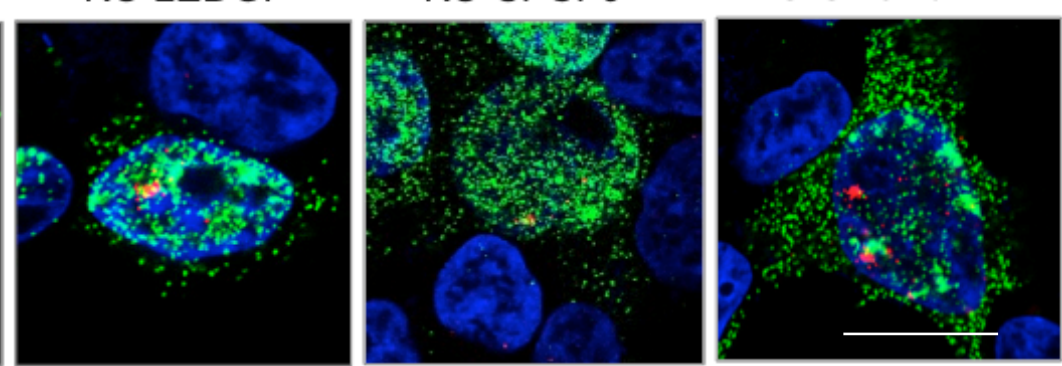
Figure 3.1. RNA HIV-1 detection in HEK 293T cells. a Sense and antisense probes were used to detect antisense HIV-1 RNA and HIV-1 RNA, respectively. b HEK 293T WT, knockout LEDGF, knockout CPSF6, and double knockout cells were infected with VSV G pseudotype HIV-1 $1_{\mathrm{NL} 4-3}$. At 16 hpi, cells were fixed and stained with antisense and sense probes for vRNA (PS-1; green), antisense RNA (PS-2; red), and nuclei (blue). Scale bars represent $10 \mu \mathrm{m}$. b HEK $293 \mathrm{~T}$ knockout LEDGF were infected with HIV-VSV. At $16 \mathrm{hpi}$, cells were stained with antisense and sense probes to detect for vRNA (PS-1; green), antisense RNA (PS-2; red) and nuclei (blue) (right panel). In parallel, cells were treated with RNase A (left panel). c HEK 293T were treated with DMSO (top panel) or ALLINI compound, $10 \mu \mathrm{M}$ BI-D (bottom panel) and infected with HIV-VSV. At $16 \mathrm{hpi}$, cells were fixed and stained with antisense and sense probes for vRNA (PS-1; green), antisense RNA (PS-2; red), and nuclei (blue). Scale bars represent $10 \mu \mathrm{m}$.

\section{ALLINIs \\ (Allosteric Integrase Inhibitors)}<smiles>Cc1nc2ccccc2c(-c2ccc3c(c2)CCCO3)c1C(OC(C)(C)C)C(=O)O</smiles><smiles>Cc1nc2ccccc2c(-c2ccc3c4c(ccnc24)CCO3)c1C(OC(C)(C)C)C(=O)O</smiles><smiles>Cc1nc(-c2nc3ccc(Cl)cc3[nH]2)c(C)c(-c2ccccc2)c1C(OC(C)(C)C)C(=O)O</smiles>

Figure 3.2. Allosteric Integrase Inhibitors (ALLINIs) used in this study. BI-D, BI-224436, and KF116 drugs were used at final concentrations of $10 \mu \mathrm{M}, 10 \mu \mathrm{M}$, and $50 \mu \mathrm{M}$ respectively, dissolved in $0.5 \%$ DMSO. 


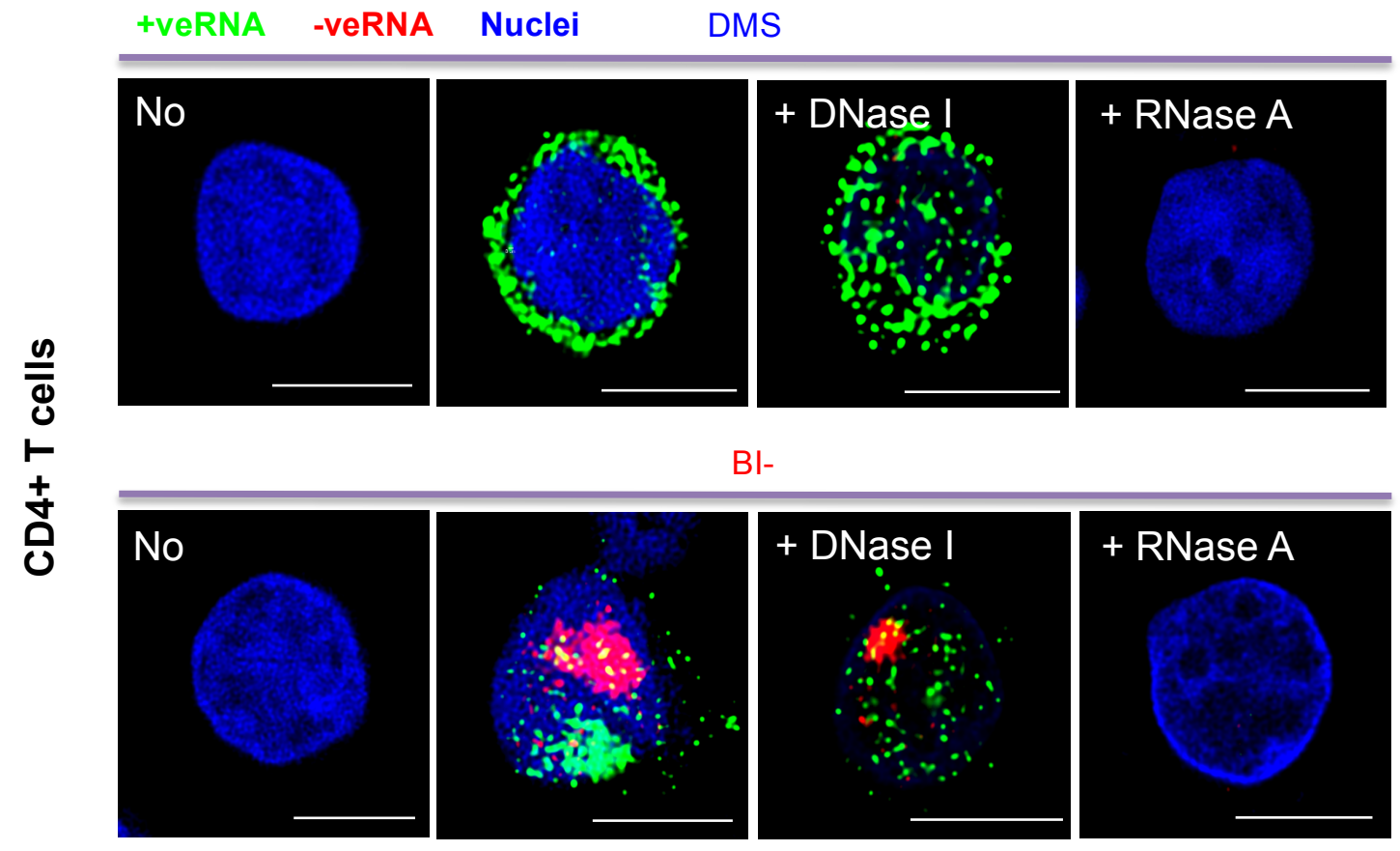

Figure 3.3. Detection of antisense RNA HIV-1 in Primary Cells. a CD4+ T cells were treated with DMSO (top panel) and $10 \mu \mathrm{M}$ BI-D (bottom panel) and infected with $\mathrm{HIV}_{\mathrm{NL4}-3}$. At $24 \mathrm{hpi}$, cells were fixed and stained. Prior to RNA labeling, cells were treated with buffer alone, RNase A, or DNase I. Antisense and sense probes were used to detect vRNA (PS-1; green), vRNA (PS-2; red), and nuclei (blue). Scale bars represent $5 \mu \mathrm{m}$.
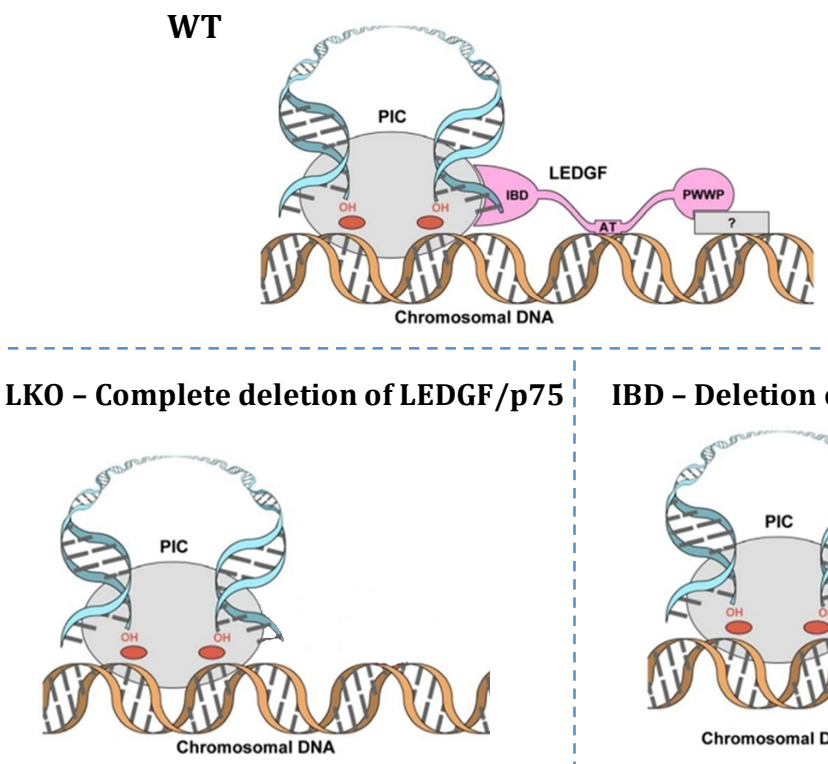

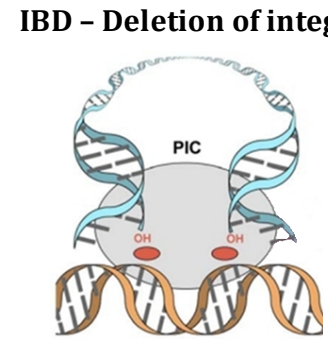

Chromosomal DNA

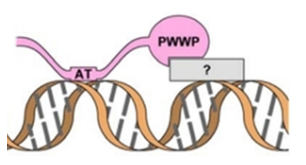

Chromosomal DNA

Figure 3.4. Knockout Jurkat cells. Adapted by Dr. Philip Tedbury from Hare \& Cherepanov, Viruses (2009) 


\section{The role of LEDGF in mediating sense versus antisense HIV transcription}

To quantify the relationship between the number of cells containing antisense transcripts and LEDGF, we first looked at disruption by genetic modification of the integrase-LEDGF interaction (IN-LEDGF/p75) in lymphocytic Jurkat cells. The genetic modifications include a complete deletion of gene PSIP1 that encode LEDGF/p75 or specific deletion of integrase binding domain (IBD) in Jurkat cells (Fig. 3.4). Jurkat WT, Jurkat knockout LEDGF and Jurkat knockout IBD cell lines were infected with HIV NL4-3 and the viral transcripts were labeled by bDNA FISH. After labeling, we detected three phenotypes of RNA expression microscopically: +veRNA (left image), +veRNA/veRNA (middle image) and -ve RNA (right image). (Fig. 3.5a). As expected LEDGF and IBD knockout cells were less infected compared with wild type cells (Fig. 3.5b) To quantify the numbers of infected cells, and the proportions exhibiting each of the three phenotypes, we employed FACS. Our data confirm that fewer LEDGF or IBD knockout cells were infected relative to wild type (Fig. 3.5c), and indicate that antisense RNA producing cells are observed at a higher frequency when the IN-LEDGF interaction is disrupted (Fig. 3.5d).

The IN-LEDGF interaction was also disrupted pharmacologically by the use of small molecule inhibitors known as LEGINs or ALLINIs, which include BI-D, BI224436 and KF116 (Fig. 3.2). ALLINI treatment of Jurkat and CD4+ T cells also reduced infection relative to untreated cells (Fig. $3.6 \mathrm{a}, \mathrm{b}, \mathrm{c}$ and d) and the detection of antisense RNA was almost 3 fold higher than wild type (Fig. 3.6 e, f). Taking all data together, the inhibition of IN-LEDGF/p75 interaction increases the proportion of cells demonstrating antisense RNA production. 
We monitored the stability of antisense HIV RNA in a time course setting, at 24, 48 and 72 hpi (Fig. 3.7a). At 48 hpi, the percentage of antisense RNA containing cells had decreased by $40 \%$ and at 72 hpi by $80 \%$, relative to the levels found at 24 hpi (Fig. 3.7b). 
a
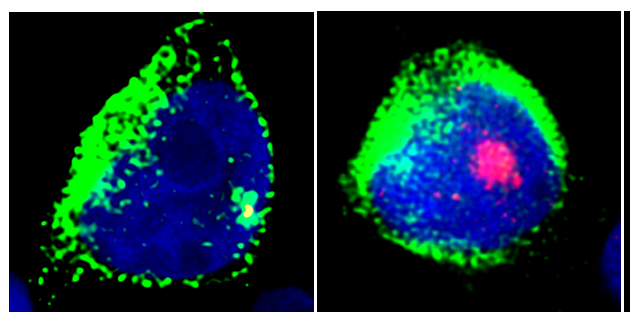

+veRNA

(sense transcript)

+veRNA

-veRNA

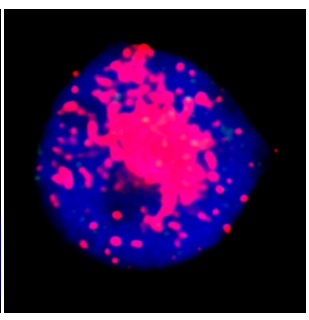

-veRNA

(antisense transcript)

b Jurkat cells

24 hpi

+veRnA -veRNA Nuclei
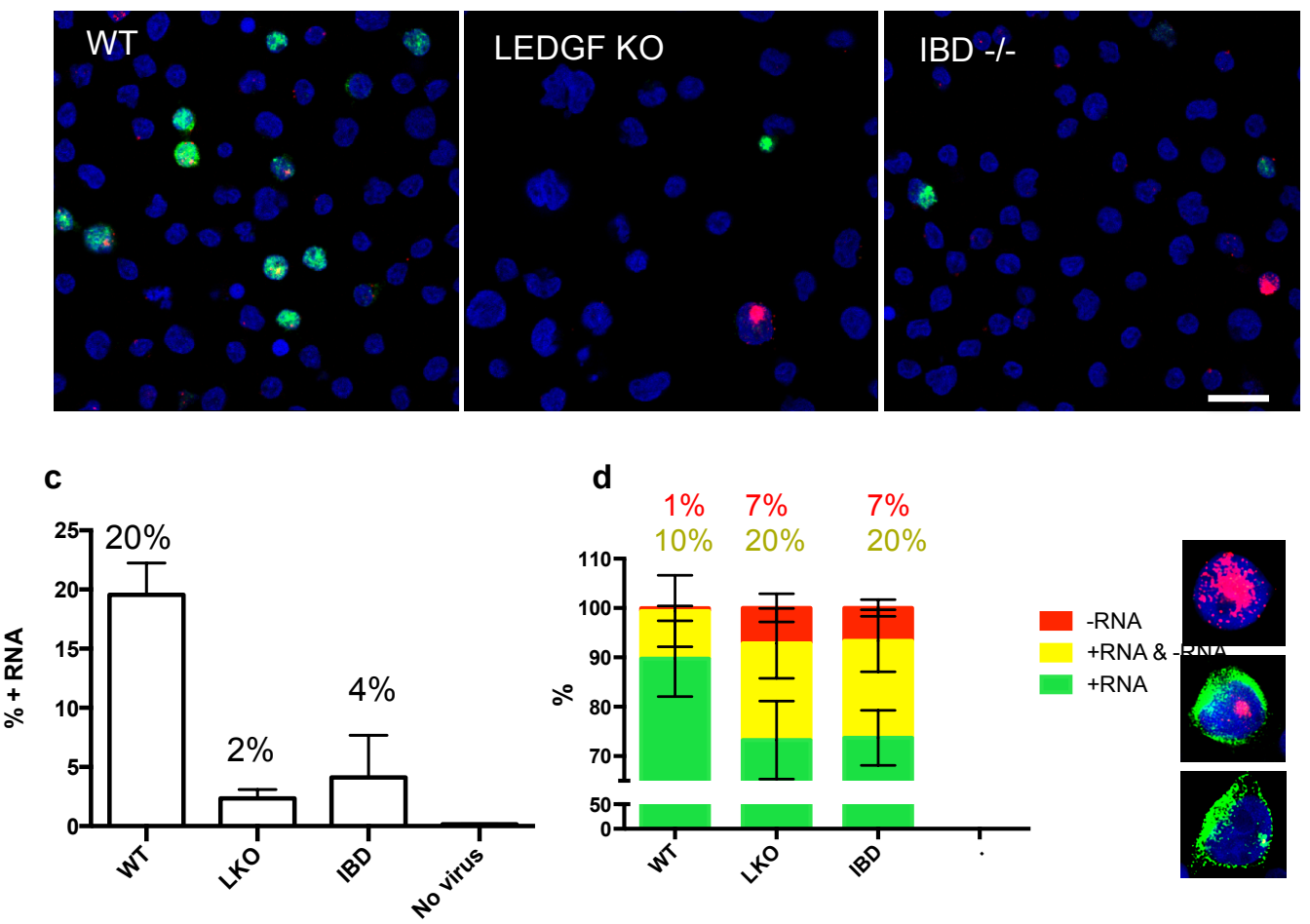

Figure 3.5. Disruption of IN-LEDGF/p75 interaction enhances HIV-1 antisense RNA. Lymphocyte

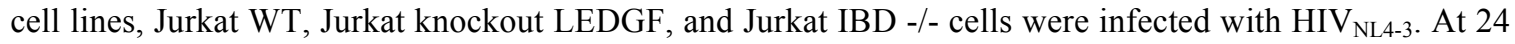
hpi, cells were fixed and stained. a After staining with antisense and sense probes to detect for vRNA (PS1; green), antisense RNA (PS-2; red), and nuclei (blue), three features of RNA expression were found: +veRNA (left), +veRNA/-veRNA (middle), and -veRNA (right). b Confocal images of infected cells, 63x. c Infected cells were counted by FACS $(\%+$ RNA) and $\mathbf{d}$. the distribution of -veRNA, -veRNA/+veRNA, and +veRNA was determined ( $n=3$ independent experiments). Scale bars represent $10 \mu \mathrm{m}$. 

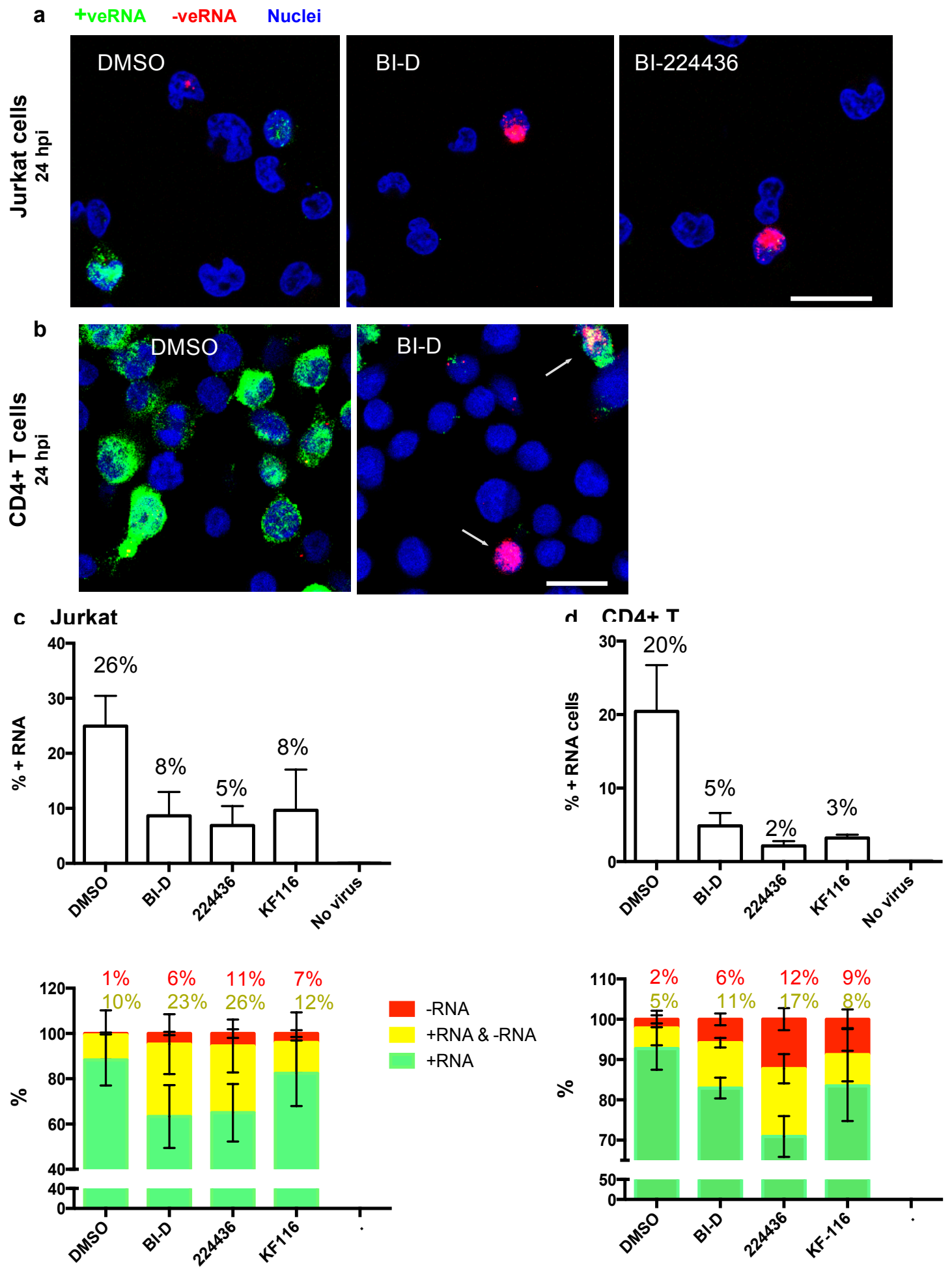

-RNA

+ RNA \& -RNA + RNA

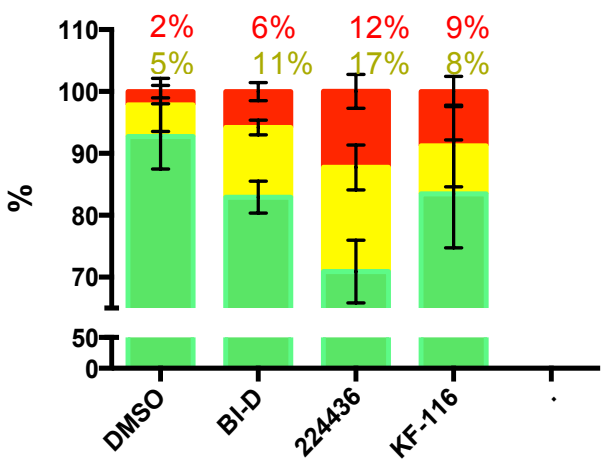

Figure 3.6. Pharmacological disruption of IN-LEDGF/p75 interaction enhances HIV-1 antisense RNA. a Jurkat cells were treated with DMSO (left image) or ALLINIs compound, $10 \mathrm{uM} \mathrm{BI-D} \mathrm{(middle}$

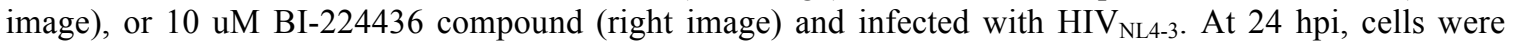
fixed and stained to detect for vRNA (PS-1; green), antisense RNA (PS-2; red), and nuclei (blue). b CD4+ $\mathrm{T}$ cells were treated with DMSO (left image) or with $10 \mathrm{uM} \mathrm{BI-D}$ (right image) and infected with HIV NL4- $_{\text {- }}$ 3. At $24 \mathrm{hpi}$, cells were fixed and stained to detect for vRNA (PS-1; green), antisense RNA (PS-2; red), and nuclei (blue). Scale bars represent $10 \mu \mathrm{m}$. c Jurkat infected cells were fixed, stained, and counted by FACS 
$(\%+\mathrm{RNA})$ (top chart), and the distribution of -veRNA, -veRNA/+veRNA, and +veRNA was determined (bottom chart) $(n=3$ independent experiments). d CD4+ T infected cells were counted by FACS (\% +RNA) (top chart), and the distribution of -veRNA, -veRNA/+veRNA, and +veRNA was determined (bottom chart) ( $n=3$ independent experiments).

a

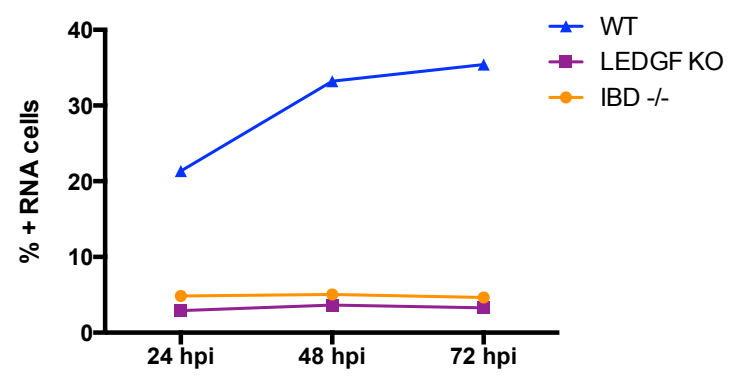

b
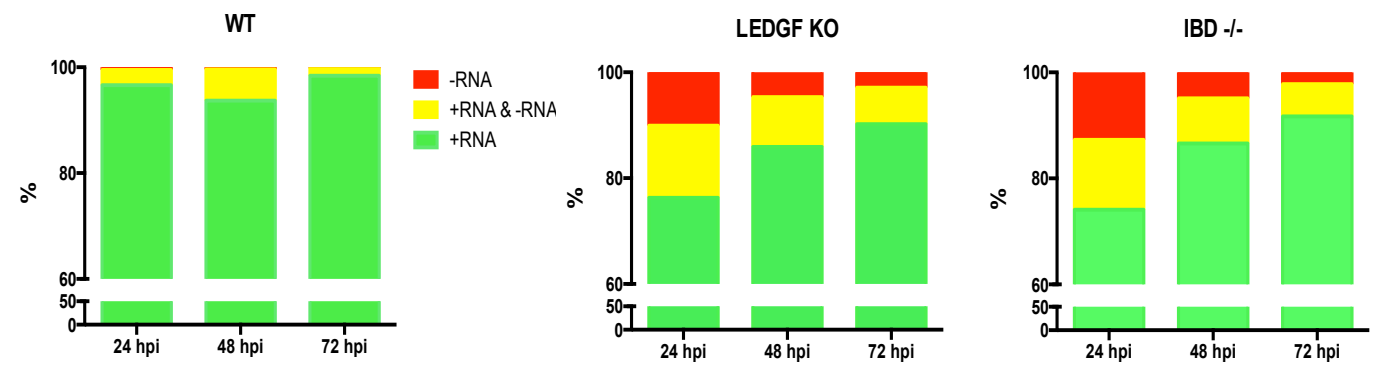

Figure 3.7. Rapid decrease of antisense RNA from infected cells. Time course experiment in lymphocyte cell lines. Jurkat WT, Jurkat knockout LEDGF, and Jurkat IBD -/- cells were infected with $\mathrm{HIV}_{\mathrm{NL} 4-3}$. At $24 \mathrm{hpi}$, cells were fixed and stained for vRNA (PS-1; green) and antisense RNA (PS-2; far red). a Percentage of + RNA cells were counted by FACS $(n=1$ experiment). b The distribution of veRNA, -veRNA/+veRNA, and +veRNA was determined ( $n=1$ experiment).

\section{Antisense transcription and latency}

Both depletion of LEDGF and expression of antisense HIV-1 RNA have been linked to elevated rates of HIV-1 latency and impaired reactivation. We infect cells with a dual reporter distinguish transduced but not actively transcribing HIV -1 cells ("latent") from actively infected cells. He hypothesized that antisense RNA may be expressed more in transuced but not actively infected cells. Actively and latently infected cells were sorted (Fig. 3.8a), following disruption of LEDGF interactions and determining the 
correlation with sense and antisense RNA transcription. Antisense RNA is limited in latently infected cells (Fig. 3.8b), while infected cells expressed similar percentage of antisense RNA (Fig.3.8c) as previously observed (Fig. 3.5d. and 3.7b)

a

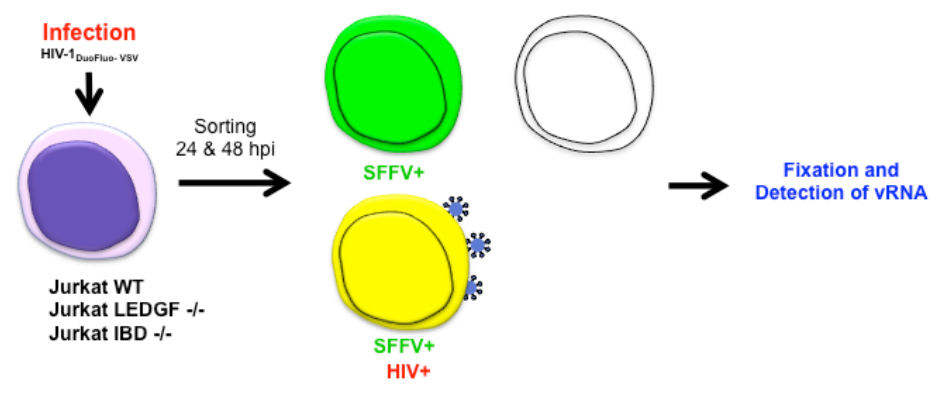

pNL43Del_env_Crim_SFFV_Zs-GFP
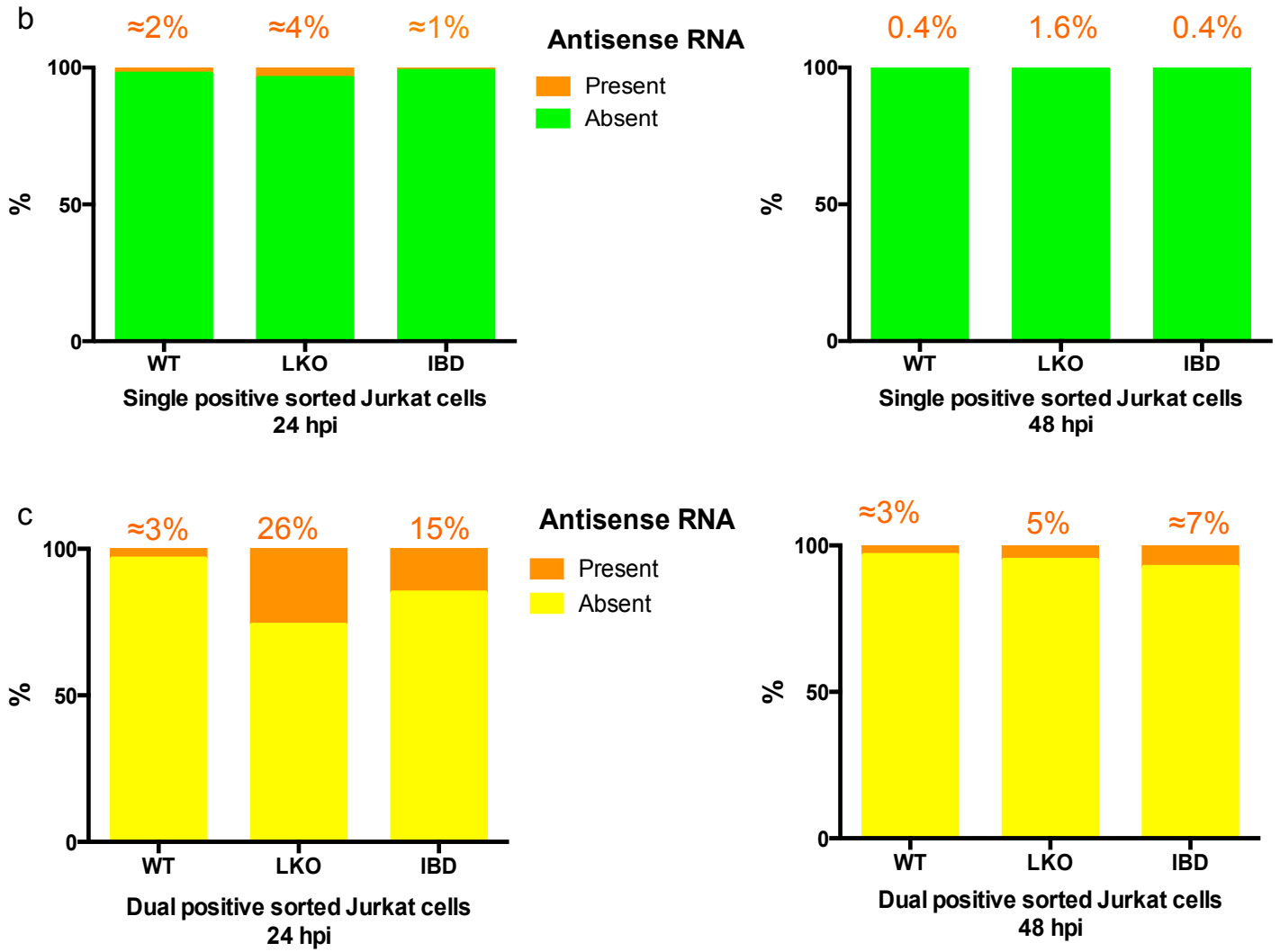

Figure 3.8. Antisense RNA is not found in latently infected cells. a Experiment design in lymphocyte cell lines. Jurkat WT, Jurkat knockout LEDGF and Jurkat IBD -/- cells were infected with HIV NL4-3-VSV dual reporter virus that expressed eGFP and Crimson under SFFV and HIV promoters, respectively. At 24 hpi and $48 \mathrm{hpi}$, cells were sorted in two groups [single positive: eGFP+(SFFV+) and dual positive: eGFP+/Crimson+(SFFV+/Crimson +$)$, washed, fixed, and stained. b After staining of single positive cells $(\mathrm{GFP}+)$ with sense probe (PS-2; ATTO 550), antisense RNA in cells was quantified by FACS at 24 hpi 
(left chart) and 48 hpi (right chart). c Dual positive sorted cells were detected with sense probe (PS-2; ATTO 550) and FACS quantified for antisense RNA expressing cells at $24 \mathrm{hpi}$ (left chart) and $48 \mathrm{hpi}$ (right chart). ( $n=1$ experiment).

\section{Imaging features of antisense HIV transcripts}

Most of the cells expressing antisense transcripts also contained sense transcripts. All analyzed images indicated antisense transcripts have a restricted location in the nuclear compartment (Fig. 3.9), which agreed with a previous report.
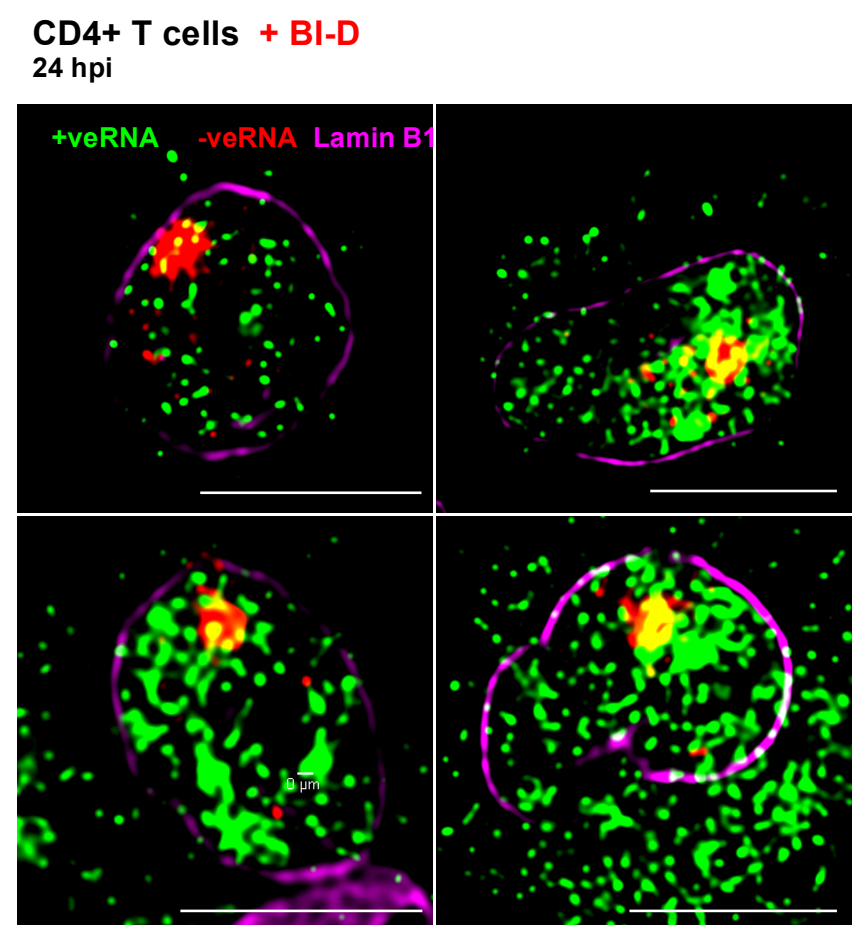

Figure 3.9 Antisense RNA HIV-1 in primary cells. CD4+ T cells were treated with $10 \mathrm{uM}$ BI-D and infected with $\mathrm{HIV}_{\mathrm{NL4}-3}$. At $24 \mathrm{hpi}$, cells were fixed and stained to detect for vRNA (PS-1; green), antisense RNA (PS-2; red), and Lamin B (magenta). Scale bars represent $5 \mu \mathrm{m}$. 


\subsection{DISCUSSION AND FUTURE DIRECTIONS}

Some retroviruses encode an antisense gene on the negative strand of their genome that is expressed from an antisense promoter within the $3^{\prime} \mathrm{LTR}$ in the opposite direction to the transcripts originating in the 5'LTR $(169,170)$. Here we investigated the expression of the antisense RNA from the HIV-1 genome, its relation with LEDGF knockout cells, and its potential relationship with latency. We adapted in situ hybridization to label HIV negative RNA also referred to as antisense transcripts, in single cell level by microscopy and FACS. These transcripts were found in the Jurkat lymphocyte, and CD4+ T cells infected with HIV. As described above, we found antisense transcripts in these cells that were previously described (171-181), but we reported for a first time higher expression of antisense RNA in Jurkat LKO, Jurkat IBD /- and CD4+ T BI-D treated cells compared with Jurkat WT and DMSO control cells. Our findings indicate that HIV antisense RNA is not stable and decreased significantly after 24 hpi. Unexpectedly, using a dual reporter HIV virus, we detected low expression of these transcripts in latent cells, but this experiment was performed within 24 to $48 \mathrm{hpi}$.

In summary, loss of the interaction between integrase and LEDGF during HIV-1 integration leads to a higher proportion of HIV-1 antisense RNA containing cells. HIV-1 sense and antisense RNA can be produced from the same provirus and antisense RNA production is short-lived.

To elucidate the role of HIV-1 antisense RNA during infection and its relationship with IN-LEDGF disruption we will first characterize antisense RNA by sequencing using next-generation sequencing and determine the transcription start site (TSS) and where in the genome is more expressed or abundant. Second, we will rescue lost LEDGF function 
in LKO cells by using LEDGF chimeric proteins. Third, determined if the enhanced antisense RNA lead to higher antisense protein expression. Fourth, we will determine if the expression of antisense RNA expressing cells may predict or associate with latency. We may addressed some of these major questions: How persistent is expression of antisense RNA?, Are these functional consequences to its expression?, Can those effects be observed by expressing antisense in trans from another copy?, Which segment(s) of antisense RNA is responsible for these effects?. 


\section{CHAPTER 4. ANTIVIRAL ACTIVITY OF MOV10 ON HEPATITIS B VIRUS INFECTION}

This work will constitute most of the material that will be submitted for publication after further developments outlined at the end of the chapter. Anticipated co-authors include: Puray-Chavez MN, Huber AD, Liu D, Ndongwe TP, Casey M, Sarafianos SG. Mechanism of action of an RNA binding protein MOV10 on HBV replication. Manuscript in preparation.

\subsection{INTRODUCTION}

Hepatitis B virus (HBV) is a partially double-stranded DNA virus that causes acute and chronic infection of the liver. Worldwide, an estimated 350 million people are chronically infected with $\mathrm{HBV}$, and 0.5 to 1 million people die every year from HBV (49-51). Upon entry, HBV encounters cell defense, known as innate immunity. This response is mediated by type I Interferon (IFN) and IFN-stimulated genes (ISG) (88-90, 188). During last years $\mathrm{DExD} / \mathrm{H}-$ box helicases shown to contribute to antiviral response by sensing viral nucleic acids or by facilitating downstream signalling events (205). An example of a helicase involve in immune response is the well-characterized RIG-like helicases (RLHs) that are part of pattern recognition receptors (PRRs) and part of DExH family of RNA helicases. Other helicases (DDX3, DDX60, DDX41, DDX1, DHX9 and DHX36) may constitute additional receptors for viral nucleic acids, and to induce IFN induction via TIR adaptor or MAVS-dependent signaling (205). In the last few years the RNA helicase MOV10 (Moloney leukemia virus 10, homolog (mouse)) has been shown to inhibit various viruses (188) among them MOV10 affect HIV-1 replication through 
different mechanisms (189-192). However, since MOV10 is induced by IFN, its role in other RNA viruses besides HIV has been vague and in some cases contradictory (188). For example, MOV10 demonstrated antiviral activity against hepatitis $\mathrm{C}$ virus (HCV) in an ISG expression library screen $(188,193)$. In contrast, MOV10 interacts with hepatitis delta virus antigen and enhances viral RNA replication $(188,194)$.

MOV10 is an RNA helicase that belongs to the DExD superfamily and Upframeshift protein-1 (Upf1)-like group of helicases (182), was first identified as a novel Argonaute-associated protein and was shown to be involved in RNA interference (RNAi) (183, 184). MOV10 is expressed from an ISG, it is known to bind a broad variety of mRNA (185) and predominantly binds to 3' UTRs upstream of regions predicted to form local secondary structures (186), also has ATP-dependent 5'-3' RNA helicase activity, and, through its helicase activity, participates in mRNA degradation and translation inhibition (187).

MOV10 has complicated functions and features (195). MOV10 is a component of mRNA processing bodies (P-bodies) and RNA interference signaling complexes (RISC), also MOV10 interacts with canonical P-body and RISC proteins including apolipoprotein B mRNA editing enzyme, catalytic subunit 3G (APOBEC3G), Argonaute 1 (AGO1), and Argonaute 2 (AGO2) (196-199). Inhibition of HIV-1 by MOV10 has been well characterized. MOV10 and APOBEC3G (A3G) localize to P bodies, incorporate into human immunodeficiency virus type 1 (HIV-1) virions, and inhibit viral replication. Others have reported that overexpression of the P-body-associated protein MOV10 can inhibit other retroviruses, including simian immunodeficiency virus (SIV), murine leukemia virus (MLV), and equine infectious anemia virus (EIAV) (101, 102). However, 
the specific effects of MOV10 in the life cycle of HBV are partially described (103) and HBV depends on reverse transcription from pre-genomic RNA to synthesize its first strand DNA, this feature allow us to propose that MOV10 may have an effect on HBV replication. Here we investigate the effect of MOV10 on HBV infection and determine which steps of the virus life cycle are affected by changes in expression of MOV10. MOV10 overexpression decreased HBV infection while MOV10 down-regulation enhanced HBV infection. Confocal imaging shows endogenous MOV10 co-localizes with HBV core protein and HBV RNA. Shortly after we collected these data, 2015, a brief communication paper presented contradictory results (103).

\subsection{MATERIALS AND METHODS}

\section{Cell lines}

HepG2 cell line was purchased from American Type Culture Collection (ATCC). These cells were maintained in Dulbecco's Modified Eagle Medium (DMEM, Invitrogen) supplemented with 10\% fetal bovine serum (FBS). HepAD38 (200) cells were maintained in DMEM supplemented with $10 \%$ FBS, $0.3 \mu \mathrm{g} / \mathrm{ml}$ tetracycline, and 400 $\mu \mathrm{g} / \mathrm{ml} \mathrm{G} 418$, as previously described (200). Cells were incubated at $37^{\circ} \mathrm{C}$ with $5 \% \mathrm{CO}_{2}$.

\section{Plasmids}

The HBV genome-containing plasmid pCMV-HBV-LE-II (pHBV) was a gift from Dr. John E. Tavis (Saint Louis University) (201). Plasmids expressing YFP-MOV10 and FLAG-MOV10 were a gift from Dr. Pathak (National Institute of Health) (202).

\section{Knockdown of endogenous MOV10}


The levels of endogenous MOV10 protein were down regulated using siRNA technology. Sequences were designed to target MOV10 RNA (5' CGgCAAGACUGUCACGUUA -3'， 5'- GgUCAGAUAUCAGCAAACA -3', 5'GCCAUGAGGCACAUUGUUA -3', and 5'- CAAUUAAGCAGGUGGUGAA -3') and ordered from Dharmacon General Electric (GE) Healthcare. The transfector used was Lipofectamine RNAiMax, and the Lipofectamine to siRNA ratio was 1:3. Levels of endogenous MOV10 were obtained in HepG2 and HepAD38 transfected cells by Western Blot.

\section{Overexpression of MOV10}

Plasmids expressing YFP-MOV10 and FLAG-MOV10 (202) driven by CMV promoter were transfected at specified concentrations in $60-70 \%$ confluent HepG2 and HepAD38 cells using Fugene 6 reagent (Promega) according to the manufacturer's instructions. 12-well plates were used with $1 \mathrm{ml}$ medium per well.

\section{Quantitative polymerase chain reaction (qPCR) analysis of HBV DNA}

Total cellular DNA was extracted using the QIAamp DNA Blood Mini Kit (Qiagen). Forward and reverse primers for total HBV DNA quantification were 5'CCTGGTTATCGCTGGATGTGT-3' and 5'-GGACAAACGGGCAACATACCTT-3', respectively (29). DNA in a $10 \mu 1$ reaction volume was subjected to amplification by denaturation at $95^{\circ} \mathrm{C}$ for $10 \mathrm{~min}$ followed by 40 cycles of denaturation at $95^{\circ} \mathrm{C}$ for $15 \mathrm{~s}$, annealing/extension at $60^{\circ} \mathrm{C}$ for $1 \mathrm{~min}$, using PerfeCTa SYBR Green FastMix (Quanta Biosciences). Amplification was carried out in an ABI 7500 machine (Applied Biosystems) A standard curve was generated with dilutions of HBV plasmid pCMVHBV-LE-II (a gift from Dr. John Tavis, Saint Louis University) (201). 


\section{RNA levels by quantitative RT-PCR}

To determine HBV RNA levels, infected and control cells were treated with TRI reagent (Sigma-Aldrich) and total RNA was purified following the manufacturer's instructions. Primers (Forward: 5'-GAGTGTGGATTCGCACTCC-3') and (Reverse: 5'GAGGCGAGGGAGTTCTTCT-3') were used for HBV 3.5 kb transcripts; (Forward: 5'TCACCAGCACCATGCAAC-3') and (Reverse: 5'-AAGCCACCCAAGGCACAG-3') were for total HBV-specific transcripts, as previously described (54), while primers specific for GAPDH amplification were 5'- CGCTCTCTGCTCCTCCTGTTC-3' (forward) and 5'- CGCCCAATACGACCAAATCCG -3' (reverse). Amplification was conducted by reverse transcription at $48^{\circ} \mathrm{C}$ for $30 \mathrm{~min}$ and denaturation at $95^{\circ} \mathrm{C}$ for 10 min, followed by 40 cycles of denaturation at $95^{\circ} \mathrm{C}$ for $15 \mathrm{~s}$ and annealing/extension at $60^{\circ} \mathrm{C}$ for 1 min using the Power SYBR Green RNA One-Step kit (Applied Biosystems) with 20 ng RNA in $10 \mu 1$ reactions with the ABI 7500 machine (Applied Biosystems).To determine relative RNA levels, $\mathrm{HBV}$ or GAPDH cycle threshold (CT) was first normalize to GAPDH CT using: $\Delta \mathrm{CT}=\mathrm{CT}_{\mathrm{HBV}}-\mathrm{CT}_{\mathrm{GAPDH}}$ and then $\left(2^{(-\Delta \Delta \mathrm{CT})}\right)$ was calculated using $\Delta \Delta \mathrm{CT}=\Delta \mathrm{CT}_{\mathrm{HBV}}-\Delta \mathrm{CT}_{\text {control }}$.

\section{Western blotting}

Cells were lysed in 1 x RIPA buffer (150 mM NaCl, $50 \mathrm{mM}$ Tris/HCl (pH 7.5), 1 mM EGTA, $1 \mathrm{mM}$ EDTA, $0.1 \%$ SDS, and 1\% Triton X-100) containing a Protease Inhibitor Cocktail (Sigma-Aldrich, P8340). The protein concentration was quantified using Bradford assay (Bio-Rad). 20 to $40 \mu \mathrm{g}$ of protein were electrophoresed on an SDSpolyacrylamide gel and transferred to a polyvinylidene difluoride Immobilon-P membrane (Millipore). Membranes were blocked with 5\% skim milk in PBS for $1 \mathrm{~h}$ then 
probed with anti-HBV core (Austral Biologicals HBP-023-9, 1:500 dilution, overnight at $4{ }^{\circ} \mathrm{C}$ ), GAPDH at 1:5,000 for $1 \mathrm{~h}$ at room temperature (Santa Cruz, Cat \#sc-365062), or MOV10 at 1:2000 overnight at $4{ }^{\circ} \mathrm{C}$ (Abcam, Cat \#ab80613), diluted in 0.1\% PBST and $1 \%$ BSA, followed by a horseradish peroxidase (HRP)-conjugated secondary antibody from Sigma at 1:5,000 dilution for $1 \mathrm{~h}$ at room temperature (anti-mouse Cat \#A5278, anti-rabbit Cat \#A0545). Bound antibodies were visualized by adding Luminata Forte Western HRP substrate (Millipore) to the membrane and imaged on LAS-3000 Imaging System from Fuji. Quantification was performed using Multi Gauge analysis software.

\section{Immunofluorescence}

Cells grown on collagen-coated coverslips were fixed at room temperature (RT) for 20 min in $4 \%$ formaldehyde, permeabilized with $0.1 \%$ Triton X-100 in PBS for 10 min, and blocked with $10 \%$ goat serum and $1 \%$ bovine serum albumin (BSA) in PBS for $1 \mathrm{~h}$. Rabbit anti-HBV core (Dako B0586, 1:1,000 dilution) or rabbit anti-HBV core (Austral Biologicals HBP-023-9, 1:500 dilution) was bound overnight at $4{ }^{\circ} \mathrm{C}$ in PBS + $0.1 \%$ BSA. Rabbit anti-MOV10 at 1:1,000 was bound for $90 \mathrm{~min}$ at room temperature (Abcam Cat \#ab80613). Samples were washed three times for 10 min each with PBS + $0.1 \%$ Tween-20 (PBS-T) then incubated at RT for $1 \mathrm{~h}$ with goat anti-rabbit or goat antimouse Alexa Fluor 488-, 568-, or 647-conjugated secondary antibodies (Thermo Scientific, 1:2,000 dilution) in PBS supplemented with $0.1 \%$ BSA and stained for nuclei using Hoechst 33342 (Thermo Scientific). Samples were washed 3x with PBS-T for 10 min each, and coverslips were mounted on microscope slides using ProLong Gold Antifade Mountant (Thermo Scientific). 


\section{Nucleic acid probes}

All probes were purchased from Advanced Cell Diagnostics to detect HBV pregenomic RNA (pgRNA), probe V-HBV-GTD-O1-C2 Cat. \#465531-C2 or Total RNA, probe V-HBV-GTD Cat. \#441351

\section{In situ vRNA detection}

HBV viral RNA (vRNA) in cells was probed using RNAscope reagents (Advanced Cell Diagnostics). The manufacturer's protocol was used with some modifications as described (203). Following fixation, cells were washed with DPBS, then 0.1\% Tween in PBS for $10 \mathrm{~min}$, and twice more in PBS for $1 \mathrm{~min}$. Prior to hybridization, coverslips were immobilized on glass slides; a small drop of nail polish was placed on a glass slide and the coverslip edge was placed on the nail polish drop. Using an ImmEdge hydrophobic barrier pen (Vector Laboratories), a circle was drawn around the coverslip and PBS was added to prevent sample dehydration. The manufacturer's protease solution (Pretreat 3) was diluted in PBS as appropriate prior to the experiment, a 1:50 dilution or not included, and incubated in a humidified HybEZ oven (Advanced Cell Diagnostics) at $40{ }^{\circ} \mathrm{C}$ for $15 \mathrm{~min}$. Protease solution was discarded and the slides were washed twice by immersion in PBS at room temperature for $1 \mathrm{~min}$. Specific pre-designed anti-sense probes (Supplementary Table 1) that recognize the HBV RNA were added to the coverslip as specified by the manufacturer (Advanced Cell Diagnostics): C1 probes were added directly. Probes were allowed to hybridize with the samples in a humidified HybEZ oven at $40{ }^{\circ} \mathrm{C}$ for $2 \mathrm{~h}$. The probes were then discarded and the coverslips were washed twice using the proprietary wash buffer. All wash steps were performed on a rocking platform 
at room temperature for $2 \mathrm{~min}$ using the proprietary wash buffer. The probes were visualized by hybridizing with preamplifiers, amplifiers, and finally, fluorescent label. Pre-amplifier 1 (Amp 1-FL) was hybridized to its cognate probe in a humidified HybEZ oven at $40{ }^{\circ} \mathrm{C}$ for $30 \mathrm{~min}$. Samples were washed twice then hybridized with Amp 2-FL in a humidified HybEZ oven at $40{ }^{\circ} \mathrm{C}$ for 15 min to suppress background staining. After two more washes, amplifier (Amp 3-FL) was hybridized to Amp 1-FL in a humidified HybEZ oven at $40^{\circ} \mathrm{C}$ for $30 \mathrm{~min}$. Samples were washed twice, then fluorescent label Amp 4-FL was hybridized to Amp 3-FL in a humidified HybEZ oven at $40{ }^{\circ} \mathrm{C}$ for $15 \mathrm{~min}$, then samples were washed twice more. For subsequent protein staining, the RNA-labeled samples were washed with PBS and immunostaining was performed as described below. Otherwise, the final step was to counter-stain nuclei with the manufacturer-supplied 4',6'diamino-2-phenylindole (DAPI, Advanced Cell Diagnostics) for $30 \mathrm{~s}$ at room temperature then remove the DAPI, wash twice with PBS and immediately mount the coverslips on slides using Prolong Gold Antifade (Invitrogen).

\section{Immunostaining}

Staining for protein was performed after staining for nucleic acids. Coverslips were blocked with $1 \%$ bovine serum albumen (BSA) and 10\% FBS in PBS containing $0.1 \%$ Tween-20 (PBST) at room temperature for $1 \mathrm{~h}$. Endogenous MOV10 was probed with Rabbit anti-MOV10 at 1:1,000 (Abcam, Cat \#ab80613) in PBST supplemented with $1 \% \mathrm{BSA}$ and incubated at room temperature for $90 \mathrm{~min}$. Samples were washed twice in PBST at room temperature for $10 \mathrm{~min}$ with rocking. Fluorescently labeled secondary antibodies were used at 1:2,000 and incubated at room temperature for $1 \mathrm{~h}$. Then the samples washed once with in PBST at room temperature for 10 min with rocking. Nuclei 
were stained either using the DAPI provided in the RNAscope kit or with $0.5 \mu \mathrm{g} / \mathrm{mL}$ Hoescht-33258 in PBS at room temperature for 10 min. Coverslips were washed twice in PBST at room temperature for 10 min with rocking and washed once with PBS for 1 min. Finally, coverslips were mounted on slides using Prolong Gold Antifade then sealed with nail polish.

\section{Imaging and imaging quantification}

Images were taken with a Leica TCS SP8 inverted confocal microscope equipped with a 63/1.4 oil-immersion objective, and a tunable supercontinuum white light laser. The excitation/emission bandpass wavelengths used to detect DAPI, Alexa 488, ATTO 550, Alexa 568, and Alexa 647 were set to 405/420-480, 488/505-550, 550/560-610, 568/580-630, and 647/655-705 nm, respectively. Confocal data sets were deconvolved using the Huygens Professional software (Version 16.10, SVI). 


\subsection{RESULTS}

\section{MOV10 knockdown increases HBV infection}

To explore whether knockdown of endogenous MOV10 affects HBV infection, MOV10 was down-regulated by siRNA in HepAD38 and HepG2 cell lines. MOV10 depletion by $50 \mathrm{nM}$ siRNA enhanced HBV infection by increment of HBcore protein, pgRNA and total DNA in HepAD38 cells. siRNA transfection was performed one day before tetracycline removal in HepAD38 cells that were subsequently harvested at $48 \mathrm{~h}$ (Fig. 4.1). Using a lower dose of siRNA (25 nM) also enhanced HBcore, pgRNA and total DNA but with less fold induction at 48 and $72 \mathrm{~h}$ post tetracycline removal (Fig. 4.2). HBcore, pgRNA and total DNA levels also increased when tetracycline was removed with simultaneous transfection using $25 \mathrm{nM}$ siRNA (Fig. 4.3). To demonstrate that our findings were not restricted to HepAD38 cells, we transfected HepG2 cells with $20 \mathrm{nM}$ siRNA followed by HBV plasmid transfection $24 \mathrm{~h}$ later. Cells were harvested $48 \mathrm{~h}$ post transfection. We found that down-regulation of MOV10 in HepG2 cells also increased the efficiency of HBV replication by induction of HBcore, pgRNA and total DNA (Fig. 4.4). We further evaluated the effect on HBV rcDNA in HepAD38 cells that were transfected with $50 \mathrm{nM}$ siRNA. One day following transfection, tetracycline was removed and cells were harvested at 3 and 6 days, using Southern Blot. We found that rcDNA was 2 fold higher than control (Fig. 4.5). 


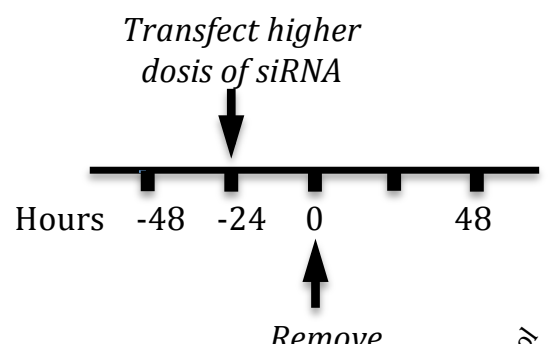

a

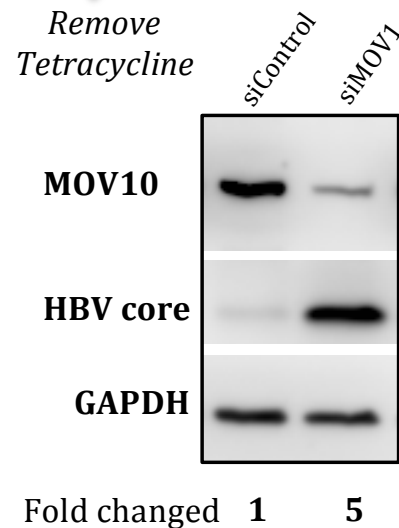

C

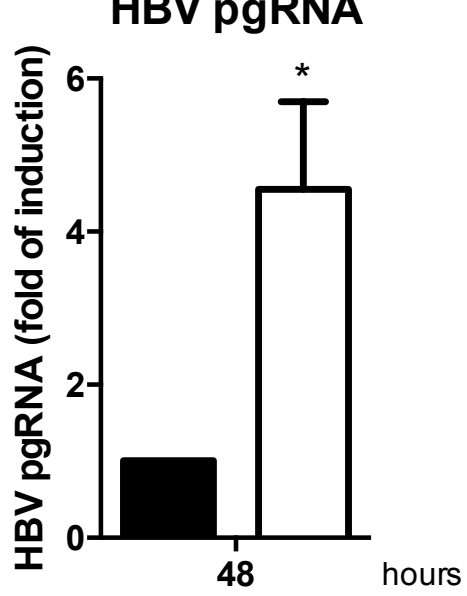

b

\section{HBV core protein}

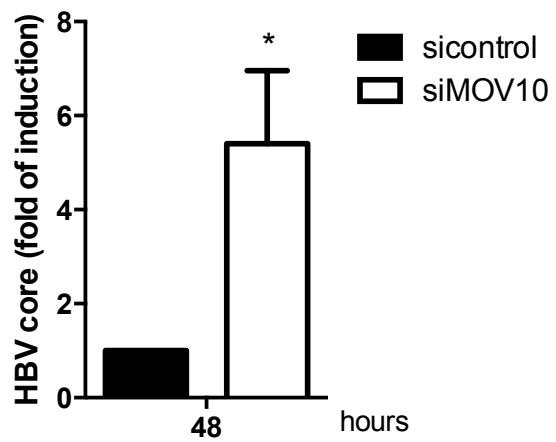

Figure 4.1. MOV10 knockdown leads to increment of HBV RNA, DNA and core protein. HepAD38 cells were transfected with $50 \mathrm{nM}$ siRNA $24 \mathrm{~h}$ before tetracycline removal; at $48 \mathrm{~h}$ post tetracycline removal (hpt), cells were harvested and analyzed. a Effect of MOV10 knockdown in HBcore protein. Cell lysates were loaded and detected by Western Blot using anti-MOV10 antibody, anti-HBVcore antibody, and anti GAPDH antibody as a reference gene expression control. b Graph of HBVcore fold induction from a which was 5 times higher than the control. c Effect of MOV10 knockdown in HBV pgRNA. Extracted HBV RNA was detected by real time RT-qPCR, and fold of induction was measured. d. Effect of MOV10 knockdown in HBV total DNA. Total DNA was quantified by qPCR SYBR Green using a standard curve, and fold of induction in MOV10 knockdown cell was determined. ( $n=2$ independent experiments) 


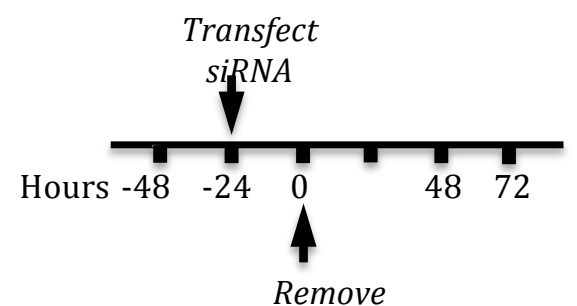

Tetracycline

a

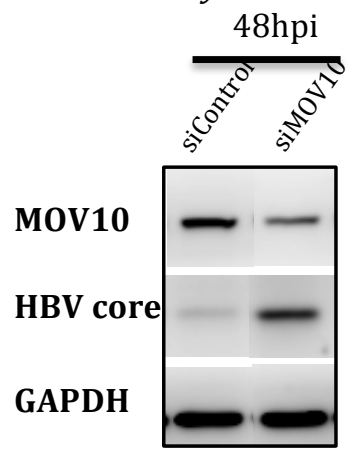

Fold changed 1
3.4

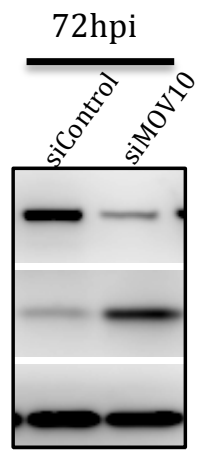

1
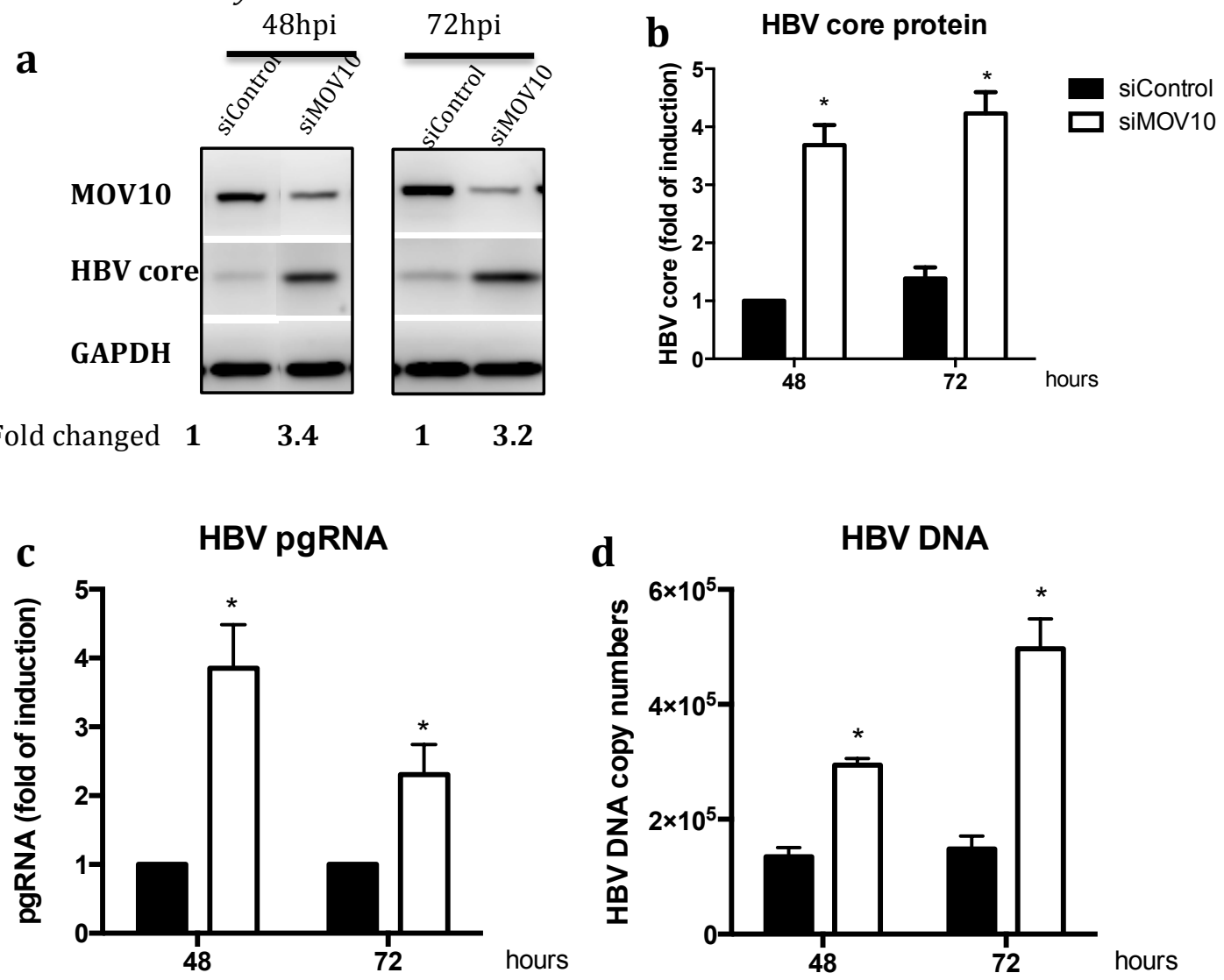

Figure 4.2. By half of dose MOV10 knockdown still enhanced HBV RNA, DNA and core protein. HepAD38 cells were transfected with $25 \mathrm{nM}$ siRNA $24 \mathrm{~h}$ before tetracycline removal; at $48 \mathrm{hpt}$ and $72 \mathrm{hpt}$, cells were harvested and analyzed. a Effect of MOV10 knockdown in HBcore protein by Western Blot using anti-MOV10 antibody, anti-HBVcore antibody, and anti GAPDH antibody as a reference gene expression control. b Graph of HBVcore fold induction from a which was around 3.2 times higher than the control. c Effect of MOV10 knockdown in HBV pgRNA. Extracted HBV RNA was detected by real time RT-qPCR, and fold of induction was measured. $\mathbf{d}$ Effect of MOV10 knockdown in HBV total DNA. Total DNA was quantified by qPCR SYBR Green using a standard curve, and fold induction in MOV10 knockdown cell was determined. ( $n=2$ independent experiments) 

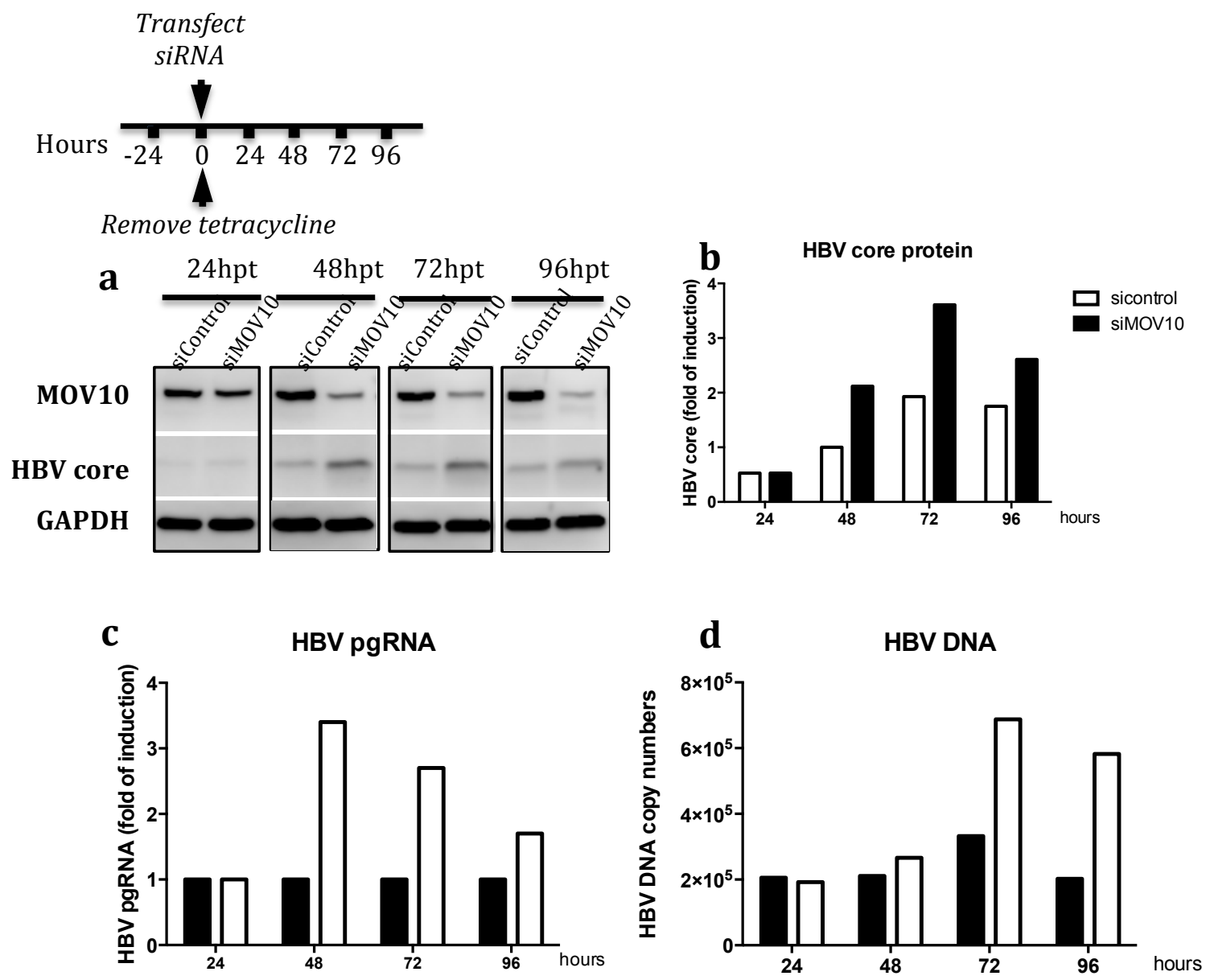

Figure 4.3. Time course of MOV10 knockdown leads to increment of HBV RNA, DNA and core protein. HepAD38 cells were transfected with $25 \mathrm{nM}$ siRNA with immediate tetracycline removal; at 24 , 48, 72, and $96 \mathrm{~h}$ post transfection (hpt), cells were harvested and analyzed. a Effect of MOV10 knockdown in HBcore protein by Western Blot using anti-MOV10 antibody, anti-HBVcore antibody, and anti GAPDH antibody as a reference gene expression control. b Graph of HBVcore fold induction from a which was 2, 1.9, and 1.5 times higher that controls at 48, 72, and 96 hpt. c Effect of MOV10 knockdown in HBV pgRNA. Extracted HBV RNA was detected by real time RT-qPCR, and fold of induction was measured. d Effect of MOV10 knockdown in HBV total DNA. Total DNA was quantified by qPCR SYBR Green using a standard curve, and fold of induction in MOV10 knockdown cells was determined. ( $n=1$ experiment) 

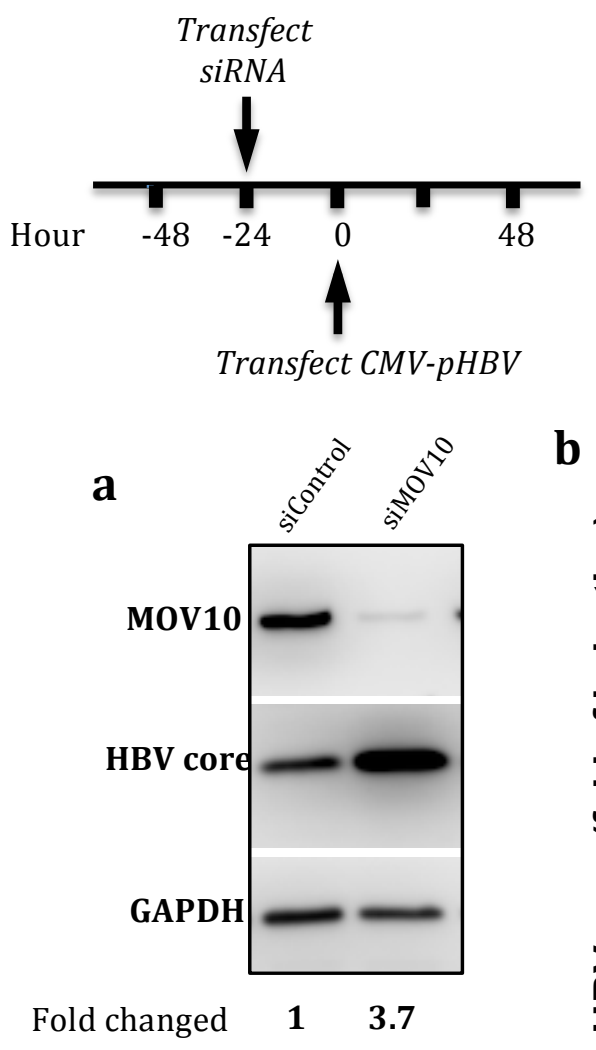

b HBV core protein
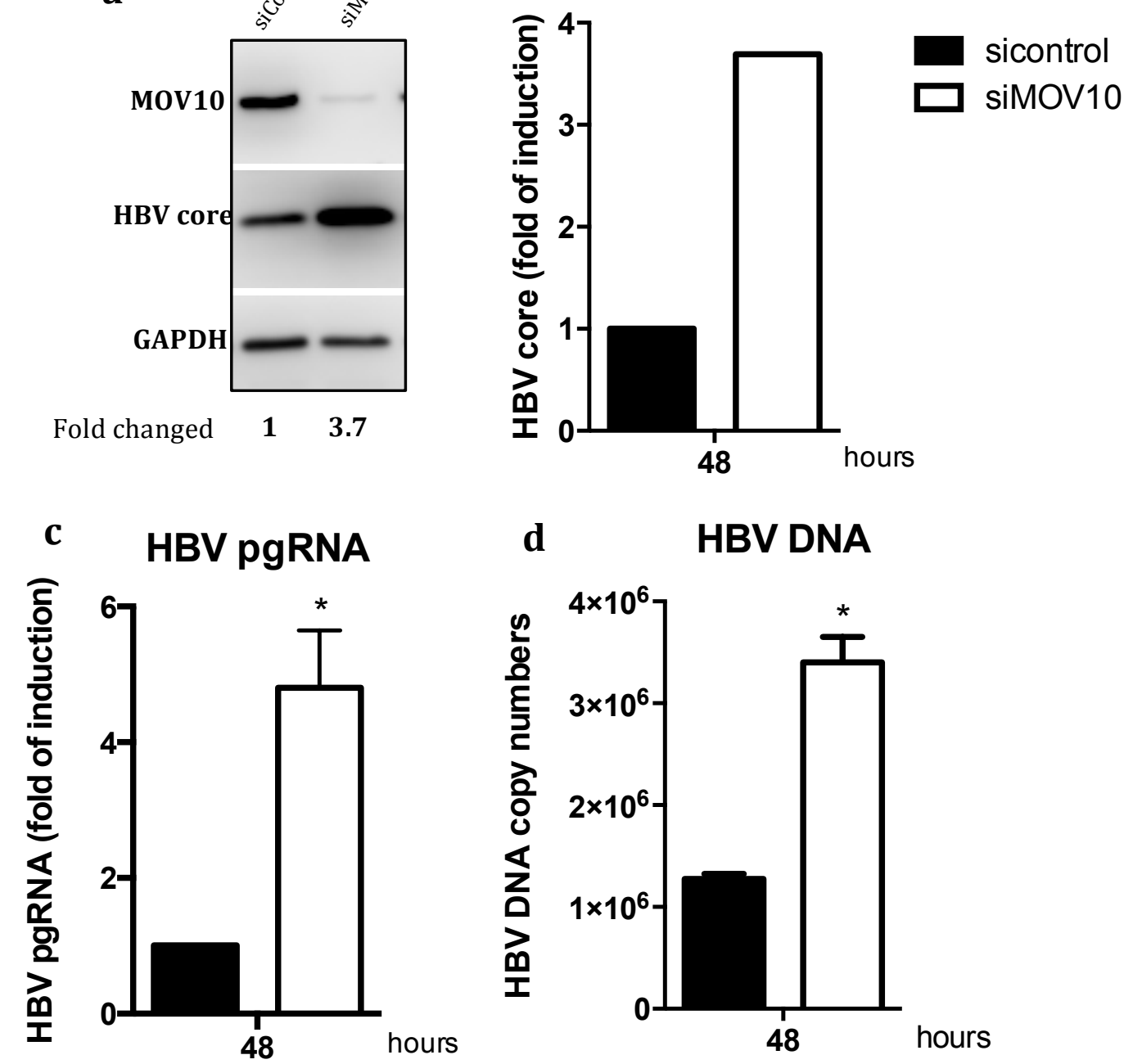

Figure 4.4. MOV10 knockdown leads to increment of HBV RNA, DNA and core protein. HepG2 cells were transfected with $20 \mathrm{nM}$ siRNA $24 \mathrm{~h}$ before $0.4 \mathrm{ng} / \mathrm{uL} \mathrm{pHBV}$ transfection; at $48 \mathrm{~h}$ post transfection (hpt), cells were harvested and analyzed. a Effect of MOV10 knockdown in HBcore protein. Cell lysates were loaded and detected by Western Blot using anti-MOV10 antibody, anti-HBcore antibody, and anti GAPDH antibody as a reference gene expression control. b Graph of HBcore fold induction from a which was 5 times higher than control. c Effect of MOV10 knockdown in HBV pgRNA. Extracted HBV RNA was detected by real time RT-qPCR, and fold of induction was measured. d Effect of MOV10 knockdown in HBV total DNA. Total DNA was quantified by qPCR SYBR Green using a standard curve, and fold of induction in MOV10 knockdown cell was determined. ( $n=2$ independent experiments) 


\section{0}

a

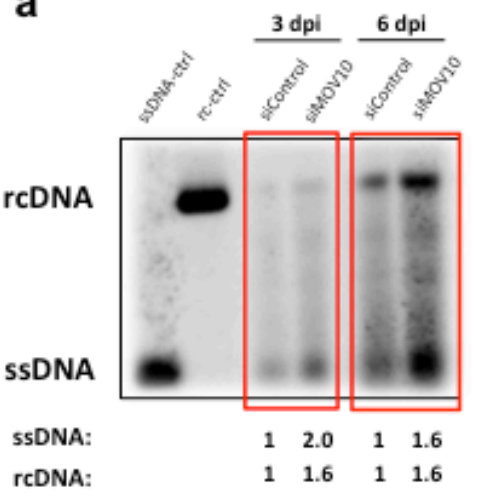

b

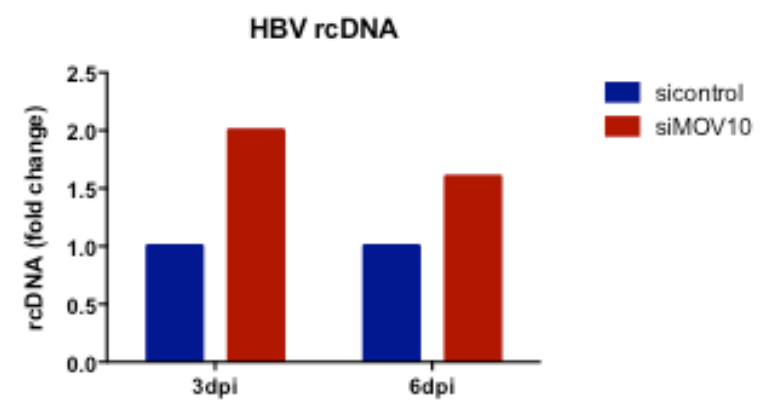

Figure 4.5. MOV10 knockdown leads to increase of HBV rcDNA. HepAD38 cells were transfected with 50nM siRNA 24 hours before tetracycline removal; at 3 and 6 days post tetracycline removal (hpt), cells were harvested and analyzed. a Effect of MOV10 knockdown in rcDNA. Cell lysates were loaded and detected by Southern Blot using specific probes for HBV. b Graph of HBV rcDNA fold induction showing almost 2 fold increase over control. $(n=1$ experiment) 


\section{MOV10 overexpression impaired HBV infection}

To determine if up-regulation of MOV10 affects HBV replication, we overexpressed MOV10 using Flag-MOV10 and YFP-MOV10 plasmids in HepAD38 cells. Enhancement of MOV10 by Flag-MOV10 transfection diminished HBV infection by reducing HBcore, pgRNA and total HBV DNA levels. Flag-MOV10 transfection was performed one day before tetracycline removal and cells were harvested at $48 \mathrm{~h}$ (Fig. 4.6). Overexpression of MOV10 YFP-MOV10 transfection moderately reduced HBcore, pgRNA and total DNA levels. YFP-MOV10 transfection was performed the same day as tetracycline removal and cells were harvested at $48 \mathrm{~h}$ (Fig. 4.7). MOV10 is an ISG that is upregulated by interferon and HBV induces interferon during infection, so as expected, endogenous MOV10 expression was elevated during HBV infection in a time course experiment. Western blot detected increased of endogenous MOV10 from day 1 through day 6 post tetracycline removal in HepAD38 cells (Fig. 4.8). 

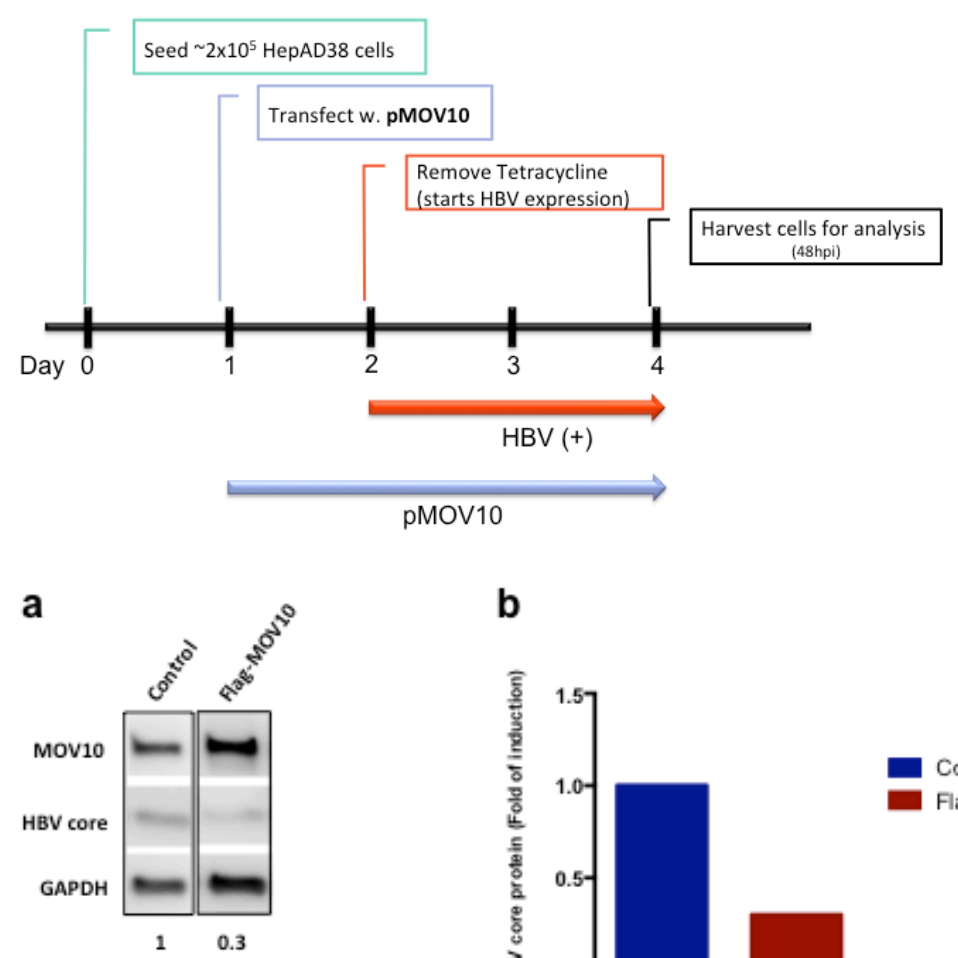

b

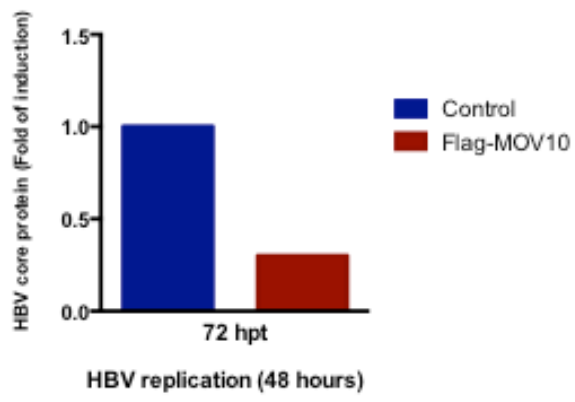

C

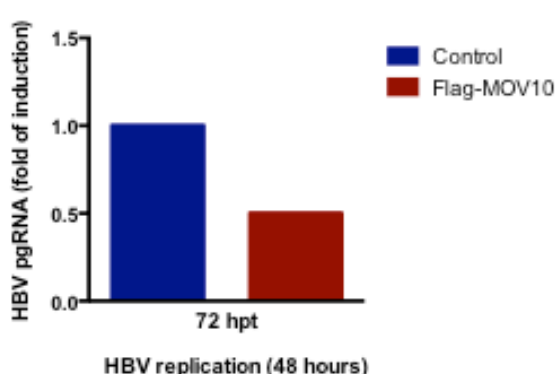

d

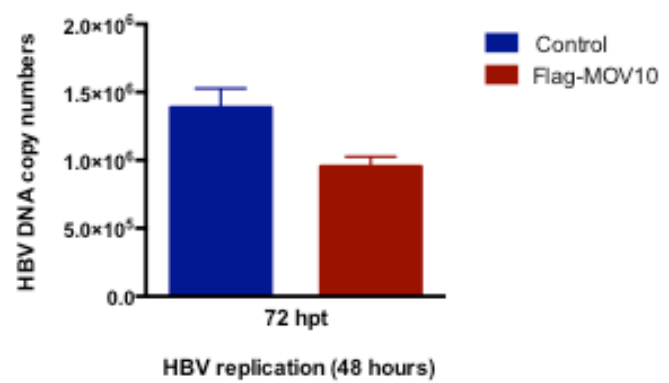

Figure 4.6. MOV10 overexpression leads to reduction of HBV RNA, DNA, and core protein. HepAD38 cells were transfected with $0.75 \mathrm{ng} / \mu \mathrm{L}$ Flag-pMOV10 $24 \mathrm{~h}$ before tetracycline removal; at $48 \mathrm{~h}$ post tetracycline removal or $72 \mathrm{~h}$ post transfection, cells were harvested and analyzed. a Effect of MOV10 overexpression in HBcore protein. Cell lysates were loaded and detected by Western Blot using antiMOV10 antibody, anti-HBcore antibody, and anti GAPDH antibody as a reference gene expression control. b This graph shows a HBcore $60 \%$ reduction as compared to the control. c Effect of MOV10 overexpression in HBV pgRNA. Extracted HBV RNA was detected by real time RT-qPCR, and fold of reduction was measured. d Effect of MOV10 overexpression in HBV total DNA. Total DNA was quantified by qPCR SYBR Green using a standard curve, and fold of reduction in MOV10 overexpression cells was determined. 

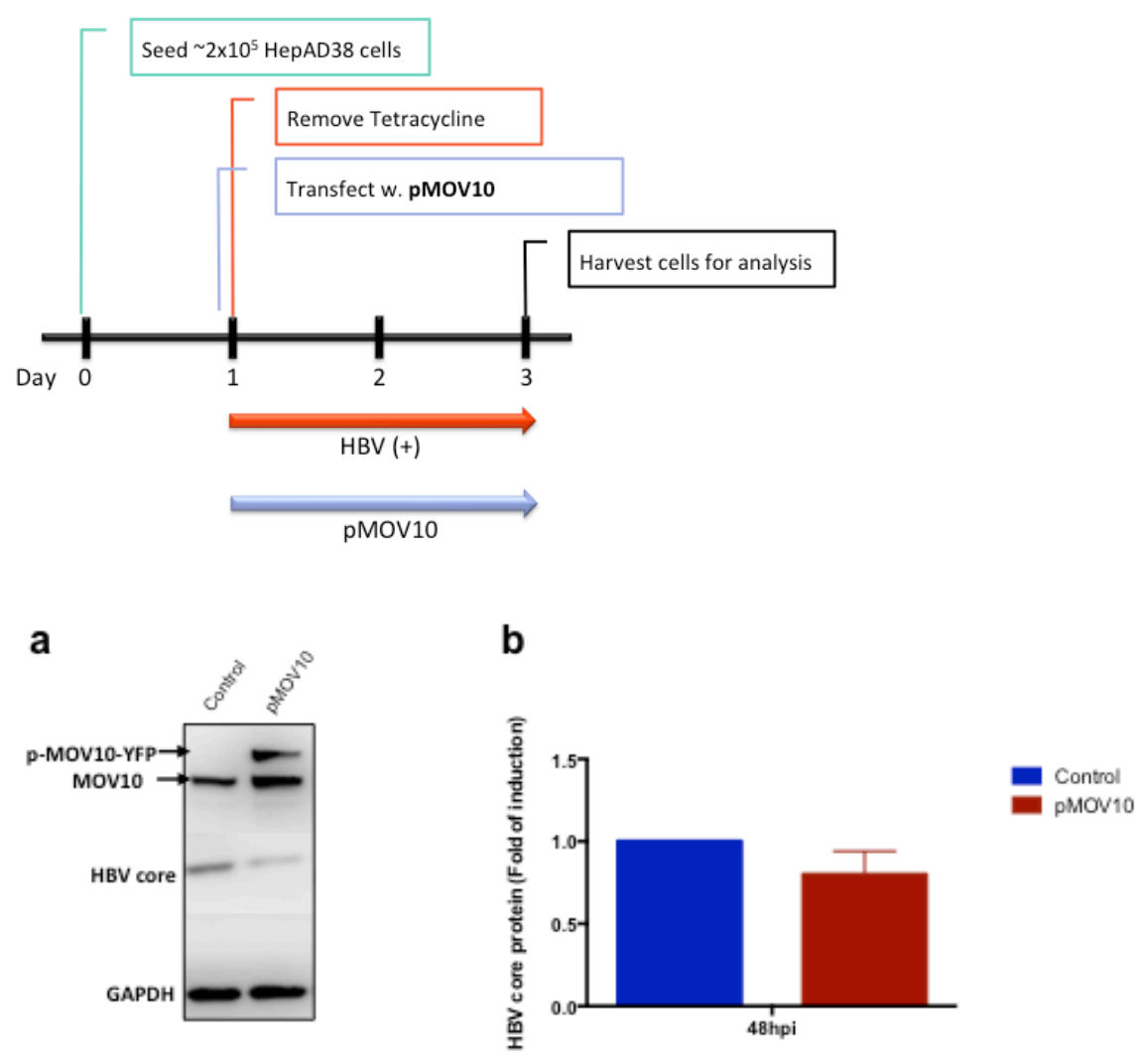

C

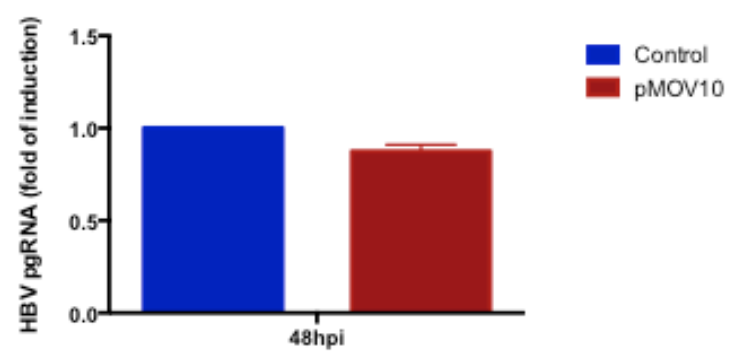

d

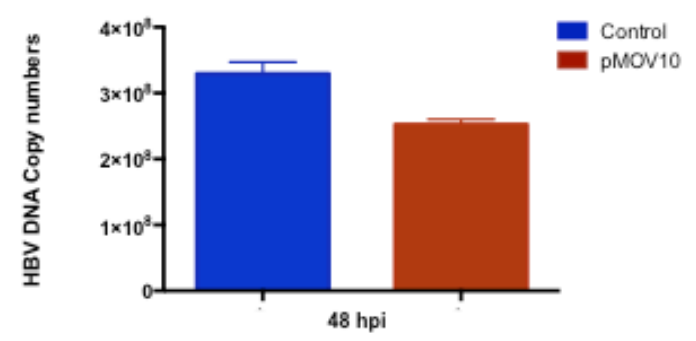

Figure 4.7. MOV10 overexpression leads to reduction of HBV RNA, DNA, and core protein. HepAD38 cells were transfected with $0.8 \mathrm{ng} / \mu \mathrm{L}$ YFP-pMOV10 with immediate tetracycline removal; at 48 $\mathrm{h}$ post tetracycline removal, cells were harvest and analyzed. a Effect of MOV10 overexpression in HBcore protein. Cell lysates were loaded and detected by Western Blot using anti-MOV10 antibody, anti-HBcore antibody, and anti GAPDH antibody as a reference gene expression control. b This graph shows a HBcore moderate reduction compared with the control. c Effect of MOV10 overexpression in HBV pgRNA. Extracted HBV RNA was detected by real time RT-qPCR, and fold of reduction was measured. d Effect of MOV10 overexpression in HBV total DNA. Total DNA was quantified by qPCR SYBR Green using a standard curve, and fold of reduction in MOV10 overexpression cells was determined. $(n=2$ independent experiments) 


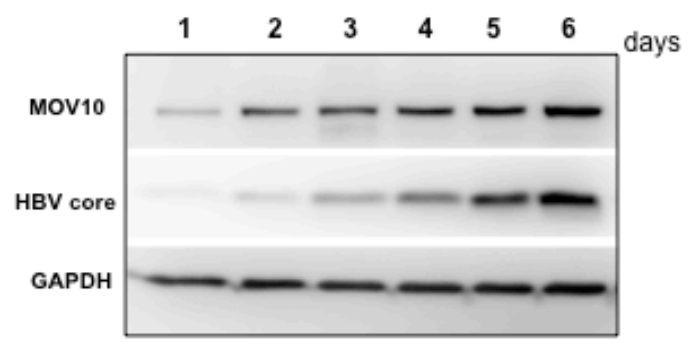

Figure 4.8 Endogenous MOV10 is upregulated during HBV infection. Tetracycline was removed from HepAD38, and samples were harvested at day 1,2,3,4,5, and 6 post tetracycline removal. Cell lysates were analyzed by Western Blot using anti-MOV10 antibody, anti-HBcore antibody, and anti-GAPDH antibody as a reference gene expression control. MOV10 expression increased over time. $(n=1$ experiment)

\section{Endogenous MOV10 co-localizes with HBV core and HBV RNA}

Endogenous MOV10 is localized in the cytoplasm and p-bodies and in HBV infected cells, HBV core protein is found in the nucleus and cytoplasm. We detected colocalization of endogenous MOV10 and HBV core in transfected cells by immunocytochemistry; additionally levels of MOV10 expression were higher in infected cells (Fig. 4.9a). We also determined co-localization of HBV RNA with endogenous MOV10 in HepAD38 cells after induction of expression (Fig. 4.10b) using in-situ hybridization. 
a
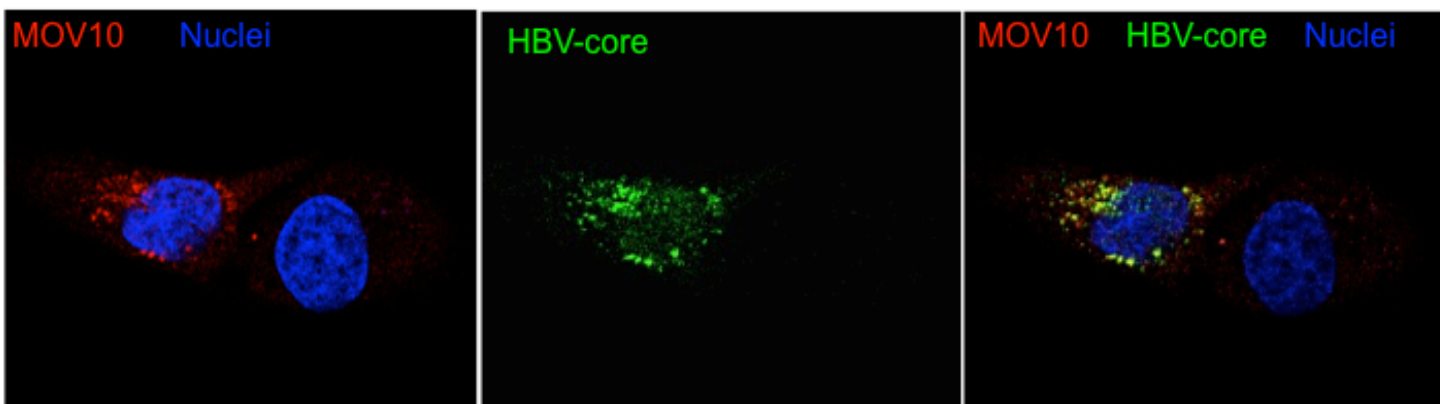

b
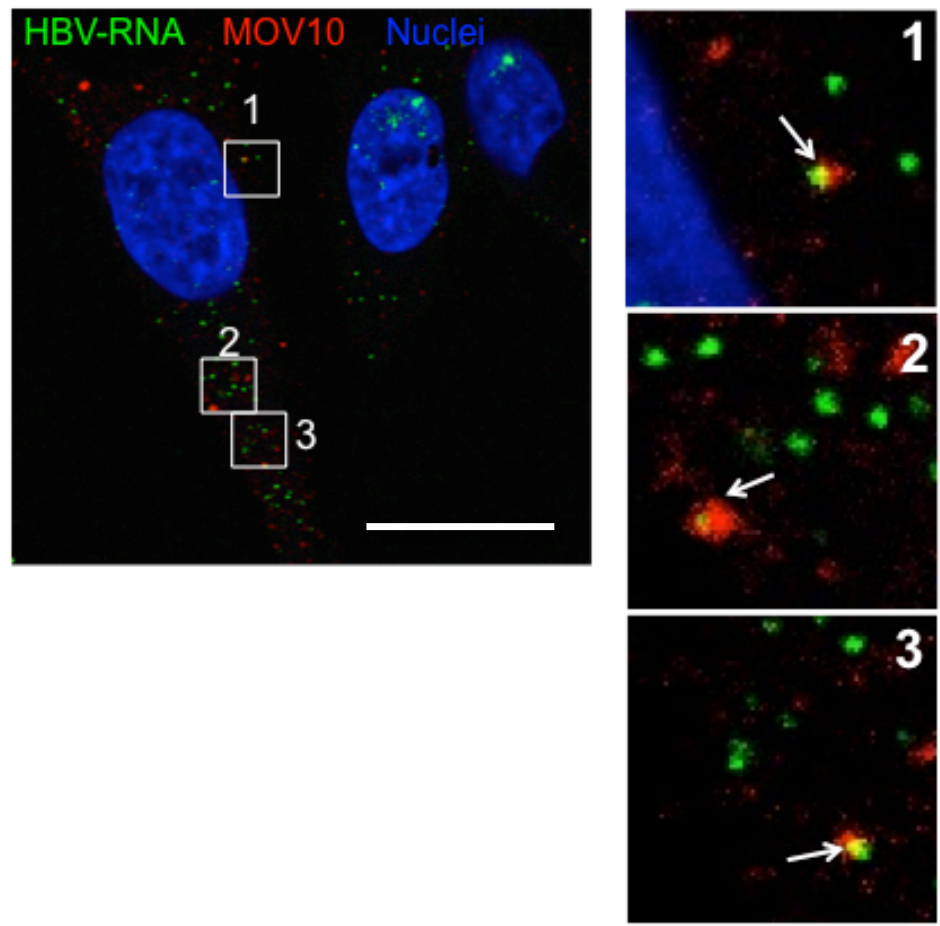

Figure 4.9. Endogenous MOV10 colocalizes with HBV core protein and RNA. a HepG2 cells were transfected with pHBV. At $48 \mathrm{hpt}$, cells were washed, fixed, and stained by immunocytochemistry using anti-MOV10 antibody (red) and anti-HBcore antibody (green) Nuclei were stained blue. b Tetracycline was removed from the media of HepAD38 cells, and 7 days later, cells were washed, fixed, and stained by in situ hybridization and immunocytochemistry using HBV RNA probe (green) and anti-MOV10 antibody (red). Nuclei were stained blue. All are confocal images. All scale bars represent $10 \mu \mathrm{m}$. 


\subsection{DISCUSSION AND FUTURE DIRECTIONS}

In this study, we investigated the effect of the MOV10 host restriction factor on HBV replication. We explored whether down-regulation of MOV10 may enhance HBV infection and if overexpression of MOV10 would restrict HBV infection. We found that MOV10 overexpression decreases HBV by inhibiting the production of core protein, viral RNA, and viral DNA; while MOV10 down-regulation enhances core protein, viral RNA and viral DNA. However, our findings are not in full agreement with Ma et. al. (103) who published in 2015 that over-expression of MOV10 caused at low dose an increment of released HBsAg and $\mathrm{HBeAg}$ and $\mathrm{HBV}$ mRNA level in transfected cells and resulted in a decrease at a high dose, but released HBV DNA was not affected. Additionally, the knockdown of endogenous MOV10 expression through siRNA treatment could suppress levels of HBsAg, HBeAg and HBV mRNA, but had no effect on HBV DNA. To further support our findings we are working on an infectious model using HepG2 NTCP cells and viruses released from HepAD38. A colleague in the lab has recapitulated our findings using the infectious system.

To understand the mechanism by which MOV10 may abrogate HBV infection, we will focus on the possible interaction of pgRNA and MOV10, since this protein is a helicase and has been reported to associate with HIV-1 RNA and cellular RNAs (34). We found that HBV core protein and HBV RNA co-localize with endogenous MOV10, but we do not have evidence yet of a specific and direct interaction.

In summary, our data suggest that while MOV10 overexpression leads to HBV reduction, suppression of MOV10 enhances HBV replication. To elucidate the mechanism how MOV10 affect HBV replication we will first rescue the lost MOV10 
function in CRISPR knockout cells by using MOV10 chimeric proteins. We will determine if MOV10 interacts with HBV RNA or HBcore protein by using RNA immunoprecipitation (RIP) and proximity ligationassay (PLA) respectively. 


\section{BIBLIOGRAPHY}

1. Sharp PM, Hahn BH. Origins of HIV and the AIDS pandemic. Cold Spring Harb Perspect Med. 2011 Sep;1(1):a006841.

2. AIDS. A Timeline of AIDS. http://aids.gov/hiv-aids-basics/hiv-aids-101/aidstimeline.

3. Greene WC. A history of AIDS: looking back to see ahead. Eur J Immunol. 2007 Nov;37 Suppl 1:S94-102.

4. WHO (2014) Global Health Observatory (GHO): HIV/AIDS. http://www.who.int/ gho/hiv/en/.

5. Nyamweya S, Hegedus A, Jaye A, Rowland-Jones S, Flanagan KL, Macallan DC. Comparing HIV-1 and HIV-2 infection: Lessons for viral immunopathogenesis. Rev Med Virol. 2013 Jul;23(4):221-40.

6. Saleh S, Vranckx L, Gijsbers R, Christ F, Debyser Z. Insight into HIV-2 latency may disclose strategies for a cure for HIV-1 infection. J Virus Erad. 2017 Jan 1;3(1):7-14.

7. Sharp PM, Hahn BH. Origins of HIV and the AIDS pandemic. Cold Spring Harb Perspect Med. 2011 Sep;1(1):a006841.

8. Duri K. HIV Diversity and Classification, Role in Transmission. Advances in Infectious Diseases. 3(2):11.

9. Taylor BS, Sobieszczyk ME, McCutchan FE, Hammer SM. The challenge of HIV1 subtype diversity. N Engl J Med. 2008 Apr 10;358(15):1590-602.

10. Huang A, Hogan JW, Istrail S, Delong A, Katzenstein DA, Kantor R. Global analysis of sequence diversity within HIV-1 subtypes across geographic regions. Future Virol. 2012 May;7(5):505-17.

11. Hemelaar J, Gouws E, Ghys PD, Osmanov S, WHO-UNAIDS Network for HIV Isolation and Characterisation. Global trends in molecular epidemiology of HIV-1 during 2000-2007. AIDS. 2011 Mar 13;25(5):679-89.

12. Hemelaar J. The origin and diversity of the HIV-1 pandemic. Trends Mol Med. 2012 Mar;18(3):182-92.

13. Narayan O, Clements JE. Biology and pathogenesis of lentiviruses. J Gen Virol. 1989 Jul;70 ( Pt 7):1617-39.

14. Campbell EM, Hope TJ. HIV-1 capsid: the multifaceted key player in HIV-1 infection. Nat Rev Microbiol. 2015 Aug;13(8):471-83.

15. Swanson CM, Malim MH. SnapShot: HIV-1 proteins. Cell. 2008 May 16;133(4):742, 742.e1.

16. Frankel AD, Young JA. HIV-1: fifteen proteins and an RNA. Annu Rev Biochem. 
$1998 ; 67: 1-25$.

17. Wacleche VS, Tremblay CL, Routy J-P, Ancuta P. The Biology of Monocytes and Dendritic Cells: Contribution to HIV Pathogenesis. Viruses. 2018 06;10(2).

18. Wilen CB, Tilton JC, Doms RW. HIV: cell binding and entry. Cold Spring Harb Perspect Med. 2012 Aug 1;2(8).

19. Becerra JC, Bildstein LS, Gach JS. Recent Insights into the HIV/AIDS Pandemic. Microb Cell. 2016 Sep 5;3(9):451-75.

20. Larsen KP, Mathiharan YK, Kappel K, Coey AT, Chen D-H, Barrero D, et al. Architecture of an HIV-1 reverse transcriptase initiation complex. Nature. 2018 May;557(7703):118-22.

21. Woodward CL, Chow SA. The nuclear pore complex: a new dynamic in HIV-1 replication. Nucleus. 2010 Feb;1(1):18-22.

22. Watts JM, Dang KK, Gorelick RJ, Leonard CW, Bess JW, Swanstrom R, et al. Architecture and secondary structure of an entire HIV-1 RNA genome. Nature. 2009 Aug 6;460(7256):711-6.

23. Figiel M, Krepl M, Poznanski J, Golab A, Šponer J, Nowotny M. Coordination between the polymerase and RNase $\mathrm{H}$ activity of HIV-1 reverse transcriptase. Nucleic Acids Res. 2017 Apr 7;45(6):3341-52.

24. $\mathrm{Hu}$ W-S, Hughes SH. HIV-1 reverse transcription. Cold Spring Harb Perspect Med. 2012 Oct $1 ; 2(10)$.

25. Delelis O, Carayon K, Saïb A, Deprez E, Mouscadet J-F. Integrase and integration: biochemical activities of HIV-1 integrase. Retrovirology. 2008 Dec 17;5:114.

26. Craigie R, Bushman FD. HIV DNA integration. Cold Spring Harb Perspect Med. 2012 Jul;2(7):a006890.

27. Savarino A. In-Silico docking of HIV-1 integrase inhibitors reveals a novel drug type acting on an enzyme/DNA reaction intermediate. Retrovirology. 2007 Mar $20 ; 4: 21$

28. Klaver B, Berkhout B. Comparison of 5' and 3' long terminal repeat promoter function in human immunodeficiency virus. J Virol. 1994 Jun;68(6):3830-40.

29. Groen JN, Morris KV. Chromatin, non-coding RNAs, and the expression of HIV. Viruses. 2013 Jun 28;5(7):1633-45.

30. Zenzie-Gregory B, Sheridan P, Jones KA, Smale ST. HIV-1 core promoter lacks a simple initiator element but contains a bipartite activator at the transcription start site. J Biol Chem. 1993 Jul 25;268(21):15823-32.

31. Kao SY, Calman AF, Luciw PA, Peterlin BM. Anti-termination of transcription within the long terminal repeat of HIV-1 by tat gene product. Nature. 1987 Dec 3;330(6147):489-93.

32. Freed EO. HIV-1 assembly, release and maturation. Nat Rev Microbiol. 2015 Aug;13(8):484-96. 
33. Chen B. HIV Capsid Assembly, Mechanism, and Structure. Biochemistry. 2016 May 10;55(18):2539-52.

34. Sundquist WI, Kräusslich H-G. HIV-1 assembly, budding, and maturation. Cold Spring Harb Perspect Med. 2012 Jul;2(7):a006924.

35. Usami Y, Popov S, Popova E, Inoue M, Weissenhorn W, G Göttlinger H. The ESCRT pathway and HIV-1 budding. Biochem Soc Trans. 2009 Feb;37(Pt 1):1814.

36. Hill M, Tachedjian G, Mak J. The packaging and maturation of the HIV-1 Pol proteins. Curr HIV Res. 2005 Jan;3(1):73-85.

37. Shaw GM, Hunter E. HIV transmission. Cold Spring Harb Perspect Med. 2012 Nov 1;2(11).

38. Tseng A, Seet J, Phillips EJ. The evolution of three decades of antiretroviral therapy: challenges, triumphs and the promise of the future. Br J Clin Pharmacol. 2015 Feb;79(2):182-94.

39. Sarafianos SG, Hughes SH, Arnold E. Designing anti-AIDS drugs targeting the major mechanism of HIV-1 RT resistance to nucleoside analog drugs. Int $\mathrm{J}$ Biochem Cell Biol. 2004 Sep;36(9):1706-15.

40. Kuo H-H, Lichterfeld M. Recent progress in understanding HIV reservoirs. Curr Opin HIV AIDS. 2018 Mar;13(2):137-42.

41. Datta PK, Kaminski R, Hu W, Pirrone V, Sullivan NT, Nonnemacher MR, et al. HIV-1 Latency and Eradication: Past, Present and Future. Curr HIV Res. 2016;14(5):431-41.

42. Finzi D, Blankson J, Siliciano JD, Margolick JB, Chadwick K, Pierson T, et al. Latent infection of CD4+ T cells provides a mechanism for lifelong persistence of HIV-1, even in patients on effective combination therapy. Nat Med. 1999 May;5(5):512-7.

43. Chun T-W, Moir S, Fauci AS. HIV reservoirs as obstacles and opportunities for an HIV cure. Nat Immunol. 2015 Jun;16(6):584-9.

44. Churchill J, Gorry P. R., Cowley D. et al., Use of laser capture microdissection to detect integrated HIV-1 DNA in macrophages and astrocytes from autopsy brain tissues, Journal of NeuroVirology, vol. 12, no. 2, pp. 146-152, 2006.

45. Knights HDJ. A Critical Review of the Evidence Concerning the HIV Latency Reversing Effect of Disulfiram, the Possible Explanations for Its Inability to Reduce the Size of the Latent Reservoir In Vivo, and the Caveats Associated with Its Use in Practice. AIDS Res Treat. 2017;2017:8239428.

46. Razooky BS, Pai A, Aull K, Rouzine IM, Weinberger LS. A hardwired HIV latency program. Cell. 2015 Feb 26;160(5):990-1001.

47. Siliciano JD, Siliciano RF. Recent developments in the effort to cure HIV infection: going beyond $\mathrm{N}=1$. J Clin Invest. $2016 \mathrm{Feb}$;126(2):409-14.

48. Chun TW, Finzi D, Margolick J, Chadwick K, Schwartz D, Siliciano RF. In vivo 
fate of HIV-1-infected T cells: quantitative analysis of the transition to stable latency. Nat Med. 1995 Dec;1(12):1284-90.

49. Zhang Y-Y, Hu K-Q. Rethinking the pathogenesis of hepatitis B virus (HBV) infection. J Med Virol. 2015 Dec;87(12):1989-99.

50. Ghouri YA, Mian I, Rowe JH. Review of hepatocellular carcinoma: Epidemiology, etiology, and carcinogenesis. J Carcinog. 2017;16:1.

51. Zamor PJ, deLemos AS, Russo MW. Viral hepatitis and hepatocellular carcinoma: etiology and management. J Gastrointest Oncol. 2017 Apr;8(2):229-42.

52. Lamontagne RJ, Bagga S, Bouchard MJ. Hepatitis B virus molecular biology and pathogenesis. Hepatoma Res. 2016;2:163-86.

53. Shih C, Yang C-C, Choijilsuren G, Chang C-H, Liou A-T. Hepatitis B Virus. Trends Microbiol. 2018 Apr;26(4):386-7.

54. Yan H, Zhong G, Xu G, He W, Jing Z, Gao Z, et al. Sodium taurocholate cotransporting polypeptide is a functional receptor for human hepatitis B and D virus. Elife. 2012 Nov 13;3.

55. Chen C, Wang JC-Y, Pierson EE, Keifer DZ, Delaleau M, Gallucci L, et al. Importin $\beta$ Can Bind Hepatitis B Virus Core Protein and Empty Core-Like Particles and Induce Structural Changes. PLoS Pathog. 2016 Aug;12(8):e1005802.

56. Marniemi J, Parkki MG. Radiochemical assay of glutathione S-epoxide transferase and its enhancement by phenobarbital in rat liver in vivo. Biochem Pharmacol. 1975 Sep 1;24(17):1569-72.

57. Watashi K, Wakita T. Hepatitis B Virus and Hepatitis D Virus Entry, Species Specificity, and Tissue Tropism. Cold Spring Harb Perspect Med. 2015 Aug 3;5(8):a021378.

58. Glebe D, Urban S. Viral and cellular determinants involved in hepadnaviral entry. World J Gastroenterol. 2007 Jan 7;13(1):22-38.

59. Glebe D, Aliakbari M, Krass P, Knoop EV, Valerius KP, Gerlich WH. Pre-s1 antigen-dependent infection of Tupaia hepatocyte cultures with human hepatitis B virus. J Virol. 2003 Sep;77(17):9511-21.

60. Le Seyec J, Chouteau P, Cannie I, Guguen-Guillouzo C, Gripon P. Infection process of the hepatitis $\mathrm{B}$ virus depends on the presence of a defined sequence in the pre-S1 domain. J Virol. 1999 Mar;73(3):2052-7.

61. Barrera A, Guerra B, Notvall L, Lanford RE. Mapping of the hepatitis B virus preS1 domain involved in receptor recognition. J Virol. 2005 Aug;79(15):9786-98.

62. Glebe D, Urban S, Knoop EV, Cag N, Krass P, Grün S, et al. Mapping of the hepatitis B virus attachment site by use of infection-inhibiting preS1 lipopeptides and tupaia hepatocytes. Gastroenterology. 2005 Jul;129(1):234-45.

63. Hagenbuch B, Meier PJ. Molecular cloning, chromosomal localization, and functional characterization of a human liver $\mathrm{Na}+/$ bile acid cotransporter. J Clin Invest. 1994 Mar;93(3):1326-31. 
64. Anwer MS, Stieger B. Sodium-dependent bile salt transporters of the SLC10A transporter family: more than solute transporters. Pflugers Arch. 2014 Jan;466(1):77-89.

65. Zhang Z, Zehnder B, Damrau C, Urban S. Visualization of hepatitis B virus entry novel tools and approaches to directly follow virus entry into hepatocytes. FEBS Lett. 2016;590(13):1915-26.

66. Jung D, Hagenbuch B, Fried M, Meier PJ, Kullak-Ublick GA. Role of liverenriched transcription factors and nuclear receptors in regulating the human, mouse, and rat NTCP gene. Am J Physiol Gastrointest Liver Physiol. 2004 May;286(5):G752-61.

67. Cooper A, Shaul Y. Clathrin-mediated endocytosis and lysosomal cleavage of hepatitis B virus capsid-like core particles. J Biol Chem. 2006 Jun 16;281(24):16563-9.

68. Huang H-C, Chen C-C, Chang W-C, Tao M-H, Huang C. Entry of hepatitis B virus into immortalized human primary hepatocytes by clathrin-dependent endocytosis. J Virol. 2012 Sep;86(17):9443-53.

69. Winer BY, Huang TS, Pludwinski E, Heller B, Wojcik F, Lipkowitz GE, et al. Long-term hepatitis B infection in a scalable hepatic co-culture system. Nat Commun. 2017 25;8(1):125.

70. Kott N. Thesis defense: Uptake mechanism of Hepatitis Virus into susceptible primary hepatocyte cultures. 2010.

71. Hagelstein J, Fathinejad F, Stremmel W, Galle PR. pH-independent uptake of hepatitis B virus in primary human hepatocytes. Virology. 1997 Mar 3;229(1):2924.

72. Watashi K, Sluder A, Daito T, Matsunaga S, Ryo A, Nagamori S, et al. Cyclosporin A and its analogs inhibit hepatitis B virus entry into cultured hepatocytes through targeting a membrane transporter, sodium taurocholate cotransporting polypeptide (NTCP). Hepatology. 2014 May;59(5):1726-37.

73. Macovei A, Petrareanu C, Lazar C, Florian P, Branza-Nichita N. Regulation of hepatitis B virus infection by Rab5, Rab7, and the endolysosomal compartment. J Virol. 2013 Jun;87(11):6415-27.

74. Rabe B, Vlachou A, Panté N, Helenius A, Kann M. Nuclear import of hepatitis B virus capsids and release of the viral genome. Proc Natl Acad Sci USA. 2003 Aug 19;100(17):9849-54.

75. Rabe B, Glebe D, Kann M. Lipid-mediated introduction of hepatitis B virus capsids into nonsusceptible cells allows highly efficient replication and facilitates the study of early infection events. J Virol. 2006 Jun;80(11):5465-73.

76. Iwamoto M, Cai D, Sugiyama M, Suzuki R, Aizaki H, Ryo A, et al. Functional association of cellular microtubules with viral capsid assembly supports efficient hepatitis B virus replication. Sci Rep. 2017 Sep 6;7(1):10620.

77. Gaudin R, de Alencar BC, Arhel N, Benaroch P. HIV trafficking in host cells: 
motors wanted! Trends Cell Biol. 2013 Dec;23(12):652-62.

78. Naghavi MH, Walsh D. Microtubule Regulation and Function during Virus Infection. J Virol. 2017 15;91(16).

79. Königer C, Wingert I, Marsmann M, Rösler C, Beck J, Nassal M. Involvement of the host DNA-repair enzyme TDP2 in formation of the covalently closed circular DNA persistence reservoir of hepatitis B viruses. Proc Natl Acad Sci USA. 2014 Oct 7;111(40):E4244-53.

80. Qi Y, Gao Z, Xu G, Peng B, Liu C, Yan H, et al. DNA Polymerase $\kappa$ Is a Key Cellular Factor for the Formation of Covalently Closed Circular DNA of Hepatitis B Virus. PLoS Pathog. 2016 Oct;12(10):e1005893.

81. Bock CT, Schranz P, Schröder CH, Zentgraf H. Hepatitis B virus genome is organized into nucleosomes in the nucleus of the infected cell. Virus Genes. 1994 Jul;8(3):215-29.

82. Newbold JE, Xin H, Tencza M, Sherman G, Dean J, Bowden S, et al. The covalently closed duplex form of the hepadnavirus genome exists in situ as a heterogeneous population of viral minichromosomes. J Virol. 1995 Jun;69(6):3350-7.

83. Liang TJ. Hepatitis B: the virus and disease. Hepatology. 2009 May;49(5 Suppl):S13-21.

84. Selzer L, Zlotnick A. Assembly and Release of Hepatitis B Virus. Cold Spring Harb Perspect Med. 2015 Nov 9;5(12).

85. Cox N, Tillmann H. Emerging pipeline drugs for hepatitis B infection. Expert Opin Emerg Drugs. 2011 Dec;16(4):713-29.

86. Lai C-L, Yuen M-F. Chronic hepatitis B--new goals, new treatment. N Engl J Med. 2008 Dec 4;359(23):2488-91.

87. Tang C-M, Yau TO, Yu J. Management of chronic hepatitis B infection: current treatment guidelines, challenges, and new developments. World J Gastroenterol. 2014 May 28;20(20):6262-78.

88. Takeuchi O, Akira S. Innate immunity to virus infection. Immunol Rev. 2009 Jan;227(1):75-86.

89. Vieira VC, Soares MA. The role of cytidine deaminases on innate immune responses against human viral infections. Biomed Res Int. 2013;2013:683095.

90. Santa-Marta M, de Brito PM, Godinho-Santos A, Goncalves J. Host Factors and HIV-1 Replication: Clinical Evidence and Potential Therapeutic Approaches. Front Immunol. 2013 Oct 24;4:343.

91. Bransteitter R, Prochnow C, Chen XS. The current structural and functional understanding of APOBEC deaminases. Cell Mol Life Sci. 2009 Oct;66(19):313747.

92. Vieira VC, Soares MA. The role of cytidine deaminases on innate immune responses against human viral infections. Biomed Res Int. 2013;2013:683095. 
93. Ma J, Li X, Xu J, Zhang Q, Liu Z, Jia P, et al. The roles of APOBEC3G complexes in the incorporation of APOBEC3G into HIV-1. PLoS ONE. 2013;8(10):e74892.

94. Shlyakhtenko LS, Lushnikov AY, Miyagi A, Li M, Harris RS, Lyubchenko YL. Atomic force microscopy studies of APOBEC3G oligomerization and dynamics. J Struct Biol. 2013 Nov;184(2):217-25.

95. Liang G, Kitamura K, Wang Z, Liu G, Chowdhury S, Fu W, et al. RNA editing of hepatitis $B$ virus transcripts by activation-induced cytidine deaminase. Proc Natl Acad Sci USA. 2013 Feb 5;110(6):2246-51.

96. Watashi K, Liang G, Iwamoto M, Marusawa H, Uchida N, Daito T, et al. Interleukin-1 and tumor necrosis factor- $\alpha$ trigger restriction of hepatitis $B$ virus infection via a cytidine deaminase activation-induced cytidine deaminase (AID). $J$ Biol Chem. 2013 Nov 1;288(44):31715-27.

97. Pavlovic J, Zürcher T, Haller O, Staeheli P. Resistance to influenza virus and vesicular stomatitis virus conferred by expression of human MxA protein. J Virol. 1990 Jul;64(7):3370-5.

98. Goujon C, Moncorgé O, Bauby H, Doyle T, Ward CC, Schaller T, et al. Human MX2 is an interferon-induced post-entry inhibitor of HIV-1 infection. Nature. 2013 Oct 24;502(7472):559-62.

99. Haller O, Kochs G. Human MxA protein: an interferon-induced dynamin-like GTPase with broad antiviral activity. J Interferon Cytokine Res. 2011 Jan;31(1):79-87.

100. Kim B-H, Shenoy AR, Kumar P, Bradfield CJ, MacMicking JD. IFN-inducible GTPases in host cell defense. Cell Host Microbe. 2012 Oct 18;12(4):432-44.

101. Izumi T, Burdick R, Shigemi M, Plisov S, Hu W-S, Pathak VK. Mov10 and APOBEC3G localization to processing bodies is not required for virion incorporation and antiviral activity. J Virol. 2013 Oct;87(20):11047-62.

102. Wang X, Han Y, Dang Y, Fu W, Zhou T, Ptak RG, et al. Moloney leukemia virus 10 (MOV10) protein inhibits retrovirus replication. J Biol Chem. 2010 May 7;285(19):14346-55.

103. Ma Y-X, Li D, Fu L-J, Fu B-Q, Chen S-J, Xu W-Z, et al. The role of Moloney leukemia virus 10 in hepatitis B virus expression in hepatoma cells. Virus Res. 2015 Feb 2;197:85-91.

104. White TE, Brandariz-Nuñez A, Valle-Casuso JC, Amie S, Nguyen LA, Kim B, et al. The retroviral restriction ability of SAMHD1, but not its deoxynucleotide triphosphohydrolase activity, is regulated by phosphorylation. Cell Host Microbe. 2013 Apr 17;13(4):441-51.

105. Ji X, Wu Y, Yan J, Mehrens J, Yang H, DeLucia M, et al. Mechanism of allosteric activation of SAMHD1 by dGTP. Nat Struct Mol Biol. 2013 Nov;20(11):1304-9.

106. Sommer AFR, Rivière L, Qu B, Schott K, Riess M, Ni Y, et al. Restrictive influence of SAMHD1 on Hepatitis B Virus life cycle. Sci Rep. 2016 27;6:26616. 
107. Goto T, Kennel SJ, Abe M, Takishita M, Kosaka M, Solomon A, et al. A novel membrane antigen selectively expressed on terminally differentiated human B cells. Blood. 1994 Sep 15;84(6):1922-30.

108. Kupzig S, Korolchuk V, Rollason R, Sugden A, Wilde A, Banting G. Bst2/HM1.24 is a raft-associated apical membrane protein with an unusual topology. Traffic. 2003 Oct;4(10):694-709.

109. Rollason R, Korolchuk V, Hamilton C, Schu P, Banting G. Clathrin-mediated endocytosis of a lipid-raft-associated protein is mediated through a dual tyrosine motif. J Cell Sci. 2007 Nov 1;120(Pt 21):3850-8.

110. Ishikawa J, Kaisho $\mathrm{T}$, Tomizawa H, Lee BO, Kobune $\mathrm{Y}$, Inazawa J, et al. Molecular cloning and chromosomal mapping of a bone marrow stromal cell surface gene, BST2, that may be involved in pre-B-cell growth. Genomics. 1995 Apr 10;26(3):527-34.

111. Miyakawa K, Matsunaga S, Watashi K, Sugiyama M, Kimura H, Yamamoto N, et al. Molecular dissection of HBV evasion from restriction factor tetherin: A new perspective for antiviral cell therapy. Oncotarget. 2015 Sep 8;6(26):21840-52.

112. Cordin O, Banroques J, Tanner NK, Linder P. The DEAD-box protein family of RNA helicases. Gene. 2006 Feb 15;367:17-37.

113. Chang T-C, Liu W-S. The molecular evolution of PL10 homologs. BMC Evol Biol. 2010 May 3;10:127.

114. Schröder M. Human DEAD-box protein 3 has multiple functions in gene regulation and cell cycle control and is a prime target for viral manipulation. Biochem Pharmacol. 2010 Feb 1;79(3):297-306.

115. Wang H, Kim S, Ryu W-S. DDX3 DEAD-Box RNA helicase inhibits hepatitis B virus reverse transcription by incorporation into nucleocapsids. J Virol. 2009 Jun;83(11):5815-24.

116. Ko C, Lee S, Windisch MP, Ryu W-S. DDX3 DEAD-box RNA helicase is a host factor that restricts hepatitis B virus replication at the transcriptional level. J Virol. 2014 Dec;88(23):13689-98.

117. Di Primio C, Quercioli V, Allouch A, Gijsbers R, Christ F, Debyser Z, et al. Single-cell imaging of HIV-1 provirus (SCIP). Proc Natl Acad Sci USA. 2013 Apr 2;110(14):5636-41.

118. Peng K, Muranyi W, Glass B, Laketa V, Yant SR, Tsai L, et al. Quantitative microscopy of functional HIV post-entry complexes reveals association of replication with the viral capsid. Elife. 2014 Dec 17;3:e04114.

119. Stultz RD, Cenker JJ, McDonald D. Imaging HIV-1 Genomic DNA from Entry through Productive Infection. J Virol. 2017 01;91(9).

120. Marini B, Kertesz-Farkas A, Ali H, Lucic B, Lisek K, Manganaro L, et al. Nuclear architecture dictates HIV-1 integration site selection. Nature. 2015 May 14;521(7551):227-31. 
121. Chin CR, Perreira JM, Savidis G, Portmann JM, Aker AM, Feeley EM, et al. Direct Visualization of HIV-1 Replication Intermediates Shows that Capsid and CPSF6 Modulate HIV-1 Intra-nuclear Invasion and Integration. Cell Rep. 2015 Nov 24;13(8):1717-31.

122. Platt EJ, Wehrly K, Kuhmann SE, Chesebro B, Kabat D. Effects of CCR5 and CD4 cell surface concentrations on infections by macrophagetropic isolates of human immunodeficiency virus type 1. J Virol. 1998 Apr;72(4):2855-64.

123. Platt EJ, Bilska M, Kozak SL, Kabat D, Montefiori DC. Evidence that ecotropic murine leukemia virus contamination in TZM-bl cells does not affect the outcome of neutralizing antibody assays with human immunodeficiency virus type 1 . J Virol. 2009 Aug;83(16):8289-92.

124. Takeuchi Y, McClure MO, Pizzato M. Identification of gammaretroviruses constitutively released from cell lines used for human immunodeficiency virus research. J Virol. 2008 Dec;82(24):12585-8.

125. Derdeyn CA, Decker JM, Sfakianos JN, Wu X, O'Brien WA, Ratner L, et al. Sensitivity of human immunodeficiency virus type 1 to the fusion inhibitor T-20 is modulated by coreceptor specificity defined by the V3 loop of gp120. J Virol. 2000 Sep;74(18):8358-67.

126. Wei X, Decker JM, Liu H, Zhang Z, Arani RB, Kilby JM, et al. Emergence of resistant human immunodeficiency virus type 1 in patients receiving fusion inhibitor (T-20) monotherapy. Antimicrob Agents Chemother. 2002 Jun;46(6):1896-905.

127. Weiss A, Stobo JD. Commentary: "The Role of T3 Surface Molecules in the Activation of Human Cells: A Two-Stimulus Requirement for IL-2 Production Reflects Events Occurring at a Pretranslational Level." Front Immunol. 2015;6:163.

128. Bleul CC, Wu L, Hoxie JA, Springer TA, Mackay CR. The HIV coreceptors CXCR4 and CCR5 are differentially expressed and regulated on human $\mathrm{T}$ lymphocytes. Proc Natl Acad Sci USA. 1997 Mar 4;94(5):1925-30.

129. Elkord E, Williams PE, Kynaston H, Rowbottom AW. Human monocyte isolation methods influence cytokine production from in vitro generated dendritic cells. Immunology. 2005 Feb;114(2):204-12.

130. Simon JH, Fouchier RA, Southerling TE, Guerra CB, Grant CK, Malim MH. The Vif and Gag proteins of human immunodeficiency virus type 1 colocalize in infected human T cells. J Virol. 1997 Jul;71(7):5259-67.

131. Fouchier RA, Meyer BE, Simon JH, Fischer U, Malim MH. HIV-1 infection of non-dividing cells: evidence that the amino-terminal basic region of the viral matrix protein is important for Gag processing but not for post-entry nuclear import. EMBO J. 1997 Aug 1;16(15):4531-9.

132. Williams PD, Staas DD, Venkatraman S, Loughran HM, Ruzek RD, Booth TM, et al. Potent and selective HIV-1 ribonuclease $\mathrm{H}$ inhibitors based on a 1-hydroxy-1,8naphthyridin-2(1H)-one scaffold. Bioorg Med Chem Lett. 2010 Nov 
15;20(22):6754-7.

133. Summa V, Petrocchi A, Bonelli F, Crescenzi B, Donghi M, Ferrara M, et al. Discovery of raltegravir, a potent, selective orally bioavailable HIV-integrase inhibitor for the treatment of HIV-AIDS infection. J Med Chem. 2008 Sep 25;51(18):5843-55.

134. Hanley MB, Lomas W, Mittar D, Maino V, Park E. Detection of low abundance RNA molecules in individual cells by flow cytometry. PLoS ONE. 2013;8(2):e57002.

135. Adachi A, Gendelman HE, Koenig S, Folks T, Willey R, Rabson A, et al. Production of acquired immunodeficiency syndrome-associated retrovirus in human and nonhuman cells transfected with an infectious molecular clone. J Virol. 1986 Aug;59(2):284-91.

136. Hulme AE, Kelley Z, Foley D, Hope TJ. Complementary Assays Reveal a Low Level of CA Associated with Viral Complexes in the Nuclei of HIV-1-Infected Cells. J Virol. 2015 May;89(10):5350-61.

137. Popovic M. Cell tropism and expression of HIV-1 isolates in natural targets. in Retroviruses of Human AIDS and Related Animal Disease. 21-27 (Colloque Des Cent Gardes, October 27-29, 1988, 1988).;

138. Gartner S, Markovits P, Markovitz DM, Kaplan MH, Gallo RC, Popovic M. The role of mononuclear phagocytes in HTLV-III/LAV infection. Science. 1986 Jul 11;233(4760):215-9.

139. Wang F, Flanagan J, Su N, Wang L-C, Bui S, Nielson A, et al. RNAscope: a novel in situ RNA analysis platform for formalin-fixed, paraffin-embedded tissues. J Mol Diagn. 2012 Jan;14(1):22-9.

140. Linhoff MW, Garg SK, Mandel G. A high-resolution imaging approach to investigate chromatin architecture in complex tissues. Cell. 2015 Sep 24;163(1):246-55.

141. Matthiesen SH, Hansen CM. Fast and non-toxic in situ hybridization without blocking of repetitive sequences. PLoS ONE. 2012;7(7):e40675.

142. Sidhu G, Beyene J, Rosenblum ND. Outcome of isolated antenatal hydronephrosis: a systematic review and meta-analysis. Pediatr Nephrol. 2006 Feb;21(2):218-24.

143. Schindelin J, Arganda-Carreras I, Frise E, Kaynig V, Longair M, Pietzsch T, et al. Fiji: an open-source platform for biological-image analysis. Nat Methods. 2012 Jun 28;9(7):676-82.

144. Player AN, Shen LP, Kenny D, Antao VP, Kolberg JA. Single-copy gene detection using branched DNA (bDNA) in situ hybridization. J Histochem Cytochem. 2001 May;49(5):603-12.

145. Porichis F, Hart MG, Griesbeck M, Everett HL, Hassan M, Baxter AE, et al. Highthroughput detection of miRNAs and gene-specific mRNA at the single-cell level by flow cytometry. Nat Commun. 2014 Dec 4;5:5641. 
146. Deleage C, Wietgrefe SW, Del Prete G, Morcock DR, Hao XP, Piatak M, et al. Defining HIV and SIV Reservoirs in Lymphoid Tissues. Pathog Immun. 2016;1(1):68-106.

147. Hulme AE, Perez O, Hope TJ. Complementary assays reveal a relationship between HIV-1 uncoating and reverse transcription. Proc Natl Acad Sci USA. 2011 Jun 14;108(24):9975-80.

148. Francis AC, Marin M, Shi J, Aiken C, Melikyan GB. Time-Resolved Imaging of Single HIV-1 Uncoating In Vitro and in Living Cells. PLoS Pathog. 2016 Jun;12(6):e1005709.

149. Wu Y, Marsh JW. Early transcription from nonintegrated DNA in human immunodeficiency virus infection. J Virol. 2003 Oct;77(19):10376-82.

150. Pocock GM, Becker JT, Swanson CM, Ahlquist P, Sherer NM. HIV-1 and M-PMV RNA Nuclear Export Elements Program Viral Genomes for Distinct Cytoplasmic Trafficking Behaviors. PLoS Pathog. 2016 Apr;12(4):e1005565.

151. Sanchez A, Golding I. Genetic determinants and cellular constraints in noisy gene expression. Science. 2013 Dec 6;342(6163):1188-93.

152. Skupsky R, Burnett JC, Foley JE, Schaffer DV, Arkin AP. HIV promoter integration site primarily modulates transcriptional burst size rather than frequency. PLoS Comput Biol. 2010 Sep 30;6(9).

153. Malim MH, Hauber J, Le SY, Maizel JV, Cullen BR. The HIV-1 rev trans-activator acts through a structured target sequence to activate nuclear export of unspliced viral mRNA. Nature. 1989 Mar 16;338(6212):254-7.

154. Karn J, Stoltzfus CM. Transcriptional and posttranscriptional regulation of HIV-1 gene expression. Cold Spring Harb Perspect Med. 2012 Feb;2(2):a006916.

155. Baxter AE, Niessl J, Fromentin R, Richard J, Porichis F, Charlebois R, et al. Single-Cell Characterization of Viral Translation-Competent Reservoirs in HIVInfected Individuals. Cell Host Microbe. 2016 Sep 14;20(3):368-80.

156. Bruner KM, Murray AJ, Pollack RA, Soliman MG, Laskey SB, Capoferri AA, et al. Defective proviruses rapidly accumulate during acute HIV-1 infection. Nat Med. 2016;22(9):1043-9.

157. Ho Y-C, Shan L, Hosmane NN, Wang J, Laskey SB, Rosenbloom DIS, et al. Replication-competent noninduced proviruses in the latent reservoir increase barrier to HIV-1 cure. Cell. 2013 Oct 24;155(3):540-51.

158. UNAIDS. Latest statistics on the status of the AIDS epidemic [Internet]. Available from: http://www.unaids.org/en/resources/fact-sheet.

159. Sacha JB, Ndhlovu LC. Strategies to target non-T-cell HIV reservoirs. Curr Opin HIV AIDS. 2016 Jul;11(4):376-82.

160. Gérard A, Ségéral E, Naughtin M, Abdouni A, Charmeteau B, Cheynier R, et al. The integrase cofactor LEDGF/p75 associates with Iws1 and Spt6 for postintegration silencing of HIV-1 gene expression in latently infected cells. Cell 
Host Microbe. 2015 Jan 14;17(1):107-17.

161. Amadori C, van der Velden YU, Bonnard D, Orlov I, van Bel N, Le Rouzic E, et al. The HIV-1 integrase-LEDGF allosteric inhibitor MUT-A: resistance profile, impairment of virus maturation and infectivity but without influence on RNA packaging or virus immunoreactivity. Retrovirology. 2017 Nov 9;14(1):50.

162. Vranckx LS, Demeulemeester J, Saleh S, Boll A, Vansant G, Schrijvers R, et al. LEDGIN-mediated Inhibition of Integrase-LEDGF/p75 Interaction Reduces Reactivation of Residual Latent HIV. EBioMedicine. 2016 Jun;8:248-64.

163. Khorkova O, Myers AJ, Hsiao J, Wahlestedt C. Natural antisense transcripts. Hum Mol Genet. 2014 Sep 15;23(R1):R54-63.

164. Larocca D, Chao LA, Seto MH, Brunck TK. Human T-cell leukemia virus minus strand transcription in infected T-cells. Biochem Biophys Res Commun. 1989 Sep 15;163(2):1006-13.

165. Ma G, Yasunaga J-I, Matsuoka M. Multifaceted functions and roles of HBZ in HTLV-1 pathogenesis. Retrovirology. 2016 Mar 15;13:16.

166. Gaudray G, Gachon F, Basbous J, Biard-Piechaczyk M, Devaux C, Mesnard J-M. The complementary strand of the human T-cell leukemia virus type 1 RNA genome encodes a bZIP transcription factor that down-regulates viral transcription. J Virol. 2002 Dec;76(24):12813-22.

167. Landry S, Halin M, Lefort S, Audet B, Vaquero C, Mesnard J-M, et al. Detection, characterization and regulation of antisense transcripts in HIV-1. Retrovirology. 2007 Oct 2;4:71.

168. Miller RH. Human immunodeficiency virus may encode a novel protein on the genomic DNA plus strand. Science. 1988 Mar 18;239(4846):1420-2.

169. Michael NL, Vahey MT, d'Arcy L, Ehrenberg PK, Mosca JD, Rappaport J, et al. Negative-strand RNA transcripts are produced in human immunodeficiency virus type 1-infected cells and patients by a novel promoter downregulated by Tat. J Virol. 1994 Feb;68(2):979-87.

170. Kobayashi-Ishihara M, Yamagishi M, Hara T, Matsuda Y, Takahashi R, Miyake A, et al. HIV-1-encoded antisense RNA suppresses viral replication for a prolonged period. Retrovirology. 2012 May 8;9:38.

171. Chang HK, Gendelman R, Lisziewicz J, Gallo RC, Ensoli B. Block of HIV-1 infection by a combination of antisense tat RNA and TAR decoys: a strategy for control of HIV-1. Gene Ther. 1994 May;1(3):208-16.

172. Vanhée-Brossollet C, Thoreau H, Serpente N, D’Auriol L, Lévy JP, Vaquero C. A natural antisense RNA derived from the HIV-1 env gene encodes a protein which is recognized by circulating antibodies of HIV+ individuals. Virology. 1995 Jan 10;206(1):196-202.

173. Ludwig LB, Ambrus JL, Krawczyk KA, Sharma S, Brooks S, Hsiao C-B, et al. Human Immunodeficiency Virus-Type 1 LTR DNA contains an intrinsic gene producing antisense RNA and protein products. Retrovirology. 2006 Nov 8;3:80. 
174. Laverdure S, Gross A, Arpin-André C, Clerc I, Beaumelle B, Barbeau B, et al. HIV-1 antisense transcription is preferentially activated in primary monocytederived cells. J Virol. 2012 Dec;86(24):13785-9.

175. Tagieva NE, Vaquero C. Expression of naturally occurring antisense RNA inhibits human immunodeficiency virus type 1 heterologous strain replication. J Gen Virol. 1997 Oct;78 ( Pt 10):2503-11.

176. Zhang $\mathrm{X}$, Ma X, Jing S, Zhang $\mathrm{H}$, Zhang Y. Non-coding RNAs and retroviruses. Retrovirology. 2018 Feb 9;15(1):20.

177. Saayman S, Ackley A, Turner A-MW, Famiglietti M, Bosque A, Clemson M, et al. An HIV-encoded antisense long noncoding RNA epigenetically regulates viral transcription. Mol Ther. 2014 Jun;22(6):1164-75.

178. Manghera M, Magnusson A, Douville RN. The sense behind retroviral anti-sense transcription. Virol J. 2017 14;14(1):9.

179. Torresilla C, Larocque É, Landry S, Halin M, Coulombe Y, Masson J-Y, et al. Detection of the HIV-1 minus-strand-encoded antisense protein and its association with autophagy. J Virol. 2013 May;87(9):5089-105.

180. Vanhée-Brossollet C, Thoreau H, Serpente N, D’Auriol L, Lévy JP, Vaquero C. A natural antisense RNA derived from the HIV-1 env gene encodes a protein which is recognized by circulating antibodies of HIV+ individuals. Virology. 1995 Jan 10;206(1):196-202.

181. Zapata JC, Campilongo F, Barclay RA, DeMarino C, Iglesias-Ussel MD, Kashanchi F, et al. The Human Immunodeficiency Virus 1 ASP RNA promotes viral latency by recruiting the Polycomb Repressor Complex 2 and promoting nucleosome assembly. Virology. 2017;506:34-44.

182. Fairman-Williams ME, Guenther U-P, Jankowsky E. SF1 and SF2 helicases: family matters. Curr Opin Struct Biol. 2010 Jun;20(3):313-24.

183. Chendrimada TP, Finn KJ, Ji X, Baillat D, Gregory RI, Liebhaber SA, et al. MicroRNA silencing through RISC recruitment of eIF6. Nature. 2007 Jun $14 ; 447(7146): 823-8$.

184. Meister G, Landthaler M, Peters L, Chen PY, Urlaub H, Lührmann R, et al. Identification of novel argonaute-associated proteins. Curr Biol. 2005 Dec 6;15(23):2149-55.

185. Castello A, Fischer B, Eichelbaum K, Horos R, Beckmann BM, Strein C, et al. Insights into RNA biology from an atlas of mammalian mRNA-binding proteins. Cell. 2012 Jun 8;149(6):1393-406.

186. Choi J, Hwang S-Y, Ahn K. Interplay between RNASEH2 and MOV10 controls LINE-1 retrotransposition. Nucleic Acids Res. 2018 Feb 28;46(4):1912-26.

187. Gregersen LH, Schueler M, Munschauer M, Mastrobuoni G, Chen W, Kempa S, et al. MOV10 Is a 5' to 3' RNA helicase contributing to UPF1 mRNA target degradation by translocation along 3' UTRs. Mol Cell. 2014 May 22;54(4):573-85. 
188. Cuevas RA, Ghosh A, Wallerath C, Hornung V, Coyne CB, Sarkar SN. MOV10 Provides Antiviral Activity against RNA Viruses by Enhancing RIG-I-MAVSIndependent IFN Induction. J Immunol. 2016 01;196(9):3877-86.

189. Izumi T, Burdick R, Shigemi M, Plisov S, Hu W-S, Pathak VK. Mov10 and APOBEC3G localization to processing bodies is not required for virion incorporation and antiviral activity. J Virol. 2013 Oct;87(20):11047-62.

190. Abudu A, Wang X, Dang Y, Zhou T, Xiang S-H, Zheng Y-H. Identification of molecular determinants from Moloney leukemia virus 10 homolog (MOV10) protein for virion packaging and anti-HIV-1 activity. J Biol Chem. 2012 Jan 6;287(2):1220-8.

191. Burdick R, Smith JL, Chaipan C, Friew Y, Chen J, Venkatachari NJ, et al. P bodyassociated protein Mov10 inhibits HIV-1 replication at multiple stages. J Virol. 2010 Oct;84(19):10241-53.

192. Wang X, Han Y, Dang Y, Fu W, Zhou T, Ptak RG, et al. Moloney leukemia virus 10 (MOV10) protein inhibits retrovirus replication. J Biol Chem. 2010 May 7;285(19):14346-55.

193. Schoggins JW, Wilson SJ, Panis M, Murphy MY, Jones CT, Bieniasz P, et al. A diverse range of gene products are effectors of the type I interferon antiviral response. Nature. 2011 Apr 28;472(7344):481-5.

194. Haussecker D, Cao D, Huang Y, Parameswaran P, Fire AZ, Kay MA. Capped small RNAs and MOV10 in human hepatitis delta virus replication. Nat Struct Mol Biol. $2008 \mathrm{Jul} ; 15(7): 714-21$.

195. Chen C, Ma X, Hu Q, Li X, Huang F, Zhang J, et al. Moloney leukemia virus 10 (MOV10) inhibits the degradation of APOBEC3G through interference with the Vif-mediated ubiquitin-proteasome pathway. Retrovirology. 2017 Dec 19;14(1):56.

196. Meister G, Landthaler M, Peters L, Chen PY, Urlaub H, Lührmann R, et al. Identification of novel argonaute-associated proteins. Curr Biol. 2005 Dec $6 ; 15(23): 2149-55$.

197. Burdick R, Smith JL, Chaipan C, Friew Y, Chen J, Venkatachari NJ, et al. P bodyassociated protein Mov10 inhibits HIV-1 replication at multiple stages. J Virol. 2010 Oct;84(19):10241-53.

198. Gallois-Montbrun S, Kramer B, Swanson CM, Byers H, Lynham S, Ward M, et al. Antiviral protein APOBEC3G localizes to ribonucleoprotein complexes found in $\mathrm{P}$ bodies and stress granules. J Virol. 2007 Mar;81(5):2165-78.

199. Ndongwe T. Probing viral replication of HCV and XMRV: Biochemical characterization, inhibition kinetics and role of host proteins in viral replication. [University of Missouri]; 2015.

200. Ladner SK, Otto MJ, Barker CS, Zaifert K, Wang GH, Guo JT, et al. Inducible expression of human hepatitis B virus (HBV) in stably transfected hepatoblastoma cells: a novel system for screening potential inhibitors of HBV replication. Antimicrob Agents Chemother. 1997 Aug;41(8):1715-20. 
201. Tavis JE, Cheng X, Hu Y, Totten M, Cao F, Michailidis E, et al. The hepatitis B virus ribonuclease $\mathrm{H}$ is sensitive to inhibitors of the human immunodeficiency virus ribonuclease H and integrase enzymes. PLoS Pathog. 2013 Jan;9(1):e1003125.

202. Burdick R, Smith JL, Chaipan C, Friew Y, Chen J, Venkatachari NJ, et al. P bodyassociated protein Mov10 inhibits HIV-1 replication at multiple stages. J Virol. 2010 Oct;84(19):10241-53.

203. Puray-Chavez MN*, Tedbury PR*, Huber AD, Ukah OB, Yapo V, Liu D, Ji J, Wolf JJ, Engelman AN, Sarafianos SG. Multiplex single-cell visualization of nucleic acids and protein during HIV infection. Nat Commun. 2017 Dec $1 ; 8(1): 1882$

204. Baxter AE, O'Doherty U, Kaufmann DE. Beyond the replication-competent HIV reservoir: transcription and translation-competent reservoirs. Retrovirology. 2018 Feb 2;15(1):18.

205. Fullam A, Schröder M. DExD/H-box RNA helicases as mediators of anti-viral innate immunity and essential host factors for viral replication. Biochim Biophys Acta. 2013 Aug;1829(8):854-65. 


\section{VITA}

Maritza N. Puray Chavez was born in Lima, Peru on September $18^{\text {th }}, 1975$. Her parents Erlinda Chavez Flores and Faustino Puray Palomino. She started to receive diplomas of excellence since second grade in primary and continue until the end of college from she graduated with honors from Universidad Nacional Mayor de San Marcos in Lima Peru in 1998, where she obtained bachelor as Medical Technologist in Clinical Laboratory.

After graduation she got a position at Peruvian National Institute of Health and started working in rabies vaccine laboratory. Then she moved to Malaria reference national laboratory at Peruvian NIH and worked there for five years, during that time she studied Master in Biochemistry and was teaching assistant in her former university. She was encourage to pursue her doctoral studies, but first she got a training at University of Washington in Seattle, where she felt completely sequestered by basic research. She

continued gaining experience being laboratory supervisor at Universidad Peruana Cayetano Heredia, laboratory director at ACSA non-profit organization, and finally chief of research laboratory at Universidad Nacional Mayor de San Marcos. In her personal life she got married with the love of her life Jorge Martin Durand Heredia in 2010.

With years of experience, she finally decided to pursue one of her postpone dreams, to achieve her doctoral studies. She was selected for Fulbright fellowship a doctorate in MPT. In August 2012, Maritza started her graduate studies at the University of Missouri-Columbia, where she completed her Ph.D. in MPT in virology under the supervision of Dr. Stefan G. Sarafianos in June 2018. In 2016, Maritza and Jorge became 
parents of the baby girl Amelia Andrea. Maritza will continue her post-doctoral position at Washington University in St. Louis. 